\title{
INVESTIGATING THE EFFECTIVENESS OF BLUE FLAG AS A TOOL FOR ENVIRONMENTAL PROTECTION
}

\author{
by \\ Laura Marie Klein \\ Bachelor of Environmental Studies, University of Waterloo, 2013 \\ A thesis \\ presented to Ryerson University \\ in partial fulfillment of the \\ requirements for the degree of \\ Master of Applied Science \\ in the Program of \\ Environmental Applied Science and Management
}

Toronto, Ontario, Canada, 2016

(c) Laura Marie Klein 2016 


\section{Author's Declaration}

AUTHOR'S DECLARATION FOR ELECTRONIC SUBMISSION OF A THESIS

I hereby declare that I am the sole author of this thesis. This is a true copy of the thesis, including any required final revisions, as accepted by my examiners.

I authorize Ryerson University to lend this thesis to other institutions or individuals for the purpose of scholarly research

I further authorize Ryerson University to reproduce this thesis by photocopying or by other means, in total or in part, at the request of other institutions or individuals for the purpose of scholarly research.

I understand that my thesis may be made electronically available to the public. 


\title{
INVESTIGATING THE EFFECTIVENESS OF BLUE FLAG AS A TOOL FOR ENVIRONMENTAL PROTECTION
}

\author{
Laura Marie Klein \\ Master of Applied Science, 2016 \\ Environmental Applied Science and Management \\ Ryerson University
}

\begin{abstract}
Beach certification schemes, such as Blue Flag, have become prevalent in the current literature as a beach management tool that is said to bridge the gap between recreation and conservation. There has been limited research done to determine if Blue Flag is actually being successfully used as a tool for environmental protection. This study investigates the effectiveness of Blue Flag as a management tool for environmental protection in Ontario. Semi-structured interviews were conducted with beach managers along the shoreline of the Great Lakes who represent a municipality involved in the Blue Flag program. The key findings of this research reveal that currently Blue Flag is not being used as an effective beach management tool for environmental protection. This study provides indication that beach managers do not think that municipalities adopting Blue Flag will have a direct impact on improving the health and protection of the Great Lakes.
\end{abstract}




\section{Acknowledgements}

I would like to first thank my supervisor, Dr. Rachel Dodds, who was the best supervisor I could have hoped for. I can't express how grateful I am for the wonderful support and advice. I have learned so much through your guidance.

I would also like to extend my appreciation to my thesis committee for taking an interest in my research and providing me with valuable feedback.

To those who participated in the interviews, thank you for taking the time to answer my questions and be engaged in my research. I could not have completed this study without your candid and detailed answers.

To my parents, thank you for your support and for believing in me. Last, thank you to my dog Oreo, who was always directly beside me providing companionship throughout the entire writing process.

Thank you. 


\section{Table of Contents}

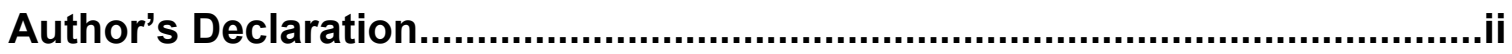

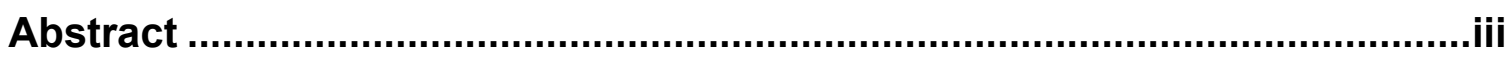

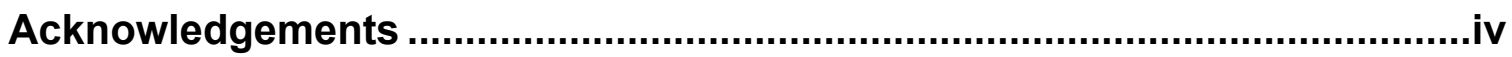

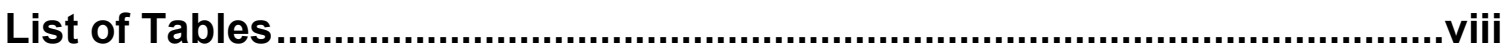

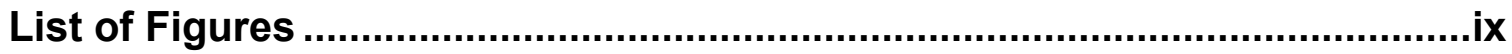

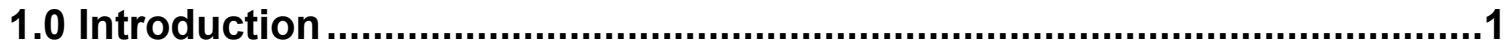

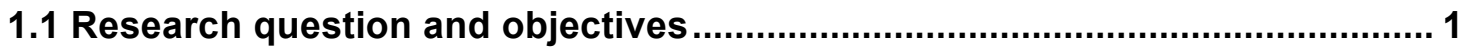

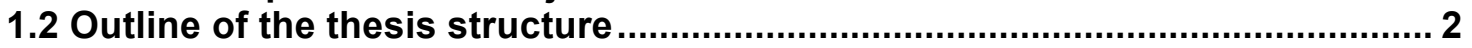

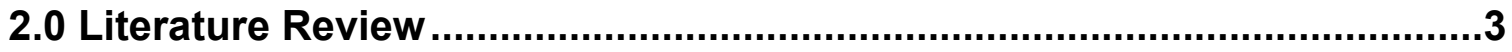

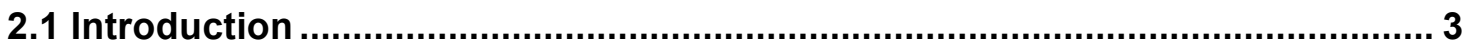

2.2 Importance of the Great Lakes and their beaches....................................... 3

2.2.1 Degradation of beaches ...................................................................... 4

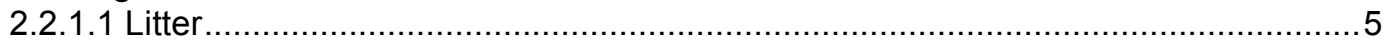

2.2.1.2 Dune and vegetation trampling..............................................................

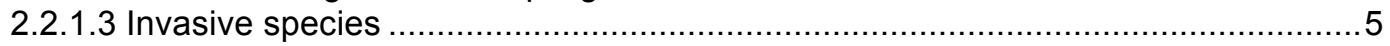

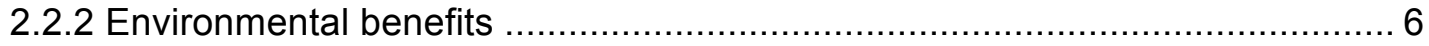

2.2.3 Economic benefits........................................................................... 7

2.3 Policies and Governance of the Great Lakes and their beaches .................... 7

2.3.1 Ontario Great Lakes Strategy ........................................................ 8

2.3.2 Great Lakes Protection Act, 2015 (Bill 66) ………….............................. 9

2.3.3 Federal government involvement...................................................... 9

2.3.4 International involvement and cooperation ............................................ 9

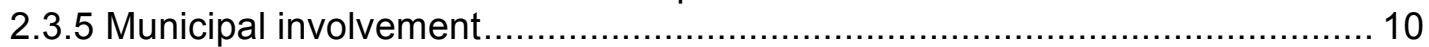

2.4 Beach management approaches ............................................................. 12

2.4.1 Defining beach management .............................................................. 12

2.4.2 Certification schemes and eco-labeling ………….................................. 13

2.4.2.1 Types of beach certification awards ......................................................... 15

2.5 Blue Flag eco-certification ......................................................................... 16

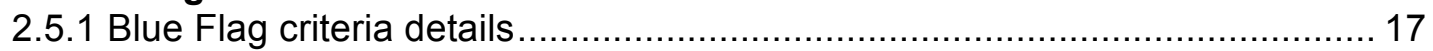

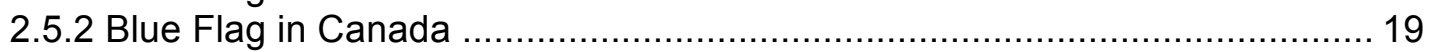

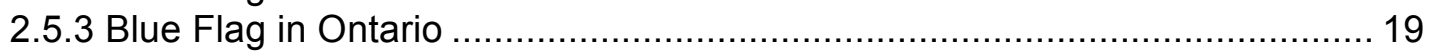

2.5.3.1 Blue Flag as an environmental management tool in Ontario.............................20

2.6 Benefits and issues of Blue Flag certification .............................................. 21

2.6.1 Economic impact........................................................................... 21

2.6.2 Marketing and public awareness ...................................................... 21

2.6.3 Environmental management benefits ................................................. 22

2.6.4 Issues of Blue Flag as a management tool ............................................ 23

2.6.4.1 Issue with emphasis solely on water quality criteria .......................................2.

2.6.4.2 Issue with mechanical beach grooming .......................................................2

2.6.4.3 Issue with increased visitation ……………………………………………26

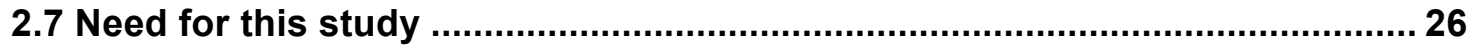

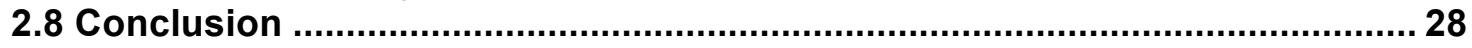

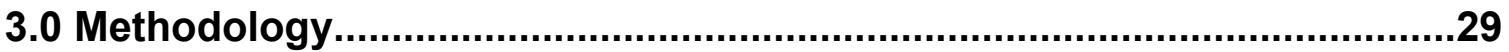

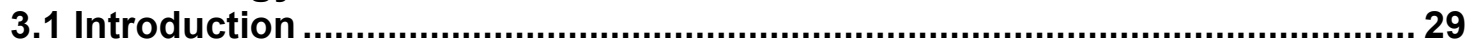

3.1.1 Research Question and Objectives ....................................................... 29 


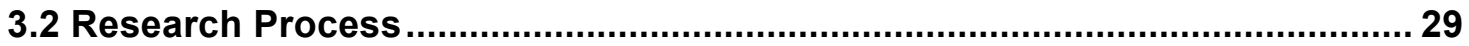

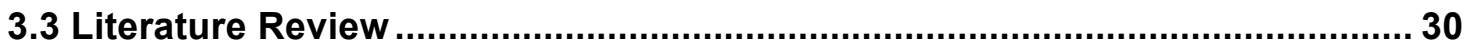

3.4 Primary Research Method Selection........................................................... 31

3.5 Sample size ...................................................................................... 32

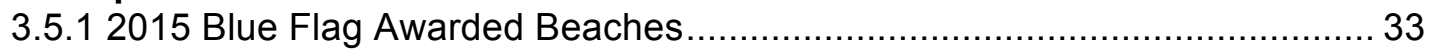

3.5.2 Past Successful Blue Flag Beaches …………..................................... 35

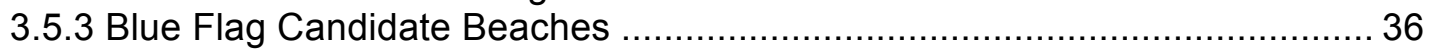

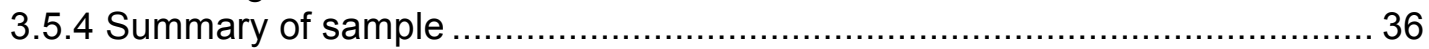

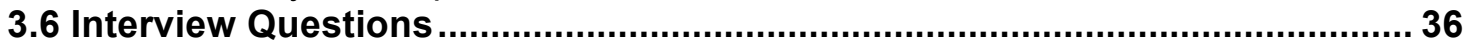

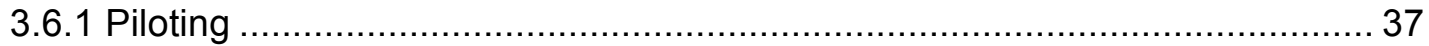

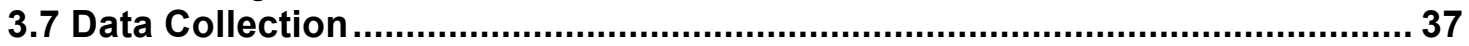

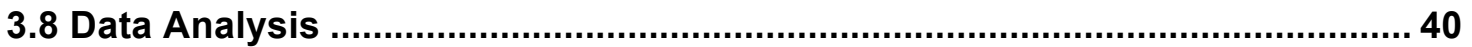

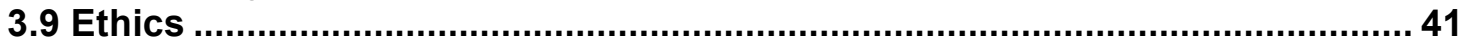

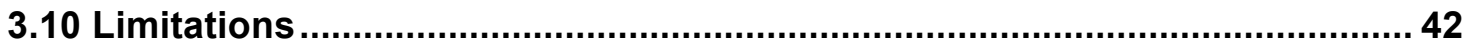

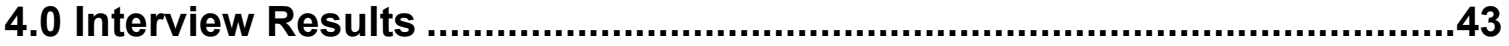

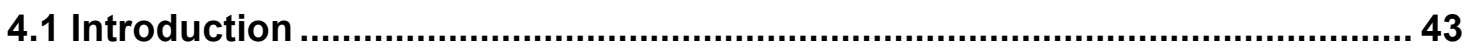

4.2 Profile of Great Lakes beaches .................................................................. 43

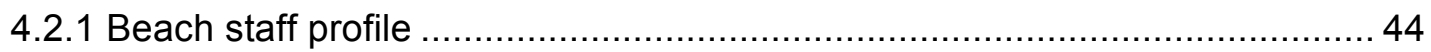

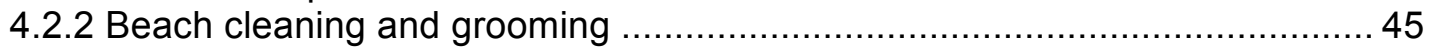

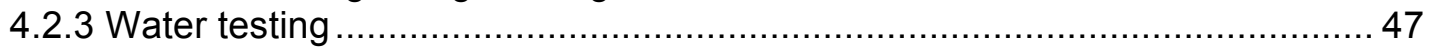

4.2.4 Challenges faced by beach managers .............................................. 48

4.2.4.1 Most significant issue at the beaches .........................................................52

4.2.5 Management success stories at the beaches ……….............................. 53

4.3 Tools and strategies for beach management............................................... 55

4.3.1 The use of Blue Flag as an environmental management tool.................... 56

4.3.1.1 Opportunity for Blue Flag to improve environmental management of the Great

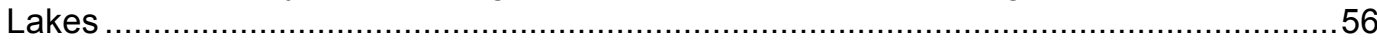

4.3.2 Partnerships as key to environmental management ................................ 57

4.3.3 Lack of clarity and specific tools or strategies for environmental management

4.4 Role of Blue Flag in environmental protection success stories ................... 59

4.4.1 Blue Flag criteria for environmental protection ………............................ 60

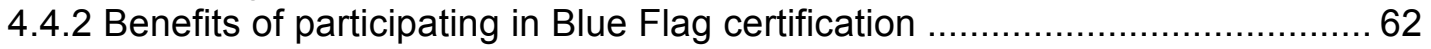

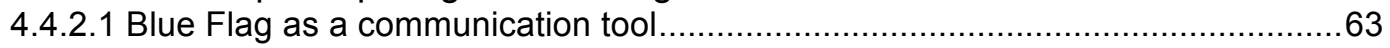

4.4.3 Changes made due to Blue Flag participation ..............................................6 64

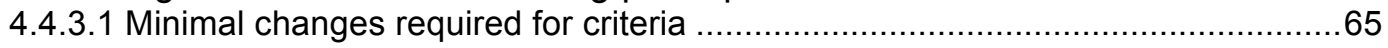

4.4.4 Motivation to receive the Blue Flag ……...................................................6 66

4.5 Future potential of Blue Flag …….............................................................68

4.5.1 Barriers for new municipalities to receive Blue Flag ……........................... 68

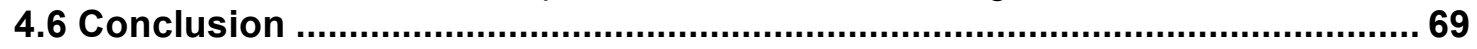

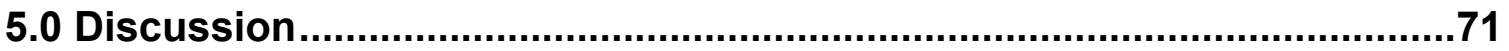

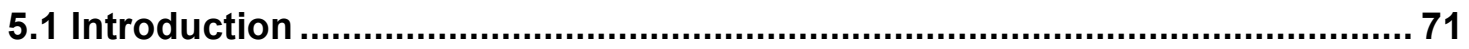

5.2 Issues with Blue Flag in Ontario ................................................................ 71

5.2.1 More effective for smaller municipalities than larger, established beaches ... 71

5.2.2 Both physical challenges and public expectation challenges ...................... 73

5.2.3 Lack of clarity and consistency ............................................................ 74

5.2.3.1 Beach committee ....................................................................................

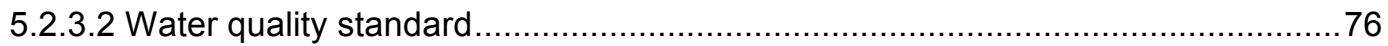

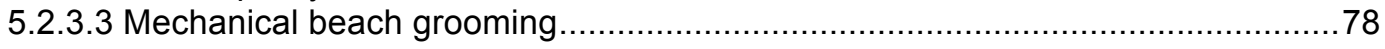

5.2.4 Not a solution to improve the Great Lakes ................................................ 79 


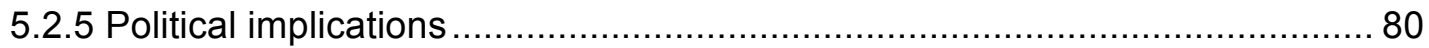

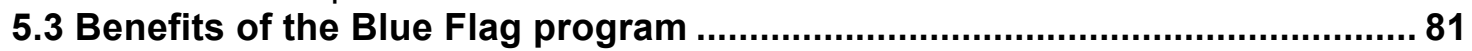

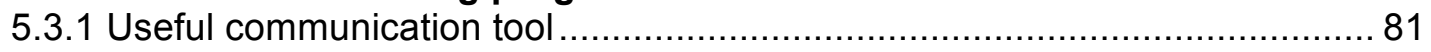

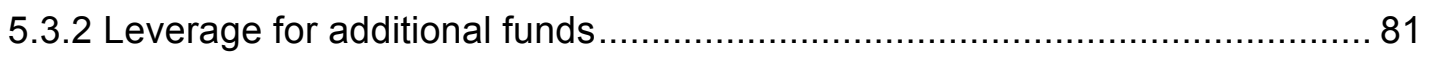

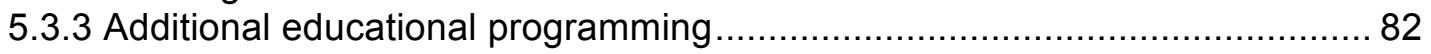

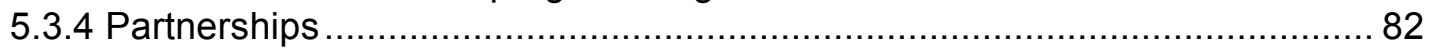

5.4 Blue Flag as a tourism and promotion tool.............................................. 83

5.5 Recommendations for improving effectiveness of Blue Flag ........................ 84

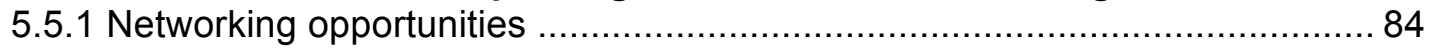

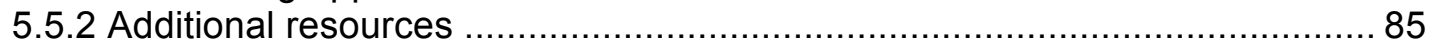

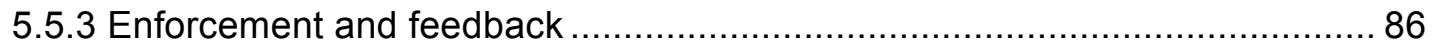

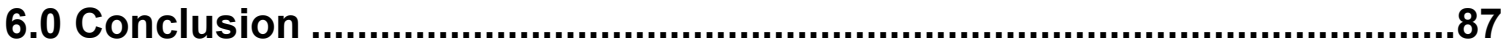

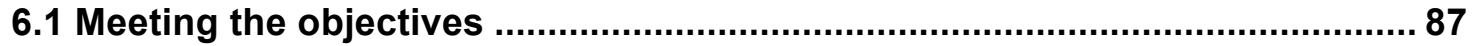

6.1.1 What are the key issues municipalities face with regard to beach protection?

6.1.2 What successes municipalities have accomplished with regard to beach

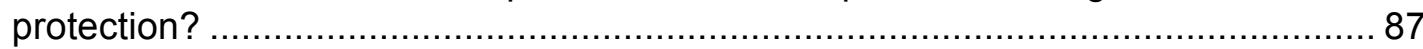

6.1.3 Which of these successes can be attributed to Blue Flag criteria? ................ 88

6.1.4 What motivations or hindrances managers have in adopting the Blue Flag

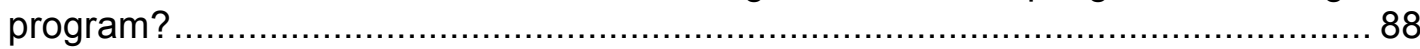

6.1.5 What extent Blue Flag is being used as a management tool for environmental protection versus a driver for tourism or economic benefit? ................................. 88

6.2 Summary of key findings and recommendations ...................................... 89

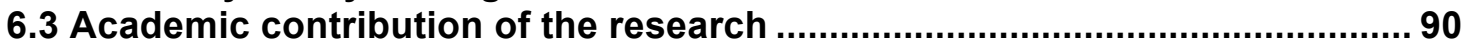

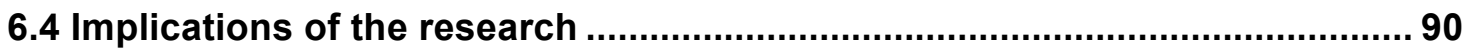

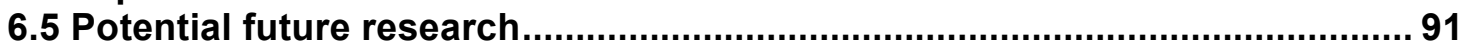

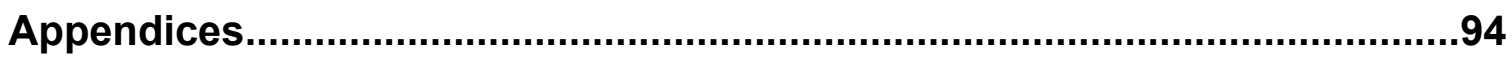

Appendix A - Blue Flag Criteria for Beaches .................................................... 94

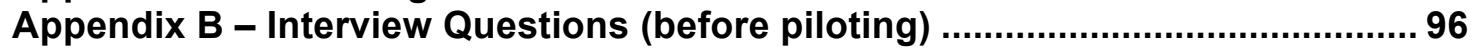

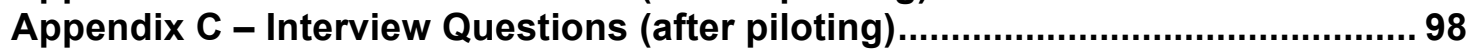

Appendix D - Email Recruitment Script ............................................................ 100

Appendix E - Example of NVivo nodes and theme organization ....................... 101

Appendix F - Interview Consent Form ........................................................... 102

Appendix G - Photos of Blue Flag beaches included in the study................... 105

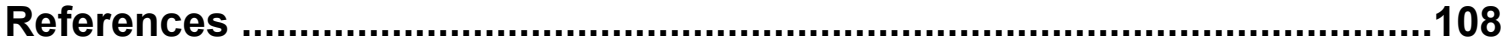




\section{List of Tables}

Table 1 The first year Ontario's Great Lakes beaches received Blue Flag .........20

Table 2 Summary of 2015 Blue Flag beaches making up the sample ................34

Table 3 Summary of interview style, length and data recording ........................40

Table 4 Number of years working in municipal position on beach management.45

Table 5 Grooming technique and frequency at Blue Flag beaches ...................46

Table 6 Frequency of water quality testing at Blue Flag beaches ....................47

Table 7 List of all beach management challenges indicated ............................49

Table 8 The most significant challenge listed by beach managers ...................52

Table 9 Beach protection success stories ...................................................53

Table 10 Strengths and benefits identified of the Blue Flag program .................63

Table 11 Changes made in order to comply with Blue Flag requirements ..........65

Table 12 Motivation of municipality to receive the Blue Flag ............................67

Table 13 Potential barriers for new municipalities to receive the Blue Flag ........69 


\section{List of Figures}

Figure $1 \mathrm{~A}$ conceptual model of the components of the beach environment that need to be considered for beach management, adapted from James (2000).

Figure 2 Blue Flag eco-award symbol (Environmental Defence, 'Steps to the Blue

Flag Award', n.d.).

Figure 3 Application process for beaches to become Blue Flag certified in Canada, adapted from Environmental Defence 'Steps to the Blue Flag Award' (n.d.).

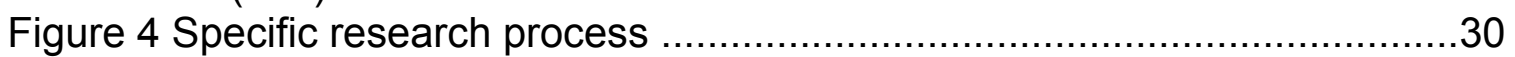

Figure 5 Map showing locations of all beaches included in sample ...................33

Figure 6 Word cloud generated from the job description of all interviewees .......44

Figure 7 Model of the key themes from the study outlining the issues, benefits, and overlapping theme 


\subsection{Introduction}

Ontario's Great Lakes beaches offer services that are vitally important for both environmental and economic benefit. Recent policy and governance actions across multiple levels of government are recognizing the importance of protecting beaches along the Great Lakes. These invaluable ecosystems are under stress from a variety of causes, including heavy use for recreation and tourism. The pressure that results from beach tourism can often lead to serious environmental degradation, and it is therefore critical that beach management be effective at protecting the beach environment and preserving it for the future. Beach managers have been criticized for inappropriate beach management strategies that focus solely on the recreation and tourism needs of the beach, and disregard measures to protect the beach environment.

One popular tool used for beach management throughout the world is the use of beach awards and eco-labels. Beach awards have been said to bridge the gap between recreation and conservation, and have become prevalent in the current literature as a beach management tool. Blue Flag is the most well-known and widely used beach award in the world. It aims to ensure that a beach can be promoted for its sustainable management, cleanliness and safety. Environmental Defence has operated the Blue Flag program in Ontario for over a decade now. Ontario's Great Lakes Strategy (2012) has identified the Blue Flag standard as the standard for healthy beaches in Ontario, and has suggested further adoption of the program here in Ontario. Despite claims that beach awards such as Blue Flag can be used as tools to benefit the beach environment, there has been very little research conducted to determine how effective this eco-award actually is for beach management and environmental protection.

\subsection{Research question and objectives}

The research question that this thesis aims to answer is: To what extent is the Blue Flag certification program an effective management tool for environmental protection of beaches? 
Five objectives were outlined in order to answer the research question:

1. What are the key issues municipalities face with regard to beach protection?

2. What are the successes municipalities have accomplished with regard to beach protection?

3. Which of these successes can be attributed to Blue Flag criteria?

4. What motivations or hindrances do managers have in adopting the Blue Flag program?

5. To what extent is Blue Flag being used as a management tool for environmental protection versus a driver for tourism or economic benefit?

\subsection{Outline of the thesis structure}

This thesis assesses the effectiveness of Blue Flag as a management tool for the environmental protection of beaches along the Great Lakes in Ontario. In order to accomplish this, the next chapter provides a review of the current literature on the significance of the Great Lakes beaches, the policies and governance addressing these beaches, beach management strategies including voluntary initiatives such as beach certification and eco-labels, and lastly the Blue Flag eco-certification program. Following the literature review, the next chapter will outline the methodological approach to this study, including an explanation for the use of a qualitative data method and sample selection. The next chapter will present the findings from the semi-structured interviews. After the results are presented, a chapter including a discussion of the significant findings and the key themes as well as recommendations will follow. Finally, a conclusion is provided that considers the implications of the research and areas for future research. 


\subsection{Literature Review}

\subsection{Introduction}

This literature review will outline the importance of Great Lake beaches in Ontario and issues with their degradation in order to provide insight on the need for a focus on beach management that results in environmental protection. Current policies and governance of Ontario's Great Lakes beaches are reviewed to provide an overview of how the role of municipalities fits amongst the other levels of government. Beach management is then defined and important components of an integrated beach management approach are identified. The use of voluntary environmental initiatives for beach management is then presented, and the popular eco-labeling award schemes are described. An overview of the Blue Flag award program is then provided, as it is the most well known and widely used beach award scheme in the world. Next, previous research on the Blue Flag program will be addressed, including public awareness of the award, economic impact of the award, and the existing literature on its use for impacting the beach environment. The exact gap in knowledge that this research addresses will then be outlined.

\subsection{Importance of the Great Lakes and their beaches}

The five Great Lakes, located in North America and bordering Canada and the United States, are undoubtedly one of the world's most important and recognizable natural features. The span of Lake Superior, Lake Michigan, Lake Huron, Lake Erie and Lake Ontario is vast as the Great Lakes basin makes up the largest freshwater basin on Earth, providing approximately $20 \%$ of the Earth's surface freshwater, and 95\% of the continent's surface freshwater (David Suzuki Foundation, 2014; Gore \& Stoett, 2009; Maack, Banas Mills, Borick, Gore, \& Rabe, 2014; Sustain Our Great Lakes, 2014a). This basin includes two Canadian provinces and eight U.S. states, covering in total over 1,200 square kilometers and spanning ten thousand miles of shoreline (Gore \& Stoett, 2009; National Wildlife Federation, 2015; Sustain Our Great Lakes, 2014a). Throughout history, Canada and the United States have depended heavily on the Great Lakes for 
water consumption, industry, transportation, recreation, and many other uses (Gore \& Stoett, 2009).

In addition to their environmental importance, the Great Lakes also offer some of Ontario's best beaches. These beaches provide both environmental benefits and economic benefits to the municipalities along the shoreline and both residents and tourists use beaches for their enjoyment. The Great Lakes St. Lawrence Cities Initiative (2009a) states "beaches are critical to the economic and environmental health of the Great Lakes-St. Lawrence region, and the quality of life for the millions of U.S. and Canadian citizens that live in the basin" (pg. 2). This is because beaches naturally provide many environmental benefits and are a very important draw for tourism and recreation in municipalities along the shoreline. The following section will outline in more detail the degradation of beaches followed by the environmental and economic benefits of beaches.

\subsubsection{Degradation of beaches}

Beaches are invaluable ecosystems that are under stress from a variety of causes. Humans have been putting pressure on beaches and altering them for their own use throughout history and many of the issues being dealt with today are not new issues. According to Marin, Palmisani, Ivaldi, Dursi and Fabiano (2009), the pressure that results from beach tourism can often lead to serious environmental degradation and resource consumption. Beach managers worldwide have been criticized for inappropriate beach management strategies that disregard the beach environment or don't include proper conservation measures (Lucrezi, Saayman \& Van der Merwe, 2016). These authors claim that beach managers who focus solely on drawing recreation and tourism have an unbalanced management style that will eventually be harmful to both the beach environment and the future of tourism at that beach. There are an abundance of negative environmental impacts on Great Lakes beaches that come in many forms, for example: litter, dune and vegetation trampling, and invasive species. Each of these issues will be described in detail below and then benefits of beaches will be outlined. 


\subsubsection{Litter}

As a popular draw for tourism and recreation, the Great Lakes beaches are heavily used areas, which can result in an abundance of garbage being left behind. Brown and McLachlan (2002) describe litter on beaches as an "escalating problem" (pg. 69). A study done on Lake Michigan determined that the majority of the litter found on beaches was in fact coming from beach visitors not disposing of trash properly and leaving it behind on the sand (Kelly, 2014). One form of litter that is very evident on beaches in Ontario is cigarette butts. Cigarette butts are the most common litter item found along the shoreline, and this is a serious environmental concern (Great Canadian Shoreline Cleanup [GCSC], n.d.). Cigarette butts leach the toxins contained within them into the water when they get wet, and the butts can be consumed by animals along the shoreline that mistake them for food (GCSC, n.d.). Plastic garbage items are another popular form of litter left at beaches that will cause series problems since plastic is non-biodegradable (Brown \& McLachlan, 2002). Litter from beaches will not only affect the beach ecosystem directly, but also will enter the Great Lakes and continue to have negative effects on a larger scale.

\subsubsection{Dune and vegetation trampling}

The popular recreational use of beaches can result in trampling of important sand dune ecosystems (Brown \& McLachlan, 2002). Visitors who do not use access points but instead just make their own paths are causing serious harm to the sand dune ecosystems. Brown and McLachlan (2002) explain that trampling will not only result in "direct damage to vegetation and the fauna", but can also impact the sand itself, which in turn affects the sand moisture and erosion (pg. 68). Some of the vegetation species in sand dunes, such as American Beachgrass (commonly known as Marram grass), are crucial for stabilizing sand, but are very sensitive to any disturbance from people.

\subsubsection{Invasive species}

Invasive species are causing significant disturbance to the Great Lakes and their beaches. Shoreline areas have been taken over by invasive plants, such as the invasive Common Reed, commonly known as Phragmites (Government of 
Ontario, 2012; Lake Huron Centre for Coastal Conservation [LHCCC], n.d.). There is concern about the negative impact that these invasive plants can cause on beaches due to their ability to push out native vegetation and form dense monocultures (LHCCC, n.d.). This can severely disrupt the sand dune ecology and impact the species that rely on that ecosystem. There has also been a change to the sand at beaches and an increase in masses of algae washing up due to invasive Zebra mussels and quagga mussels that are taking over near shore ecosystems of the Great Lakes (Government of Ontario, 2012).

\subsubsection{Environmental benefits}

Sandy beaches provide important ecosystem services, such as nutrient recycling, water filtration, coastal protection, and nesting and foraging sites for fauna (Amyot \& Grant, 2014; Lucrezi, Saayman \& Van der Merwe. 2015). These services help to keep the Great Lakes healthy and maintain their ecological integrity. Some of Ontario's most special and vulnerable ecosystems, such as sand dunes, are actually beaches. These sand dunes are an ecologically fragile and rare ecosystem, but they are also very rich in biological diversity (Peach, Bowles \& Porter, 2007). Dune systems at Great Lakes beaches are of national and global significance because of how unique they are (Peach, et al., 2007). Dune systems also conserve the beach system by trapping sand in the vegetation, which will reduce erosion and loss of the sand in the long term (Peach, et al., 2007). Beaches along the Great Lakes also provide essential habitat for breeding and feeding for a variety of species, especially waterfowl and shorebirds during migration (Sustain Our Great Lakes, 2014b). Species include the federally rare endangered Piping Plover that exclusively nests on sandy beaches and has returned to Ontario's Great Lakes beaches after a 30-year absence (Peach, n.d.). Pitcher's thistle and dwarf lake iris are federally endangered or threatened plant species found along the Great Lakes shoreline that occur no where else in the world, making them a very important part of the beach biodiversity (Sustain Our Great Lakes, 2014b). 


\subsubsection{Economic benefits}

Beaches are prime recreational grounds that attract people to the water and therefore business to the surrounding area (Amyot \& Grant, 2014). According to multiple research studies, sandy beaches are the most utilized type of shoreline, and development of cottages and other outdoor recreation is very often oriented towards a freshwater lake, generating tourism and revenue for the area (Jaakson, Buszynski, \& Botting, 1976; Schlacher, Dugan, Schoeman, Lastra, Jones, Scapini, McLachlan \& Defeo, 2007). Beach tourism is considered to be a vital component to economic growth that allows for more recreation and leisure than any other in the world (Nelson, Morgan, Williams, \& Wood, 2000). In fact, the economic value of beaches is often perceived to be even higher than the ecological values that they provide (Schlacher et al., 2007). For example, the Ontario government recognizes that many beaches along the Great Lakes are well-known tourist attractions for their contribution to a large part of many local communities' economy (such as Wasaga Beach, Grand Bend and Sauble Beach) (Government of Ontario, 2012). Research also suggests the average beach user can spend up to $\$ 50$ per day at the beach, putting money into a municipality that otherwise would not be receiving it (Great Lakes St. Lawrence Cities Initiative, 2009a). A study conducted by Dodds (2010) looked specifically at beaches in Ontario along the Lake Huron shoreline, concluding that beaches are an important part of tourism with beach visitors spending an average of $\$ 42$ $\$ 56$ per day during their trip. The Wasaga Beach Tourism Strategy (2007) estimated that approximately two million visitors came to their beach in 2006, contributing about $\$ 80$ to $\$ 105$ million in spending. Another study estimates that the recreational value of Ontario's beaches is an estimated \$200 to \$259 million annually (Krantzberg, \& deBoer, 2008). Beaches along the Great Lakes are clearly a valuable resource for Ontario, and governance that makes protecting and restoring the beaches a priority is necessary.

\subsection{Policies and Governance of the Great Lakes and their beaches} In recent decades there has been wide recognition of the need for greater awareness of beach ecosystems (Arizia, Sarda, Jimenez, Mora \& Avila, 2008) 
and it is clear that ecosystems and beaches are a valuable resource for the Great Lakes. Multiple levels of government are involved in the management and protection of beaches and a number of policies address this. At a provincial level, the Ontario government has recognized the importance of including beach protection in both policies and governance. The Ontario Great Lakes strategy and Great Lakes Protection Act specifically mention beach protection as a goal. The Canada-Ontario Agreement is both federal and provincial, and also specifically mentions beaches as a priority. Groups consisting of both Canadian and American representatives have formed to allow municipalities and individual citizens to have a way to participate in the governance of the beaches and stay informed about science and policy affecting them. Each of these policies will be described in detail below.

\subsubsection{Ontario Great Lakes Strategy}

At a provincial level, Ontario's Great Lakes Strategy was released in 2012, which states that it is focusing on generating actions to improve restoring the Great Lakes water, beaches and coastal areas, while also aiming to conserve biodiversity and handle invasive species (Government of Ontario, 2012). One of the five key goals specified in this document is "to protect and restore wetlands, beaches, shorelines and other coastal areas of the Great Lakes-St. Lawrence River Basin" (Government of Ontario, 2012, pg. 29). An overview of Ontario's Great Lakes Strategy highlights beach closures as one of the major negative cumulative effects and degrading waterfronts and beach postings are real issues for these lakes (Ministry of the Environment and Climate Change, 2015). The strategy states:

"Wetlands, beaches, waterfronts and other coastal areas are where people meet the lakes, but also where pressures on the lakes are most evident, in the form of unwanted algae, contaminated sediment, shoreline alterations and other impairments caused by human activity. Nearshore areas are the most biologically diverse and productive areas in the lakes restoring and protecting them will have lake-wide benefits...The declining health of nearshore waters now has binational attention. It is a focus for Ontario communities and the Ontario government, as well as for the federal government and our neighbours to the south." (Government of Ontario, 2012, pg 46). 
As part of Ontario's Great Lakes Strategy, the Great Lakes Guardian Community Fund was created. This fund was created with the purpose of supporting individual projects that would help to restore and protect more localized areas of the Great Lakes. Specific goals for this fund include improving coastal areas and specifically beaches (Government of Ontario, 2016a).

\subsubsection{Great Lakes Protection Act, 2015 (Bill 66)}

The Great Lakes Protection Act was re-introduced in February 2015 and then was passed on October 7, 2015 by the provincial government (Lake Ontario Waterkeeper, n.d.). It was recognized that it was essential for a law to be created that sets targets and provides tools for better protection of the Great Lakes. One of the purposes stated in the Great Lakes Protection Act, 2015 was "To protect and restore watersheds, wetlands, beaches, shorelines and other coastal areas of the Great Lakes-St. Lawrence River Basin" (Bill 66, Great Lakes Protection Act, 2015, pg 3). It is unknown specifically how this will take place, but it is a step in identifying the shoreline, and beaches in particular, as an important resource.

\subsubsection{Federal government involvement}

The Canada-Ontario Agreement (COA) on Great Lakes Water Quality and Ecosystem Health (2014) was created to assist Ontario with the Great Lakes Strategy mentioned above, but also to help the Federal government meet commitments under the Canada-U.S. Great Lakes Water Quality Agreement (Government of Ontario, 2016b). The COA has five main priorities, one of which is to improve wetlands, beaches and coastal areas (Government of Ontario, 2016b). The government website describing the COA states that the near shore areas of the Great Lakes are both important and fragile, which justifies why this particular ecosystem is being specifically addressed.

\subsubsection{International involvement and cooperation}

A coalition of municipal officials representing municipalities along the Great Lakes, known as The Great Lakes and St. Lawrence Cities Initiative (GLSLCl), was formed in 2003 to create an outlet for local governments to collaborate on the goal of protecting and restoring the Great Lakes (Great Lakes and St. Lawrence Cities Initiative 'About Us', n.d.). This group consists of mayors from 
both Canada and the United States who represent their municipality along the Great Lakes. One of the original initiatives of the GLSLCl was called "Great Beaches and Coasts", because this group recognized the importance of healthy beaches (Great Lakes and St. Lawrence Cities Initiative 'Great Beaches and Coasts', n.d.) Another organization formed of individuals from both Canada and the United States is known as The Great Lakes Beach Association (GLBA) (Great Lakes Beach Association [GLBA], 2016). The GLBA began in 2001 as a way for any stakeholder to be included in a discussion about beach issues and sharing ideas for achieving cleaner beaches (GLBA, 2016). The GLBA is an informal organization that includes individuals from many different backgrounds including public health, regulatory agencies, municipalities, provinces, states, researchers, and environmental groups. This group focuses all efforts specifically on beaches along the Great Lakes, and offers a yearly conference so that engaged stakeholders can learn more.

\subsubsection{Municipal involvement}

Despite the recent actions of higher levels of government, the funding and management of beaches is primarily the responsibility of municipalities as there is no formal federal mechanism to support these activities (Great Lakes St. Lawrence Cities Initiative, 2009a). Local governments in Canada are spending an estimated 7.4 million Canadian dollars per year to work towards ensuring the public safety and cleanliness of public beaches (Great Lakes St. Lawrence Cities Initiative, 2009a). Although targets and policy goals for protecting beaches along the Great Lakes have been headlined by provincial or national initiatives, it is municipalities that have the most direct link. There are almost 300 public beaches along Ontario's Great Lakes shoreline that municipalities will have a direct link in managing (Government of Ontario, 2012).

One of the key areas that municipalities are responsible for managing is their public beach. A public beach in Ontario is defined as

"any public bathing area owned/operated by a municipality to which the general public has access, and where there is reason to believe that there 
is recreational use of the water (e.g., beach signage, sectioned off swimming area, water safety/rescue equipment, lifeguard chairs, etc.)" (Government of Ontario, 2014, pg.12).

Municipalities play an important role in beach management because not only do they receive most of the benefits related to the beach, but also have to deal with all of the problems that its presence causes, such as water quality issues, increased litter, and impacts to sand dunes (Ariza, Jimenez, \& Sarda, 2008). Municipal staff members must be involved in all aspects of beach management; including public education, beach grooming, waste removal, and maintenance of property such as boardwalks, public washrooms and trails (Great Lakes St. Lawrence Cities Initiative, 2009a).

Local health units must monitor water quality at public beaches to ensure certain standards are met, and will post if a beach has environmental conditions that are not safe for recreational use (Haliburton, Kawartha, Pine Ridge District Health Unit, n.d.). Health Canada, the Federal department responsible for assisting Canadians to maintain and improve their health, creates the guidelines for recreational water quality standards at public beaches (Health Canada, 2012). The Ontario Ministry of Health and Long Term Care generates the Beach Management Protocol that outlines these health standards for the province that must be followed (Ministry of Health and Long Term Care, 2014). However it is the local health units that do the required testing and official posting of problematic water quality results at all public beaches to ensure that illness and injury at public beaches is limited.

Currently, very few tools exist for municipalities to take a leadership role when it comes to protecting the Great Lakes shoreline even though they are responsible for all day-to-day management. In Ontario, municipalities are responsible for providing people with drinking water, developing pollution control plans, and managing storm water and wastewater (Great Lakes St. Lawrence Cities Initiative, 2009b). Municipalities, therefore, have a direct role to play in supporting the environmental health of beaches, and proper beach management tools are 
necessary to assist municipal beach managers with this. The following section outlines beach management approaches.

\subsection{Beach management approaches}

\subsubsection{Defining beach management}

There is not one universally accepted form of beach management, and research into effective beach management is a relatively new discipline (Williams and Micallef, 2009). The development of an effective beach management strategy is not easy (McLachlan, Defeo, Jaramillo \& Short, 2013). Beach management generally includes two key components: management for providing recreational use, and management for environmental protection (James, 2000; McLachlan et al., 2013). Traditionally beach management focused on the human use of the beach and had the goal of maintaining the beach as a recreational resource (James, 2000). Recently, however, there is a need for management styles that take into account the value of beaches as a natural resource and the aim to preserve their fragile ecosystems (Botero, Pereira, Tosic \& Manjarrez, 2015; McLachlan et al., 2013). According to James (2000), it is essential that beach management practices extend beyond improving the beach only as a recreational resource for human use, and begins to also address protecting the beach as a natural resource. Beach management needs to integrate the wellbeing of the physical beach environment alongside human needs (Williams and Micallef, 2009). This holistic or integrated approach to beach management is taken so that decisions can be informed by all factors that are affecting the system and thus, hopefully become more sustainable (Botero et al., 2015; James, 2000; Lucrezi et al., 2016). According to Williams and Micallef (2009), beach management has three main aspects: 1) physical aspects (geology, geomorphology, waves, currents); 2) socioeconomic criteria (recreation, access, safety, landscape, health, environmental issues); and 3) biological content (flora, fauna). A management system should address several multidisciplinary elements in order to achieve environmental protection, and according to Lucrezi et al., (2016) "there is virtually no aspect of the beach environment that does not require management attention" (pg. 20). James (2000) discusses the links within 
a beach system that need to be addressed by a management tool. This author argues that the human uses, the ecology, and the management cannot be considered separately when trying to achieve environmental protection. For a visual representation of the beach ecosystem components and important relations for beach management, see Figure 1 below.

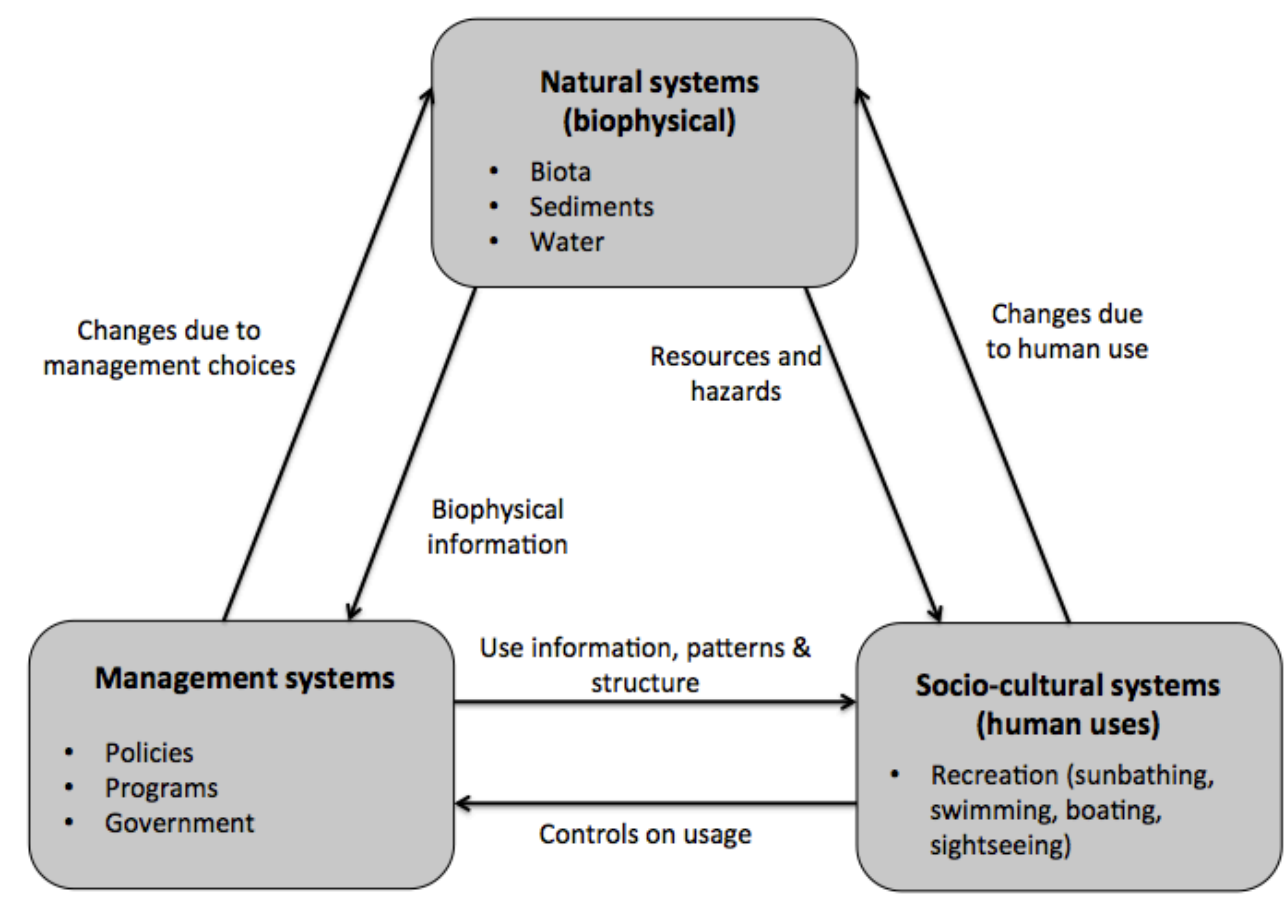

Figure $1 \mathrm{~A}$ conceptual model of the components of the beach environment that need to be considered for beach management, adapted from James (2000).

\subsubsection{Certification schemes and eco-labeling}

Common strategies being adopted to manage beaches more sustainably are voluntary environmental initiatives (VEl's), such as environmental guidelines and certification schemes (Creo \& Fraboni, 2011; Sarda, Valls, Pinto, Ariza, Lozoya, Fraguell, Marti, Rucabado, Ramis \& Jimenez 2015). VEl's are a set of guidelines and criteria a business or municipality must follow and achieve in order to obtain a certain environmental status and certification. A VEI can be defined as the following:

"VEls aim to encourage firms to voluntarily reduce pollution, increase energy efficiency, adopt environmental management practices, and make 
other efforts to improve their environmental performance beyond the requirements established by existing regulations" (Khanna \& Brouhle, 2009, pg. 144).

Certifications, a type of VEI, have been described as "the process of assuring consumers and industry that the company being assessed has met a set of minimum standards" (Dodds and Joppe, 2005, pg. 16). These voluntary certifications ensure that a tourism operation is following a distinct environmental process or standard, which can help address any negative environmental issues associated with it (Blackman, Naranjo, Robalino, Alpizar \& Rivera, 2014). Beaches often fall under the scope of tourism for certification schemes. One certification approach that has developed to address beach management and is now widely used, is the use of an award scheme (Lucrezi et al, 2016; Sarda et al., 2015). This approach is also known as eco-labeling. An eco-label can be defined as the following:

"an award that is given to a business or activity that has significantly better performance compared to the other businesses in its sector. Only the best performers that show exemplary performance, according to the established criteria, receive the eco-label" (Graci \& Dodds, 2015, p.200).

Eco-labels and beach awards are a type of certification scheme that has become prevalent in the current literature as a beach management approach. Ecolabeling was introduced in order to try to lessen any negative social and environmental impacts, and to confirm a high level of environmental performance and accountability (Buckley, 2002; Kozak \& Nield, 2004; Zielinski \& Botero, 2015). Eco-labels can also be used as a marketing and promotion tool to communicate to consumers and influence their choices (Zielinski \& Botero, 2015). Although there are over 100 different labels in the tourism industry alone (Font, 2002), this research scope will only examine those pertinent to beach management. For more information on ecolabeling systems and certifications, and processes for tourism eco-awards in general, see Buckley (2002), Font (2002), Graci and Dodds (2015), and Kozak and Nield (2004).

Within beach management, the most well-known and widely used certification 
scheme is Blue Flag (Ariza, Sarda, et al., 2008; Lucrezi, \& van der Merwe, 2015; Marin et al., 2009; Nelson et al, 2000; Pencarelli, Splendiani \& Fraboni, 2016; Williams \& Micallef, 2009;). According to Font (2002), the first milestone in environmental certification was when a Blue Flag award was first given out to a beach. Since that time, the use of beach awards has become popular, and the various awards and quality assurance systems at beaches are widespread for promoting beach tourism (Morgan, 1999). Ariza, Sarda, et al., (2008) describes the purpose of beach award schemes as a way for beach users to be able to identify the quality of the beach and use that information when deciding to visit a beach. In addition to promoting tourism, it has been suggested that beach award schemes are useful management tools that can encourage environmentally sustainable management. Beach award schemes are said to bridge the gap between recreation and conservation, and are considered to be a strategy for sustainable beach management (Nelson \& Botterill, 2002). According to Williams and Micallef (2009) beach certification can be an effective tool for environmentally sound management, and the authors state that "the adoption of a rigorous beach quality evaluation scheme is an effective strategy through which improvements in beach quality and beach user satisfaction may be achieved" (pg. 62). Creo and Fraboni (2011) discuss how coastal municipalities are using voluntary certification schemes to work towards incorporating sustainability. Types of beach award schemes will now be discussed.

\subsubsection{Types of beach certification awards}

Beach award schemes and eco-labels have criteria that are specified as a measure of quality, and when beaches meet the standards that have been set out they may receive the award (Arizia, Sarda, et al., 2008). There is an abundance of beach award schemes used internationally. The award used most throughout the world is Blue Flag, but there is no one beach award used universally (Williams \& Micallef, 2009). Some other common examples of beach awards are outlined below.

The Good Beach Guide is a website created by a prominent marine charity with 
the goal of helping people find the best beaches in the United Kingdom (Marine Conservation Society, n.d.). The website includes beaches based off of a criteria relating to water quality and a variety of other beach descriptions (Williams \& Micallef, 2009). The Green Sea Partnership is a rating scheme used in Wales that requires beach managers to demonstrate their use of best practices in order to show dedication to beach protection along the coast (Williams \& Micallef, 2009). The United States has implemented the National Healthy Beaches Campaign and the Clean Beaches Council, which runs the award scheme known as the Blue Wave Campaign (McKenna, Williams, \& Cooper, 2011). This beach scheme has a separate rating system of 33 criteria for resort beaches and 27 criteria for rural beaches (Williams \& Micallef, 2009). GuidaBlu is an Italian ecolabel designed to evaluate coastal municipalities (Williams \& Micallef, 2009). Portugal has created the Gold quality award that is only based off of water quality results, unlike most award schemes that take into account other components of the beach (Williams \& Micallef, 2009). For more detailed information and a list of additional beach awards see Williams and Micallef, (2009) who included an entire chapter on this beach management approach. For the rest of the literature review the most popular beach award, Blue Flag, will be discussed in detail.

\subsection{Blue Flag eco-certification}

Blue Flag has become the most well-known and respected beach award scheme in the world (Ariza, Sarda, et al., 2008; Lucrezi, \& van der Merwe, 2015; Marin et al., 2009; Nelson et al, 2000; Pencarelli, et al., 2016; Williams \& Micallef, 2009). The Blue Flag program is often used as an example to explain what an eco-label is because of how well established the program is as a performance standard in the tourism industry (Buckley, 2002; Graci \& Dodds, 2015; Kozak \& Nield, 2004). According to Lucrezi et al (2016) "The Blue Flag award exemplifies beach certification" (pg. 2). The global Blue Flag website describes itself as "a worldrenowned eco-label trusted by millions around the globe" (Blue Flag 'Our Programme', n.d.).

Blue Flags now fly internationally at over 4,000 beaches across 47 different 
countries (Blue Flag 'Blue Flag Sites All', n.d). The Blue Flag program was originally started by a non-profit organization known as the Foundation of Environmental Education, with the first Blue Flags appearing on beaches in France (Boevers, 2008; Lucrezi, \& van der Merwe, 2015; Nelson et al, 2000.). The program was started as a pilot project in 1985, and was officially launched in Europe in 1987. In 2001, the Blue Flag program expanded outside of Europe for the first time to South Africa (McKenna et al., 2011). Countries outside of Europe continued to apply for and receive the Blue Flag award, and an international set of strict criteria began to be used when determining if a beach is applicable to receive the award. A Blue Flag can only be requested for a beach by the municipal authority that managers it, so the environmental responsibility that a Mayor or Council chooses to pursue is extremely relevant. Figure 2 below provides an image of the Blue Flag's symbol that appears as the flag flying at all Blue Flag beaches.

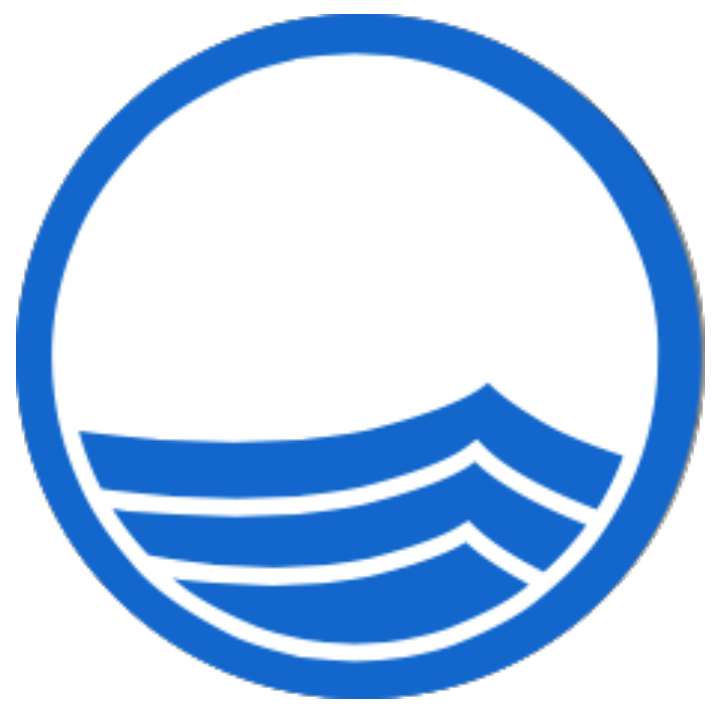

Figure 2 Blue Flag eco-award symbol (Environmental Defence, 'Steps to the Blue Flag Award', n.d.).

\subsubsection{Blue Flag criteria details}

The Blue Flag is awarded to beaches that have met strict international standards in four different categories: water quality, environmental education, environmental management and safety and services. These standards are in the form of a list of 33 criteria that are provided to beaches wanting to be awarded 
the flag (see Appendix A for a full copy of the criteria). The majority of these criteria are considered imperative, meaning that beaches must comply with them in order to receive and maintain Blue Flag status. There are a couple criteria that are considered guideline criteria, meaning they are not mandatory, but are strongly encouraged. These guideline criteria include promoting sustainable transportation at the beach and having a supply of drinking water available at the beach (Environmental Defence 'Criteria for Beaches', n.d.).

A Blue Flag is awarded annually for the beach season (Williams \& Micallef, 2009). The process of applying to the program involves an application to the national jury where it is reviewed, and if approved, is then forwarded to the international jury for final review before the flag is awarded. If a beach does not yet meet all of the criteria to achieve Blue Flag but is formally working towards the process, it is considered a candidate beach. For a visual presentation of the application process, see Figure 3.

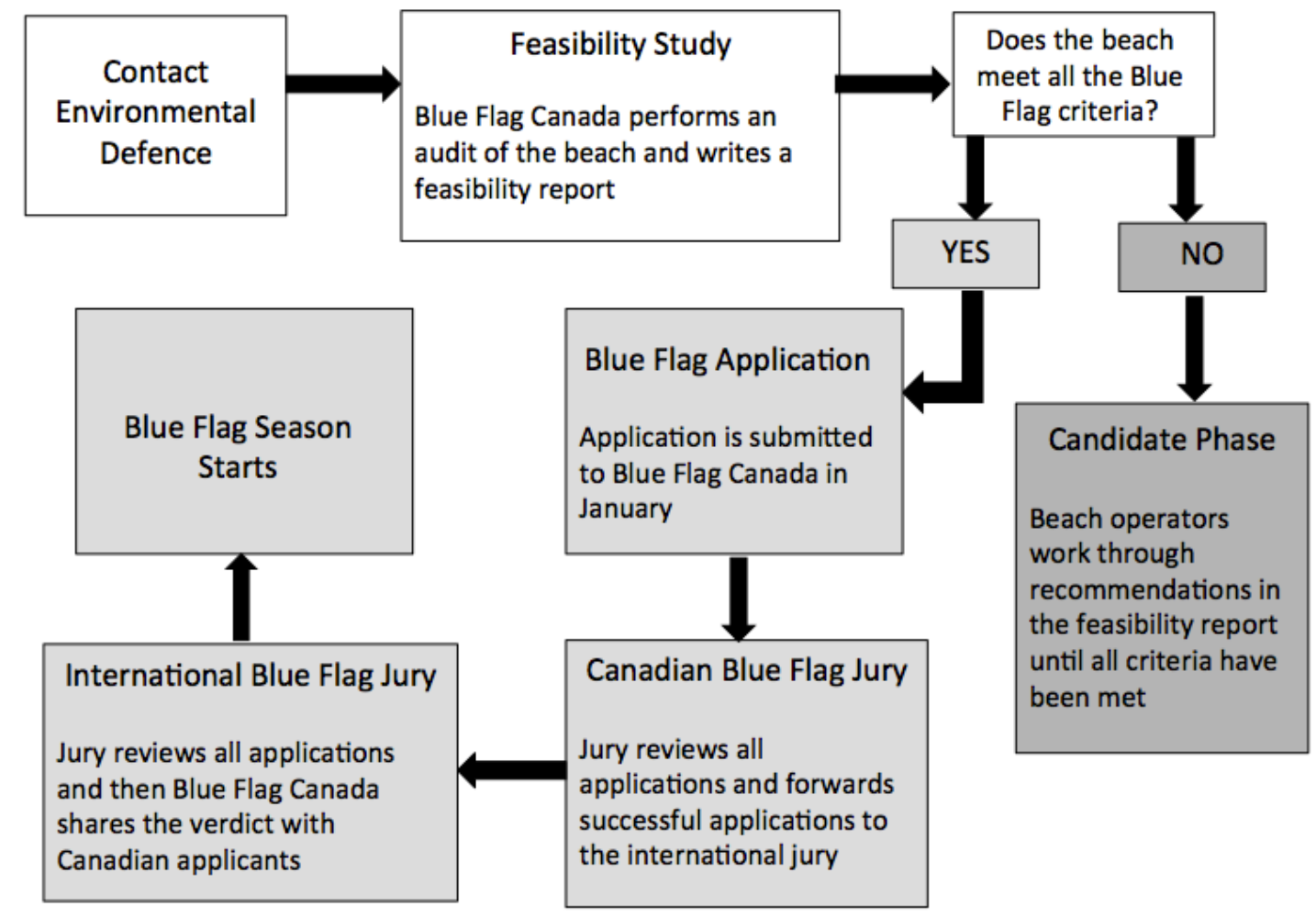

Figure 3 Application process for beaches to become Blue Flag certified in Canada, adapted from Environmental Defence 'Steps to the Blue Flag Award' (n.d.). 
Once a beach receives a Blue Flag, it needs to continue to meet the imperative criteria for the entire beach season. Audits are conducted in order to ensure that beaches are consistently adhering to the criteria and the Flag may be withdrawn from a beach that is not meeting the required standards. These audits may be completed by a Blue Flag representative with the knowledge of the beach managers, or may be conducted by volunteers that are unknown to the beach managers. The Blue Flag is promoted by displaying a flag, leaflets, information boards and pamphlets at each awarded beach (Morgan, 1999).

\subsubsection{Blue Flag in Canada}

For over a decade Canada has had beaches participating in the Blue Flag award scheme. It was first introduced in Toronto, Canada in 2005. Blue Flag was used in Toronto as a symbol to increase the public's trust that its beaches were swimmable and clean (Mondoux \& May, 2011). Environmental Defence, a Canadian environmental organization, is the coordinator of the Blue Flag program in Canada. Four provinces, Manitoba, Nova Scotia, Ontario and Quebec, were participating in the Blue Flag program in 2015.

\subsubsection{Blue Flag in Ontario}

Eighteen beaches in Ontario obtained Blue Flag beach status for the summer of 2015 , which is eleven years since the first award in Ontario was given out.

Seventeen of the Blue Flag beaches in Ontario were located along Lake Huron (including Georgian Bay), Lake Erie, or Lake Ontario, which are three of the five Great Lakes. The first year that these seventeen beaches received their Blue Flag is shown below in Table 1. The remaining Blue Flag beach in 2015 was located on Lake Ramsey. 
Table 1 The first year Ontario's Great Lakes beaches received Blue Flag

\begin{tabular}{l|r}
\hline Ontario Blue Flag Beach & First Year Awarded \\
\hline Cherry Beach & 2005 \\
\hline Hanlan's Point Beach & 2005 \\
\hline Ward's Island Beach & 2005 \\
\hline Woodbine Beach & 2005 \\
\hline Station Beach & 2007 \\
\hline Wasaga Beach Area 1 & 2007 \\
\hline Wasaga Beach Area 2 & 2007 \\
\hline Wasaga Beach Area 5 & 2007 \\
\hline Centre Island Beach & 2007 \\
\hline Gibraltar Point Beach & 2007 \\
\hline Bayfield Main Beach & 2009 \\
\hline Grand Bend Beach & 2009 \\
\hline Kew Balmy Beach & 2009 \\
\hline Port Stanley Main Beach & 2010 \\
\hline Bluffer's Park Beach & 2011 \\
\hline Canatara Park Beach & 2014 \\
\hline Wuabuno Beach & 2014 \\
\hline
\end{tabular}

\subsubsection{Blue Flag as an environmental management tool in Ontario}

According to the international Blue Flag website, the program works hard to be the leader in sustainable management of beaches (Blue Flag 'Our History', n.d.). Municipalities can voluntarily adopt a Blue Flag as a way to work towards sustainable development at their beach. One of the points of action in Ontario's Great Lakes Strategy in 2012 was to "explore opportunities to enhance adoption of the internationally recognized Blue Flag beach certification program at Great Lakes beaches" (Government of Ontario, 2012, pg. 46). More recently, in Ontario's Great Lakes Strategy 2016 Progress Report, which addresses what progress has been made in protecting Ontario's Great Lakes beaches, the Blue Flag beach program is again highlighted. This report states that there is strong support for using the Blue Flag beach program as the standard for healthy beaches in Ontario due to the fact that Toronto beaches have the award (Government of Ontario, 2016c). According to this report, there are currently workshops being held to increase awareness of the program and encourage wider adoption at public beaches in Ontario as one way to improve the Great Lakes. 


\subsection{Benefits and issues of Blue Flag certification}

To date, most research on Blue Flag has focused on public awareness and economic impacts, with very little research assessing the effectiveness of Blue Flag as tool for environmental management.

\subsubsection{Economic impact}

Studies that have been conducted on the economic impacts of Blue Flag seem to suggest that there is a motivation for a municipality to seek Blue Flag status to increase revenue generation in their community (Blackman et al., 2014; Capacci, Scorcu, \& Vici, 2015; Dodds, 2010). A study in Italy by Capacci et al. (2015), concluded there is a significant link between a beach being awarded Blue Flag and an increase in foreign tourism, however, this decision is often delayed until the following year, since many tourists will have already made their beach destination plans before the annual Blue Flag award is given out for the season. Blackman et al., (2014), found that in Costa Rica, a Blue Flag certified beach could provide significant economic benefits to private hotels by signaling high environmental quality and therefore increasing the demand by beach visitors in the area. Within Ontario, Dodds (2010) conducted a local study along the Lake Huron shoreline, which concluded that implementing the Blue Flag program could be an ideal option for beaches to ensure visitors have a long and satisfactory beach visit, possibly resulting in a return visit, and therefore economic gain. These studies provide information that supports the economic benefit of Blue Flag certification to a municipality.

\subsubsection{Marketing and public awareness}

Blue Flag has become well known for its ability to act as a public marketing tool (Ariza, Sarda, et al., 2008). Font (2002) states that having a Blue Flag will have a noticeable impact on destination choice by beach users. Blue Flag ecocertification is often supported in Ontario by the media with press releases and news articles when a new beach receives the award or the status is maintained multiple seasons in a row. Many researchers have found, however, that there are discouraging results about how well known beach awards, and specifically Blue Flag, are known and understood by the public (Dodds, 2014; Lucrezi \& 
Saayman, 2014; Lucrezi, \& van der Merwe, 2015; Lucrezi et al, 2015; Marin et al., 2009; McKenna, et al., 2011; Morgan, 1999; Nelson and Botterill, 2002; Nelson et al., 2000).

Over fifteen years ago Morgan (1999) stated there is limited public knowledge about beach awards. Nelson et al. (2000) found that in the UK there is a definite lack of understanding from the public about beach awards, with only $35 \%$ of beachgoers knowing what Blue Flag means, illustrating that it is uncertain what value the public actually places on these awards. McKenna et al., (2011) came to a similar conclusion after research in Ireland, Wales, Turkey and the USA between 2002 and 2007, finding that beach awards are likely not a significant factor in motivating beach visits from people who otherwise would not be visiting. In this study, only $27 \%$ of people could name the Blue Flag as a beach award, yet factors such as range of activities available, scenery, and proximity are more important to attract visitors to beaches (McKenna et al., 2011). Marin et al., (2009) conducted research on how beach user perception affects beach management and found that although $81 \%$ of people claimed they knew what Blue Flag was, only $8 \%$ of people surveyed could actually define what the program did. Dodds (2014) conducted a study on the potential for environmentally sustainable recreation in the Lake Simcoe watershed. One of the key findings of that research was that only $23 \%$ of people interviewed were aware of Blue Flag, and there is very little knowledge of the Blue Flag program within the watershed.

\subsubsection{Environmental management benefits}

Previously mentioned studies on economic impact and public awareness make up the bulk of Blue Flag research, however, few of them attempted to gain an understanding of exactly how the Blue Flag will be used as an effective management tool for environmental protection at beaches. There is some support for using Blue Flag as the standard for proper beach management. A study by Creo and Fraboni (2011) conducted research specifically aimed to understand the role that the Blue Flag award can play to give guidance to local 
authorities about sustainable tourism development. It is important to note that this study was supported by the Foundation for Environmental Education, who operates the Blue Flag program. The researcher sent questionnaires to all municipalities with Blue Flag awarded beaches in Italy, and concluded that the Blue Flag program is a voluntary certification initiative that can be used as a tool for incorporating environmental decision making into municipalities. Some of the key results of this research were that due to the Blue Flag criteria over $84 \%$ of respondents said that there had been an increase in municipal recyclable waste sorting, over $63 \%$ of municipalities introduced new environmental activities, and in over $66 \%$ of cases general actions to improve environmental sustainability were made. A recent study by Pencarelli et al., (2016) aimed to determine what the benefits of Blue Flag are to local authorities. This study was conducted in 2013 in Italy. Questionnaires were sent out to both policy-makers and employees within the municipalities. The authors determined from the responses of the policy-makers that one of the perceived benefits of the program was that participating municipalities were continuously working to achieve higher environmental standards, and therefore sustainable management was improved. Policy-makers were asked if Blue Flag improved standards of environmental management in the following areas: waste collection, environmental education activities, wastewater treatment, pedestrian zones, cycle paths, and obtaining other certifications. The management areas that the most policy-makers said had 'very significant' improvements were in separate collection of waste on the beach (61\%), and environmental education activities for students (56\%). These studies suggest that Blue Flag is resulting in improved environmental protection of beaches in Italy; however, other literature contradicts this claim, which will be discussed in the next section.

\subsubsection{Issues of Blue Flag as a management tool}

Although Blue Flag is the most popular eco-award and municipalities use it as a management plan, there are criticisms over the use of the award (Boevers, 2008; Lucrezi et al, 2016; Micallef and Williams, 2002; Mir-Gual, Pons, Martín-Prieto and Rodríguez-Perea, 2015; Zielinksi \& Botero, 2015). There is doubt that beach 
awards in general are appropriate schemes to be relied on for management of a beach. For example, Lucrezi et al., (2016) state, "while some of the components of the Blue Flag are relevant for beach management, the programme is inadequate either to guarantee beach quality or properly assist beach management" (pg. 2). Micallef and Williams (2002) stated that although there are quality awards in use, including Blue Flag, none of them successfully take into account the biological, physical and socio-economic requirements that need to be balanced to effectively manage a beach. Research conducted by Boevers (2008) questioned whether the Blue Flag criteria really are an appropriate strategy to use for true environmental beach protection. After conducting a literature review on the Blue Flag award, Boevers (2008) stated that "the program appears to favor accommodations for tourists over interests for protecting ecosystem attributes" (p.527). A recent study by Mir-Gual, et al., (2015) conducted in Spain was one of the first to try to actually measure whether or not the Blue Flag management system really ensures that a beach will have improved environmental health, or if it is managing strictly to meet the needs of visitors. The authors used fifteen different environmental variables to analyze 481 beaches in Spain, and came to the conclusion that there is not a correlation between a beach receiving a Blue Flag award and any significant increase in its environmental quality (Mir-Gual, et al., 2015). The paper argues that the ecocertification focused entirely on the quality of the beach in terms of what someone visiting the beach would want, and does not take into account the natural ecosystem (Mir-Gual, et al., 2015). These authors go so far as to say that this type of certification should not be classified as 'eco' labels, but as more of a measure of amenities offered to the visitors. Another recent study aimed to identify the effectiveness of beach certification schemes, including Blue Flag. This study established a list of sustainability indicators after reviewing the literature, and then compared nine beach certification schemes to these criteria as a measure of effectiveness (Zielinski and Botero, 2015). The results stated that Blue Flag beaches have a 37\% level of compliance with indicators of sustainability. Some of the components missing from the Blue Flag that had been 
identified as an indicator of sustainability were: control of introduction of invasive species, defined and enforced limits to construction, and information on sustainable tourism and integrated beach management to the public (Zielinski and Botero, 2015).

Boevers (2008) recommended that future research be done to determine what difference the Blue Flag award is making, and stated that if an eco-label is claiming to improve the environment at a beach, the beach managers should validate this claim by detailing the improvements that the program has made. There is currently no evidence supporting that beach certification schemes definitely result in higher sustainability, and therefore there has been no conclusion on how useful beach awards, such as Blue Flag, really are as tools for sustainability and environmentally sound management (Zielinski \& Botero, 2015). Therefore these studies support the need for this research, which is to determine the effectiveness of Blue Flag as a management tool for environmental protection.

\subsubsection{Issue with emphasis solely on water quality criteria}

Some studies suggest that there is an emphasis on water quality in the Blue Flag criteria above all other aspects. The biggest criticism with this focus is that the sampling strategy used to determine acceptable water quality that will meet the Blue Flag criteria is controversial for its accuracy (Lucrezi \& Saayman, 2014; Micallef \& Williams, 2002). Sampling is conducted on a weekly basis usually, and researchers question if this sparse sampling should be considered as an accurate indicator of consistent water quality (Lucrezi \& Saayman, 2014). Others point out that in addition to water quality, Blue Flag also focuses on beach cleanliness and safety as well, however equally important elements of beach management are still being left out and ignored (Lucrezi \& Saayman, 2014; Micallef \& Williams, 2004).

\subsubsection{Issue with mechanical beach grooming}

One specific criticism of Blue Flag mentioned in the literature is its lack of specific focus on the ecological health of a sandy beach (Boevers, 2008). Popular 
tourism beaches are heavily used, which has led to some municipal authorities grooming them on a regular basis to make them more aesthetically appealing and to clean up garbage left behind by visitors (Lake Huron Centre for Coastal Conservation [LHCCC], 2012). The Blue Flag criteria does recommend beach cleaning which is criticized by some because mechanical beach cleaning is a style of grooming that will harm the beach ecology (Boevers, 2008; Lucrezi \& Saayman, 2014). Grooming will dry out the sand and can have negative and long-term effects on erosion at a beach (LHCCC, 2012). Removal of naturally deposited plant debris through beach grooming can also lower sandy shore biodiversity dramatically and have negative impacts on beach species and habitats (Brown \& McLachlan, 2002; LHCCC, 2012). Gilburn (2012) determined that beaches with a beach award are much more likely to utilize mechanical grooming than a beach without an award.

\subsubsection{Issue with increased visitation}

It is a clear management issue if beach managers are focusing specifically on the beach users' needs and ignoring environmental protection. An additional issue arises if the Blue Flag eco-certification does really increase visitors significantly, because the beach may be further harmed by overuse. A study by Ariza, Jimenez and Sarda (2008), assessing beach management in the Mediterranean, found that $29 \%$ of beach managers considered their beaches to be overcrowded during the summer season. A few beach managers even indicated that a reduction of visitors up to $50 \%$ would be better. There were no plans, however, created to attempt to manage the level of beach use to a more desirable level, and there was no plan to try to do so in the near future. To have both a beach that is used intensively for recreation and also effectively conserved may not be possible as these two primary objectives are mutually exclusive (McLachlan et al., 2013).

\subsection{Need for this study}

Beach award schemes such as Blue Flag have been said to bridge the gap between recreation and conservation (Nelson \& Botterill, 2002). Claims have been made that beach certification can be an effective tool for environmentally 
sound management that will lead to improvements in beach quality (Williams \& Micallef, 2009). However, it is evident that the literature on Blue Flag as an effective management tool for beaches has gaps. First, very little of the research completed on Blue Flag has actually focused on its capability to protect the environment, but instead has focused on the public perception of the award and on the economic potential of it. The few studies that have investigated how Blue Flag can protect and conserve the environment do not come to a consensus with each other in their conclusions.

While Creo \& Fraboni (2011) suggests that Blue Flag is useful for incorporating environmental issues into beach management for local authorities, there is little detail given as to why this is the case. Pencarelli et al., (2016) stated that a perceived benefit of Blue Flag could be improved environmental quality. However, that was based off of the opinion of policy makers in the municipalities, not the beach managers, and the scope of the environmental management changes only included waste collection, environmental education, wastewater treatment, pedestrian zones and cycle paths. Other literature questions how useful Blue Flag can really be when it focuses on promoting the beach for tourism, and finds that the Blue Flag program is lacking in the ability to assist beach management to ensure that beaches are being managed properly (Ariza, Jimeniz \& Sarda, 2008; Lucrezi et al., 2016; Morgan, 1999). Two recent studies that aimed to evaluate if the Blue Flag program really does result in increased sustainability determined this not to be the case (Mir-Gual, et al., 2015; Zielinkski \& Botero, 2015). A limitation of Zielinkski and Botero's (2015) research, however, was that they didn't look at actual beach scenarios or management, rather just an evaluation of criteria. The Mir-Gual, et al. (2015) study analyzed quantitative data by comparing Blue Flag beaches against fifteen indicators, but did not conduct any qualitative data to learn if beach managers were in fact utilizing Blue Flag as a tool. 
Therefore, although it has been suggested that Blue Flag can be a useful tool for beach managers for environmental protection, there has not been any research aimed specifically at determining how accurate that is. In addition, only one study has been conducted focusing on Blue Flag beaches in North America. The majority of all research that has been done on eco-award beach management has taken place internationally, with the bulk of the studies taking place in Europe on ocean beaches. While this research can help to inform what the situation in Ontario may be, it is not entirely transferrable to Ontario's freshwater beaches. Therefore, there is a need to determine if Blue Flag is an effective management tool for beaches here in Ontario by evaluating the actual scenarios and management taking place at all Blue Flag beaches.

\subsection{Conclusion}

It is clear that, as a heavily used type of shoreline along the Great Lakes, beach protection and environmental management needs to be a priority. It is also clear that the Blue Flag award scheme is the best known and most widely used eco award scheme not only in Ontario, but globally. In Ontario, one of the only current ways that municipalities can actively participate in protecting the Great Lakes is by taking care of their beaches along the shoreline. Ontario's Great Lakes Strategy presents the Blue Flag program as a way to protect the Great Lakes beaches, and describes the program as setting the standard for healthy beaches. It is important to ensure that beach management utilizing Blue Flag is resulting in effective environmental protection. Otherwise the negative impacts from heavy use of the Great Lakes beaches will not only negatively impact the health of the beaches themselves, but by extension the health of the Great Lakes. This study therefore seeks to determine whether Blue Flag is an effective management tool for environmental protection of beaches. This thesis will add to the very limited body of research that assesses whether Blue Flag is an effective management tool for beaches, and will be the first study to include research directly from the beach managers in Ontario. 


\subsection{Methodology}

\subsection{Introduction}

The purpose of the methodology section is to outline how this investigation into beach protection using the Blue Flag certification as an environmental management tool was undertaken. This methodology gives the research question and objectives, outlines the research process, and details the specific steps taken to reach completion of the thesis.

\subsubsection{Research Question and Objectives}

The research question that this thesis aims to answer is: To what extent is the Blue Flag certification program an effective management tool for environmental protection of beaches?

Five objectives were outlined in order to answer the research question:

1. What are the key issues municipalities face with regard to beach protection?

2. What are the successes municipalities have accomplished with regard to beach protection?

3. Which of these successes can be attributed to Blue Flag criteria

4. What motivations or hindrances do managers have in adopting the Blue Flag program?

5. To what extent is Blue Flag being used as a management tool for environmental protection versus a driver for tourism or economic benefit?

\subsection{Research Process}

Mainly primary research was used for this thesis. A review of the literature was used to determine the gap in knowledge and assist in defining the research question and objectives, and a qualitative approach was selected for data collection to answer the research question. The next steps of the process were: piloting the questions, conducting the interviews, and analyzing the data. Figure 4 provides a flow chart illustration of the specific research process. Each step is illustrated here and will be outlined and explained in greater detail below. 


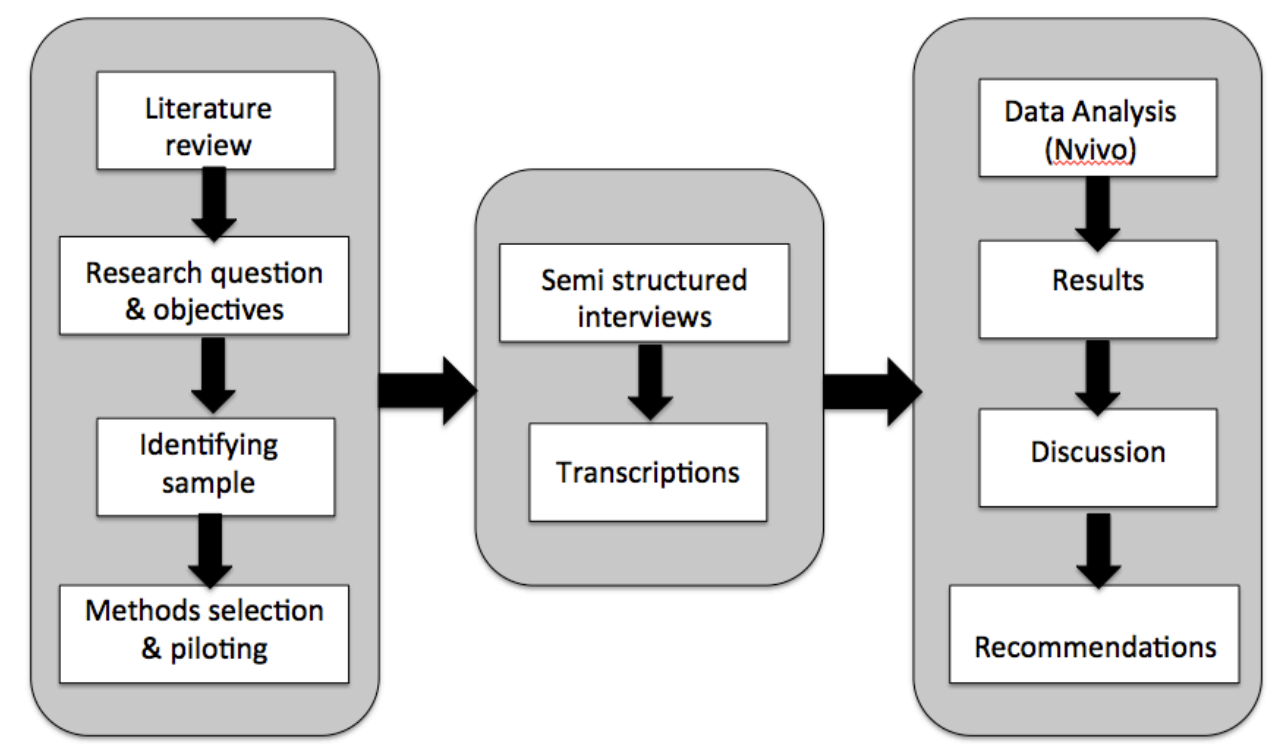

Figure 4 Specific research process

\subsection{Literature Review}

The first step taken in this research was completing a literature review. Academic journals, books, government and environmental organization publications were examined for the literature review. Boote and Beile (2005) identify four key objectives that are important for a literature review to accomplish which explain the use of it in this thesis. The first was to set the general study context and to define the scope of the research. Second, a literature review was needed to establish where the research fits within existing literature. This was important to ensure that any new research was useful and built on the lessons and gaps from previous research to further knowledge of the topic (Boote \& Beile, 2005). Sekaran (2000) states that a literature review is a necessary step to ensure work is not being duplicated and also to make sure key information from previous research is being included. Third, the strengths and weaknesses from previous similar research could be identified and learned from (Boote \& Beile, 2005). Last, the literature review made it clear for the researcher what still needs to be learned about the topic (Boote \& Beile, 2005).

Main themes of the research included in the literature review were: the Great 
Lakes and their beaches, policies and governance of Great Lakes' beaches, municipal beach management, strategies for beach management, beach ecolabels, Blue Flag certification, research on public awareness and economic impacts of Blue Flag, and last the contribution of Blue Flag to environmental management. This literature review identified there was a gap in knowledge about municipal beach management in Ontario along the Great Lakes as well as about the use of Blue Flag as a management tool for environmental protection of beaches.

\subsection{Primary Research Method Selection}

A qualitative research approach was selected to collect the data as it was deemed to be the most appropriate method for this study. Qualitative data is generally gathered in the form of words, and is a nondirective and informal method (Neuman \& Robson, 2009). A quantitative data approach was not selected because it may not have captured the full extent of the knowledge that the beach managers could provide to answer the research question and objectives. Quantitative research approaches gather all similarly structured data from a large sample, for example a survey or an experiment (Neuman \& Robson, 2009; Palys \& Atchison, 2014). This would allow for statistical analysis to be conducted and results to be generalized to a broader group, but would not allow for an inductive approach to be taken that would allow beach managers to discuss any and all themes that they felt were relevant (Palys \& Atchison, 2014). Qualitative semi-structured interviews were therefore chosen as the main data collection method for this research.

Semi structured interviews have the benefit of providing enough structure to address specific research themes with an explicit purpose, but still allow for each participant to give a unique perspective and offer something new to the research (Galletta, 2013; Neuman \& Robson, 2009). Galletta (2013) explains that a semistructured interview is a method with 'unique flexibility' that will allow for a narrative to take place that is guided and informed by the objectives of the researcher. The desired information for this research required an investigation of 
the unique perspectives of the beach managers. The beach managers all had knowledge about their beach management issues, their environmental protection successes, and their motivations and hindrances to receive a Blue Flag yet specific details had never been asked about the process or its effectiveness. This research, therefore, aimed to learn more about Blue Flag as a tool for municipalities to manage their beaches as a way for local governments to be involved in shoreline protection along the Great Lakes. The managers did not answer from a fixed set of possible answers but answered only from their own experience, which helped to ensure that the true opinions and thoughts of each individual were articulated (Neuman \& Robson, 2009). In a qualitative interview the interviewer expressed interest and encouraged elaboration, which gave the beach managers the chance for full explanation and justification to ensure that their rich amount of information was articulated (Neuman \& Robson, 2009).

\subsection{Sample size}

In order to determine to what extent Blue Flag is an effective management tool for environmental protection of beaches, two sampling strategies were used in combination for the collection of data. The first strategy used was purposive sampling, also known as judgment sampling or strategic sampling. Using this type of sampling strategy, the researcher selects the sample for a specific purpose, in order to gain an in-depth understanding (Neuman \& Robson, 2009). This strategy was useful for the study because it ensured that all views of the people directly involved in the program were represented (Palys \& Atchison, 2014). The second sampling strategy employed for this research was snowball sampling. Snowball sampling allows the researcher to grow the network of individuals included in the sample when an interviewee recommends speaking to someone they have a link to (Neuman \& Robson, 2009). A combination of these two sampling strategies was selected to ensure that the sample was focused enough to provide the most relevant information, but also open enough to include individuals of whom the researcher was unaware. The sample was made up from three different types of beach managers: those who held a Blue Flag designation in 2015, those who held Blue Flag at any time in a previous season, and beaches 
in the Blue Flag candidate phase during the fall of 2015. The specific sample will be detailed below. See Figure 5 for a map showing the location of all beaches included in the sample.

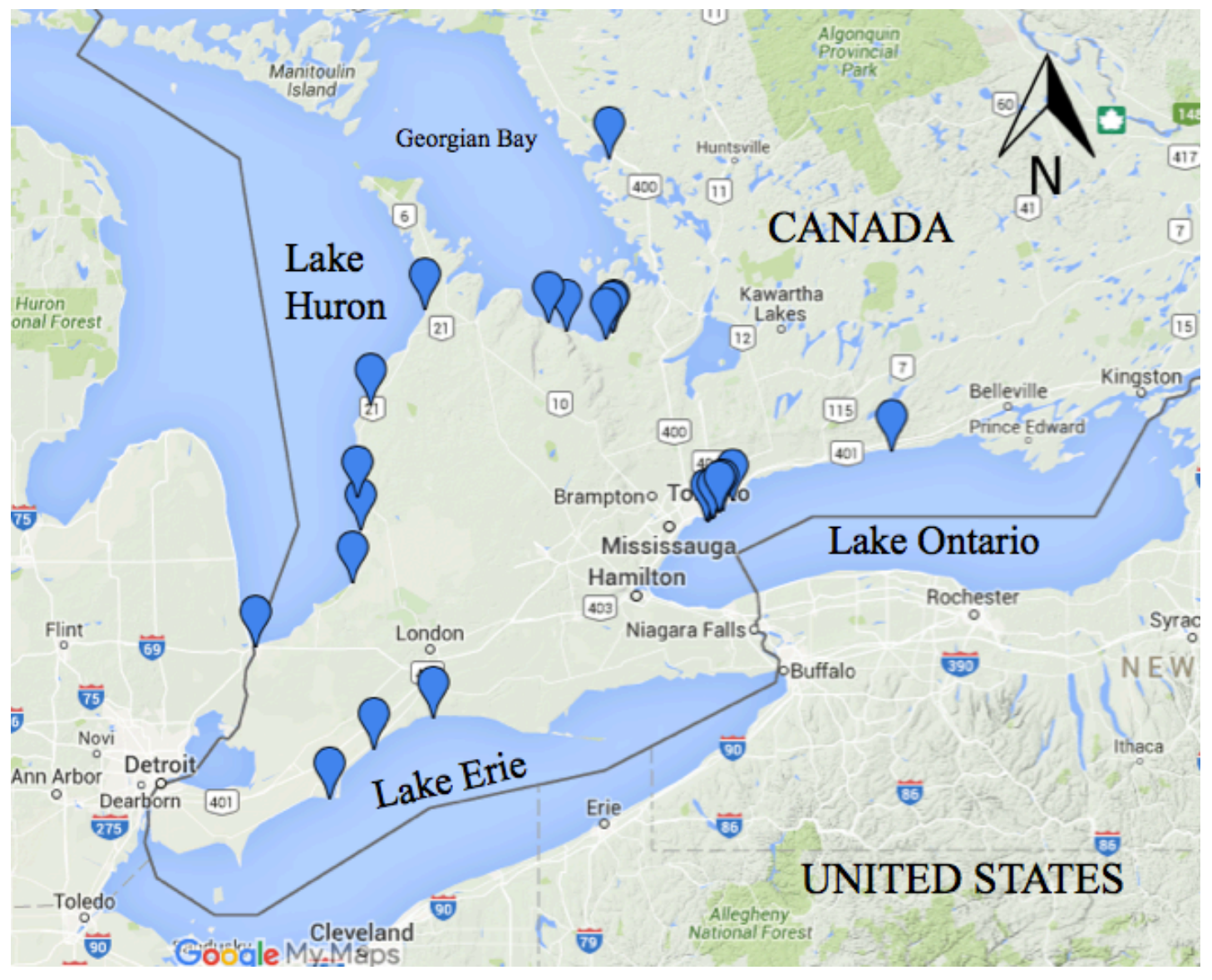

Figure 5 Map showing locations of all beaches included in sample

\subsubsection{Blue Flag Awarded Beaches}

Using purposive sampling, beach managers at beaches along the Great Lakes in Ontario that had been awarded the flag in 2015 were selected as the main interview sample for this research. This was the initial selected sample because these individuals have the most knowledge of the management that is taking place at the beaches with Blue Flag status. The Blue Flag Coordinator at Environmental Defence, who administers the program in Canada, provided the primary researcher with the names and contact information of the beach manager at each beach. This contact information was for the staff member who 
submitted the Blue Flag application representing his or her municipality in 2015. The primary researcher used this contact list for recruitment into the research. It was essential to include the managers at all Blue Flag beaches along the Great Lakes in order to meet the objectives of the research by learning about their experiences managing their public beach. In the 2015 season, there were seventeen beaches that were awarded and maintained a Blue Flag along the Great Lakes, including Georgian Bay (personal communication, June 2015, Environmental Defence). The managers at these beaches therefore became the main sample for the research. In some municipalities one beach manager is responsible for multiple Blue Flag awarded beaches. Through discussions with the Blue Flag Coordinator, the primary researcher learned that a total of ten beach managers made up the entire group of 2015 Blue Flag beach managers (Toronto beaches were represented by three beach managers). The complete group was included in the sample.

Table 2 Summary of 2015 Blue Flag beaches making up the sample

\begin{tabular}{l|l|l}
\hline Municipality & Beach & Water Body \\
\hline Municipality of Bluewater & Bayfield Main Beach & Lake Huron \\
\hline Municipality of Lambton & Grand Bend Beach & Lake Huron \\
\hline Port Stanley & Port Stanley Main Beach & Lake Erie \\
\hline Kincardine & Station Beach & Lake Huron \\
\hline Wasaga Beach Provincial & $\begin{array}{l}\text { Wasaga Beach Area 1 } \\
\text { Wasaga Beach Area 2 } \\
\text { Wasaga Beach Area 5 }\end{array}$ & Georgian Bay \\
\hline City of Toronto & $\begin{array}{l}\text { Bluffer's Park Beach } \\
\text { Centre Island Beach } \\
\text { Cherry Beach }\end{array}$ & Lake Ontario \\
Gibraltar Point Beach & \\
Hanlan's Point Beach & \\
& Kew Balmy Beach & \\
Ward's Island Beach & \\
Woodbine Beach & \\
\hline City of Sarnia & Canatara Park Beach & Lake Huron \\
\hline Town of Parry Sound & Waubuno Beach & Georgian Bay \\
\hline
\end{tabular}


One Ontario beach that was awarded and maintained the Blue Flag award for the 2015 season was excluded from the main sample of this research. Bell Park Beach, which is located in the City of Greater Sudbury on Ramsey Lake, was not included because it does not fall within the scope of the research, as it was not a public beach located on the Great Lakes.

\subsubsection{Past Successful Blue Flag Beaches}

In addition to the main sample of 2015 Blue Flag awarded beaches, four other beaches were selected to be included in the interview sample. These include the beaches in Ontario along the Great Lakes that in the past had achieved Blue Flag status for at least one summer season, but did not hold the designation in 2015. Sauble Beach, located along Lake Huron, had the Blue Flag revoked in June 2015 because of a decision to rake on a beach that provides habitat to Piping Plover. This was the first time in Ontario a Blue Flag certification was revoked (Gowan, 2015). Sauble Beach was awarded the Blue Flag at the beginning of the summer season, but made changes to their raking strategy throughout the summer. Sauble Beach is one of the only locations in Ontario where the Piping Plover continues to nest. The decision by the municipality of Sauble Beach to allow additional raking on their beach was determined to be in violation of the environmental management criteria that Blue Flag supports, so the flag was withdrawn. Goderich beach, also located along Lake Huron, was only able to meet the criteria for Blue Flag water quality one summer and can no longer obtain it, so it no longer had a Blue Flag in 2015. Two beaches in the Town of The Blue Mountains, located along Georgian Bay, achieved Blue Flag status in the past but no longer submit an application.

These beaches were included in the sample selection because beach managers in these three municipalities have a very unique perspective. They are able to compare a past summer season with a Blue Flag to more recent beach seasons without the flag. The other beaches that have obtained Blue Flag consistently do not have this comparison. This insight will be especially helpful to address two of the objectives of the research: a) Which successes can be attributed to Blue Flag 
criteria; b) What hindrances do managers have in adopting the Blue Flag program. In order to recruit beach managers from these three beaches the primary researcher had to get contact information by getting a general email address from the website of each municipality, and ask that the information be forwarded onto the beach managers.

\subsubsection{Blue Flag Candidate Beaches}

Through communication with the Blue Flag Coordinator, the primary researcher learned about three other beaches along the Great Lakes that were candidate beaches (personal communication, June 2015, Environmental Defence). These beaches had expressed interest in meeting all of the necessary criteria and becoming Blue Flag certified in a future summer. The candidate beaches included: Erieau beach and Port Glasgow beach on Lake Erie, and Cobourg beach on Lake Ontario. These beaches were included in the sample because they were still able to provide insight on: beach management struggles, any success stories at the beach, the role of Blue Flag during the certification process, and the motivation to obtain Blue Flag certification. The primary researcher was given contact details for these beach managers from the Blue Flag Coordinator. All three of the candidate beach managers were contacted on multiple occasions to attempt to schedule an interview, but only one of these beach managers participated in an interview for this research.

\subsubsection{Summary of sample}

In summary, the total sample was made up of twenty-four (24) beaches. Seventeen (17) of these beaches were awarded Blue Flag status in 2015, four (4) beaches had Blue Flag status in the past but no longer hold it successfully, and three (3) beaches are a Blue Flag candidate beach. All beaches in the sample that obtained Blue Flag in 2015 or that held the Blue Flag designation in the past were represented by an interview, but only one (1) of the candidate beaches was represented. Therefore this research has a $92 \%$ response rate (22 beaches out of 24).

\subsection{Interview Questions}

The interviews used an interview guide that consisted of fourteen multiple part, 
open-ended questions. It was estimated that the interviews would take approximately sixty to ninety minutes to complete, depending on the answers and detail that each beach manager provided. The questions were written based off the Kvale (1996) typology of questions that should be covered in a qualitative interview. These types of questions include: introducing questions, follow-up questions, direct/indirect questions, probing questions, specifying questions, structuring questions and interpreting questions. Please see Appendix B for a draft copy of the interview questions.

\subsubsection{Piloting}

Interview questions were piloted to ensure that they make sense and can be easily understood and answered. Piloting was also useful to ensure that the questions were answering the research objectives. Three experts were chosen to pilot the guide. First, Geoff Peach, Coastal Resources Manager at the Lake Huron Centre for Coastal Conservation, was selected due to his many years of experience working on the conservation and protection of beaches and coastal environments along the Great Lakes. Second, Mari Veliz, Healthy Watersheds Coordinator at Ausable Bayfield Conservation Authority, was selected due to her association with Healthy Lake Huron and also her involvement with this researcher's supervisor, Dr. Rachel Dodds, who has conducted research on Blue Flag in the past. Last, Karen Alexander, Inventory and Monitoring Technician at Ontario Parks, was selected due to her recent research on beach management in provincial parks, and her extensive knowledge of shoreline management. Piloting took place between October 13, 2015 and November 6, 2015. Minimal changes were made to the interview guide during the piloting process. The changes made were as follows: the term 'trampling' was given more explanation, question six was reworded, and the second follow up question was added to question seven. Please see Appendix $C$ for a copy of the final interview questions.

\subsection{Data Collection}

The potential interview candidates selected were contacted first by email using a recruitment script in November 2015 (see Appendix D). As beach managers 
responded that they were willing to participate in an interview, they were then contacted again to set up a time, date and location for the interview. In-person interviews were selected as the best option over phone interviews for the data collection. An in-person interview has the benefit of there being a greater chance a rapport will develop and questions will be answered candidly (Palys \& Atchison, 2014). All interviews were set up to be convenient for the interviewee, at a location and time that worked for them. Beach managers who did not respond within a few days of original contact were followed up with by emails for a few weeks, and then phone calls, which also used a recruitment script.

In two cases, the initial staff member contacted also asked that another staff member be included who had additional knowledge on the beach management at their particular beach. So at these two meetings the interview involved the primary researcher and two staff members involved in beach management. In two cases, the initial staff member contacted based on the information from Environmental Defence recommended that a different staff member be contacted. At one beach, this was because the beach manager was on maternity leave. At the other beach, this was because the staff member who submits the Blue Flag application is not actually involved in any on the ground beach management decisions or actions. In both of these cases the primary researcher decided to interview the recommended staff member(s) who would be able to provide the best and more detailed information.

In total, fifteen interviews took place, representing twenty-two beaches. This is because municipalities with more than one Blue Flag beach may have the same beach manager representing them, and because in one case, one beach was represented by two separate interviews. Three interviews were conducted to represent the eight Toronto beaches (one beach manager represented the eastern beach, one beach manager represented the beaches on Toronto Island, and one beach manager represented the beaches on the mainland in the City of Toronto). One interview was conducted to represent the three Wasaga Beach 
designated beaches. One interview was conducted to represent the two beaches in The Blue Mountain. Lastly, in one instance, the initial beach manager in one municipality that was interviewed realized during the interview that someone else would be able to better answer some of the questions. In this case, the primary researcher then contacted the suggested person after the interview, and conducted a separate interview with him/her. So in this case there were two interviews with two different people conducted representing one beach, in order to get all of the best information.

Interviews took place between November $9^{\text {th }}, 2015$, and February 17th, 2016. Interviews lasted approximately 60 minutes, with the shortest interview lasting only 35 minutes, and the longest interview taking one hour and 35 minutes plus additional time touring the beach. Of the fifteen interviews that were completed, eleven were done in person, as this was the preferred method. The other four interviews were done over the phone for logistical reasons. The primary researcher took hand written notes during the interview, and a digital voice recorder was used to ensure that all notes accurately reflect the conversation that took place. All but two beach managers that were interviewed agreed to be audio-recorded, so thirteen interviews have a corresponding audio-file. The interviews were all transcribed verbatim and used for data analysis. Handwritten notes by the primary researcher during the interview were also included as a data source because they provided some thoughts that may have not been spoken out loud. Table 2 summarizes the type of interview, length of interview, and type of data recording for all interviews. 
Table 3 Summary of interview style, length and data recording

\begin{tabular}{l|l|l|l}
\hline \multicolumn{1}{c|}{ Interviewee } & $\begin{array}{c}\text { Type of } \\
\text { Interview }\end{array}$ & $\begin{array}{l}\text { Length of } \\
\text { Interview }\end{array}$ & $\begin{array}{l}\text { How Data was } \\
\text { Recorded }\end{array}$ \\
\hline Beach Manager 1 & In-person & 58 minutes & Audio recording \\
\hline Beach Manager 2a, 2b & In-person & 75 minutes & Audio recording \\
\hline Beach Manager 3 & In-person & 50 minutes & Audio recording \\
\hline Beach Manager 4a, 4b & In-person & 77 minutes & Audio recording \\
\hline Beach Manager 5 & In-person & 88 minutes & Audio recording \\
\hline Beach Manager 6 & Phone & 46 minutes & Hand-written notes \\
\hline Beach Manager 7 & In-person & 48 minutes & Audio recording \\
\hline Beach Manager 8 & In-person & 64 minutes & Audio recording \\
\hline Beach Manager 9 & In-person & 95 minutes & Audio recording \\
\hline Beach Manager 10 & In-person & 68 minutes & Audio recording \\
\hline Beach Manager 11a, 11b & In-person & 65 minutes & Audio recording \\
\hline Beach Manager 12a, 12b & In-person, & 53 minutes & Audio recording \\
& Phone & 42 minutes & \\
\hline Beach Manager 13 & Phone & 35 minutes & Hand-written notes \\
\hline Beach Manager 14 & Phone & 50 minutes & Audio recording \\
\hline
\end{tabular}

\subsection{Data Analysis}

In order to analyze the data, the transcribed interviews and all interview notes were utilized. Thematic analysis was used to uncover the patterns and themes within the data. The first step of data analysis was a thorough read through of each transcript while listening to the audio files in order to determine themes and patterns within the research. A memo was created for each of the interviews during this process. The memo included information of what the researcher felt to be the most important quotes, patterns and key words from each interview. This allowed the researcher to become very familiar with the data, and to start to determine key themes. The second step was then to upload all of the transcripts into NVivo as word documents. The NVivo program was used as a tool to organize the qualitative data into 'nodes', which represent similar ideas and information from each interview into the same space. This step of analysis involved reading through the transcripts a second time in order to categorize lines or sections of the interviewees' responses that represented a specific concept or theme (Palys \& Atchison, 2014). According to these authors, this allowed for the data to be organized in a way that allowed for comparisons in 
order to understand the over-arching ideas within it. The primary researcher specifically used inductive coding as the process for data analysis. An inductive approach does not use an existing structure or codebook, but instead it starts with only generalizations and abstract ideas, and concepts are defined as analysis takes place (Neuman \& Robson, 2009). Inductive coding allowed for the researcher to organize the material without being constrained to any predetermined categories that may have altered the results to depict only the expected outcomes. As each transcript was analyzed and coded, new 'nodes' were created that the information appropriately fit into until all relevant data was organized. The nodes were used to determine potential themes, which were then compared against the key themes that emerged from the memo notes. This ensured consistency and reliability in determining key themes. For an example of some of the nodes and how they were organized, see Appendix E. NVivo was also used as a tool to do word queries and create word clouds to visually depict the information contained within certain 'nodes'. The transcripts were excluded from this paper in order to maintain the confidentiality of the interviewees.

\subsection{Ethics}

Ethics approval for this research was originally obtained from Ryerson University on December 8, 2014, with amendments being approved on June 2, 2015, after the scope of the research changed. On November 30, 2015, the research project was approved for renewal for an additional year to ensure that all interviews completed after that date still had full ethics approval. Ethics approved the consent form, email scripts, and the general questions for the interviews. A consent form outlining the purpose of the project, the risks involved, how the data would be used, and details on confidentiality was sent to each potential interviewee with the initial contact email (see Appendix $F$ for a copy of the consent form). All interview participants signed a consent form to indicate that they understood their participation was voluntary, and that they would not be receiving any reimbursement for the interview. Ethics approval requires that the specific names of interview participants cannot be stated in the thesis to protect 
the privacy of the participants and ensure that they are not identified and negatively affected by their participation in this study.

\subsection{Limitations}

There are four limitations in the methodology of this research. First, two beach managers that were included in the sample did not participate. This may have affected the findings because some viewpoints were excluded. This limitation was lessened by the fact that it was two candidate beaches that did not participate, so the experience of these beach managers with Blue Flag was limited. All beach managers representing 2015 Blue Flag beaches and beaches that held the status in the past did participate.

Another limitation is that four of the interviews were held over the phone instead of in person, which was the preferred method. The phone interviews still allowed for the full interview to take place, and it was still possible to ask for clarity and further details on certain answers. It was still possible to develop a rapport with the interviewee, and the main benefits of a qualitative interview were still utilized.

Third, the use of transcriptions for data analysis does not have the capacity to include tone of voice and other indications of the interviewees' opinions. To overcome this, notes from the interviews were cross-referenced and the audio files were listened to while creating memo notes of important themes, taking these cues into account.

Last, the potential for bias exists when interviews are the primary source of data collection. The interviewer can introduce bias into the research with the phrasing of questions or with a misinterpretation of the data, and the interviewees may bias the results by purposefully not answering truthfully, or by answering the question without proper knowledge of the subject. Efforts were made to reduce this type of bias by: giving beach managers the option to not answer a question, recording the interviews to minimize misinterpretation, and coding the data. 


\subsection{Interview Results}

\subsection{Introduction}

This section will outline the findings of the primary research. In order to keep the identities of the beach managers confidential they will not be directly named, but will be labeled as BM1 through BM14. For beaches that were represented by two managers the letters ' $a$ ' and ' $b$ ' will be used to distinguish them. In these cases the ' $a$ ' and ' $b$ ' beach managers were only counted as one beach manager out of fourteen so that the beach they represented did not get a disproportionate amount of representation.

This findings chapter will first outline a profile of the beaches to provide context that will include common management practices taking place at beaches, main challenges and issues at the beaches, and what success stories beaches have in terms of beach management and environmental protection. It will then give results on what tools and strategies are being utilized by beach managers in order to manage the beaches, and will discuss the role they see this having for the Great Lakes. Next the chapter will discuss the role of the Blue Flag program at the beaches, including how it has been used to successfully manage the beach, the benefits beaches receive, and the changes at the beach that can be accredited to the program. Lastly the chapter will cover the future potential for Blue Flag, and what barriers other municipalities may face when trying to achieve the status.

\subsection{Profile of Great Lakes beaches}

The beaches included in the study are all located along the Great Lakes in Ontario. However, not all five Great Lakes in Ontario have Blue Flag beaches, so the beaches in this research are found on Lake Huron (including Georgian Bay), Lake Erie, and Lake Ontario. All of the beaches in the study are public municipal beaches except for Wasaga Beach, which is located in a provincial park, and therefore provincially managed with a specific mandate set out by the Provincial Parks and Conservation Reserves Act. The beaches are all primarily sand beaches, and while the majority are natural beaches (meaning the sand was 
deposited historically through natural processes), there was one beach that the beach manager identified as being a manmade beach that requires the sand to be brought into it.

The beaches vary in size significantly, with the longest beach being Wasaga Beach, which has a $14 \mathrm{~km}$ long shoreline (although only sections of it are designated as Blue Flag), and the shortest beach being just over $100 \mathrm{~m}$ long on the shoreline in Parry Sound. All beaches in this study have at least part of their beach supervised by lifeguards, which is a requirement of the Blue Flag criteria, but not a requirement of all Ontario public beaches. Four (29\%) of the beaches included in this sample identified they had at least one species at risk present on their beach in 2015 .

\subsubsection{Beach staff profile}

Beach managers being interviewed were all asked to give their job title, and a short description of what they do. The majority of job titles given were either as a role in recreation or a role in parks. See Figure 6 for a visual representation of the job title of the people involved in managing the beaches and overseeing the Blue Flag program.

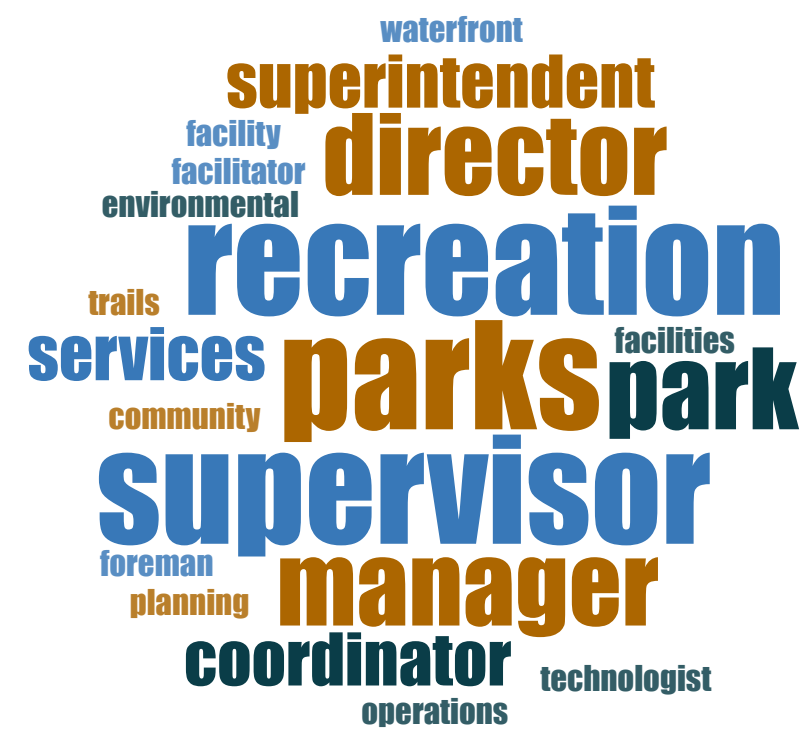

Figure 6 Word cloud generated from the job description of all interviewees 
None of the interviewees gave a job title or description that indicates that beaches are their main role. BM2a made it clear that they have many other responsibilities and stated "I oversee all recreational facilities, beaches being just one of those". BM14 said, "the area that we take care of with our staff is quite large, it's not just the beach". Most beach managers indicated that there were seasonal beach staff present at their beach(es), but the role of these staff members was primarily garbage clean up and/or lifeguarding. Many of the beach managers interviewed had been in their positions or other similar positions within the municipality for many years, which gave them extensive experience in managing the beach, both before the Blue Flag program was adopted, and after. Only two $(11 \%)$ of all the beach managers interviewed (including both beach managers separately if more than one beach manager represented a beach) had been involved in beach management at their municipality for three years or fewer. The rest of the beach managers $(78 \%)$ interviewed had held a position in their municipality associated with beach management for a range of seven to twenty-eight years, or did not specify exactly how long they had worked in the municipality or on beach management.

Table 4 Number of years working in municipal position on beach management

\begin{tabular}{l|r|r} 
Range of years & $\boldsymbol{n}$ & $\boldsymbol{\%}$ \\
\hline $1-5$ years & 2 & $11 \%$ \\
\hline $6-10$ years & 5 & $28 \%$ \\
\hline $11-15$ years & 2 & $11 \%$ \\
\hline $16-20$ years & 3 & $17 \%$ \\
\hline $21-25$ & 1 & $6 \%$ \\
\hline $26+$ & 2 & $11 \%$ \\
\hline Unspecified & 3 & $17 \%$ \\
\hline Total: & $\mathbf{1 8}$ & $\mathbf{1 0 0 \%}$
\end{tabular}

\subsubsection{Beach cleaning and grooming}

Beach managers were asked how their beaches are cleaned and how garbage is collected. All beaches have some type of formal garbage removal process, which is a requirement in the Blue Flag criteria. The beach grooming techniques utilized at the beaches varied, however, the most commonly answered type of grooming 
was with the use of a mechanical rake or groomer. Mechanized beach grooming and raking is a conventional beach management strategy that takes place at public beaches in order to remove garbage and smooth out the sand. Mechanical beach grooming can cause harm to the natural beach environment and have long-term implications for the dune system health. A summary of the beach grooming techniques is presented in Table 4.

Table 5 Grooming technique and frequency at Blue Flag beaches

\begin{tabular}{|c|c|c|c|c|}
\hline Style of Grooming & \multicolumn{2}{|l|}{$\boldsymbol{n}$} & \multicolumn{2}{|c|}{$\%$} \\
\hline $\begin{array}{l}\text { Mechanical } \\
\text { Regularly scheduled } \\
\text { Occasional }\end{array}$ & 12 & $\begin{array}{r}10 \\
2\end{array}$ & $86 \%$ & $\begin{array}{l}71 \% \\
14 \%\end{array}$ \\
\hline Hand raking only & 2 & & $14 \%$ & \\
\hline Total: & 14 & & $100 \%$ & \\
\hline
\end{tabular}

Twelve (86\%) of the beach managers said they used a mechanical groomer in the 2015 beach season for beach grooming. The occurrence of this grooming varied from daily, to only a few times per beach season. Ten $(71 \%)$ beach managers specified grooming took place on regularly scheduled intervals throughout the summer. This included daily, every other day, twice per week, and weekly. Two (14\%) beach managers who indicated that mechanical grooming is used but not regularly scheduled, said that it takes place occasionally only when it is deemed necessary, or before certain events and busy weekends. The remaining two (14\%) beach managers said mechanical grooming was not used at their beach, and only hand raking was utilized. BM5 said that a conscious choice had been made to stop using a mechanical groomer in 2015 in order to take a more natural approach. BM5 described this by saying instead of continuing to use a mechanical groomer

"[We] decided to change that approach and what we did is we hand raked garbage off the beach. We took away two large trees that were on the beach in the water by machine. We collected some agricultural debris off the beach that might have been contaminated and other than that we left it completely natural.... The goal was to have a more natural process that wouldn't disturb the ecology of the beach". 
BM6, the other beach manager who indicated that mechanical grooming does not take place, was unsure of details about why that choice had been made, but stated that the lifeguards and maintenance staff do hand raking and are responsible for cleaning the beach, but that mechanical grooming is not utilized.

Only one $(7 \%)$ beach manager that utilizes mechanized beach grooming at the beach said that it was for managing Escherichia (E. coli) bacteria. The thought process behind this is that the beach groomer will rake through the sand and turn it over and expose it to the sun, which will kill harmful bacteria. BM7 described this process as "highly effective". All other beach managers who indicated mechanized grooming takes place at the beach said it is for removing garbage and/or to aesthetically smooth out the sand. BM11a provided an example of this by saying, "we do drag a landscape rake once a week just to smooth out the holes the kids dig and to make it look a little nicer".

\subsubsection{Water testing}

In Ontario, is it required that the local public health unit tests water quality at public beaches for E. coli bacteria. Therefore, all beaches included in the research had water quality tested regularly during the swimming season, as required by provincial guidelines. The occurrence of those tests varied depending on the beach, however, because some Blue Flag beaches test more regularly than required, and criteria of the Blue Flag program requires testing for intestinal enterococci (streptococci) in addition to E. coli bacteria that the province does not. The frequency of water quality testing at the beaches is summarized below in Table 5.

Table 6 Frequency of water quality testing at Blue Flag beaches

\begin{tabular}{l|r|r}
\hline Number of days per week water is tested & $\boldsymbol{n}$ & $\boldsymbol{\%}$ \\
\hline One day per week & 7 & $50 \%$ \\
\hline Two days per week & 3 & $21 \%$ \\
\hline Three days per week & 1 & $7 \%$ \\
\hline Seven days per week (daily) & 3 & $21 \%$ \\
\hline Total: & 14 & $100 \%$
\end{tabular}


Seven $(50 \%)$ beach managers indicated the beach or beaches they represent were tested once per week, which is the provincial requirement. Three (21\%) beach managers said that a total of two tests happen per week, one beach manager $(7 \%)$ said that water testing takes place three times a week, and the remaining three (21\%) managers indicated that the beaches are tested daily. This difference in the frequency of water testing depended primarily on the funding available and the capacity of the health unit or municipality completing the water testing. Each beach had at least one test per week completed by the health unit, and in some cases the municipality supplemented the additional weekly testing. This is an approximate schedule, because there is also flexibility within these testing dates. It is common that if a negative water quality result is found then another test will take place immediately in order to get an acceptable result, which would result in an additional test that week.

\subsubsection{Challenges faced by beach managers}

Beach managers were asked what their biggest challenges are with regards to management at their beach(es). Throughout the interviews beach managers discussed many challenges, and all of those challenges are summarized in Table 6. 
Table 7 List of all beach management challenges indicated

\begin{tabular}{l|r|r}
\hline Challenges in beach management & $\boldsymbol{n}$ & $\boldsymbol{\%}$ \\
\hline Litter & 7 & $50 \%$ \\
\hline Water quality & 6 & $43 \%$ \\
\hline Public perception and expectation & 6 & $43 \%$ \\
\hline Balancing environment and recreation & 6 & $43 \%$ \\
\hline Managing sand dunes & 4 & $29 \%$ \\
\hline Overcrowded space & 3 & $21 \%$ \\
\hline Limited parking & 3 & $21 \%$ \\
\hline Invasive species (Phragmites) & 3 & $21 \%$ \\
\hline Vandalism & 2 & $14 \%$ \\
\hline Garbage collection & 2 & $14 \%$ \\
\hline Managing species at risk (SAR) & 2 & $14 \%$ \\
\hline Breakdown of grooming equipment & 1 & $7 \%$ \\
\hline Recycling contamination & 1 & $7 \%$ \\
\hline Lack of council support & 1 & $7 \%$ \\
\hline Dogs on the beach & 1 & $7 \%$ \\
\hline Water levels & 1 & $7 \%$ \\
\hline Out of date management plan & 1 & $7 \%$ \\
\hline Lack of enforcement & 1 & $7 \%$ \\
\hline
\end{tabular}

$n=14$

Note: total will not equal $100 \%$ as respondents may have provided more than one answer

Litter was the most commonly mentioned challenge that seven (50\%) beach managers listed as a challenge they have to deal with, at least occasionally. BM3 described their issue with litter saying:

"Some people will bring food items and stuff and at the end of the day they just get up and walk... and you look at all these people, if each one of them on that beach brings over like a knapsack or a cooler with like drinks and fruit and you know munchies or whatever and they're going to be leaving that there, that's a lot of volume".

Water quality was another challenge revealed by many of the beach managers. Six $(43 \%)$ beach managers mentioned that they still have issues maintaining good water quality consistently. Explanations given for the poor water quality were birds, infrastructure at the waterfront, or heavy rainfalls. BM11a described the challenge saying: 
"I think we've seen an increase of water quality testing coming back that's above the thresholds. A lot of that is with development. As development increases in the area and specifically along the areas where drainage does go from developments out to the water....and when we've looked into it, it's just the weather conditions, just heavy rains with the right wind will push that water that's went into the bay through the drainage into the water fronts."

Six $(43 \%)$ of the beach managers specifically said that public perception and certain expectations are a challenge. BM9 provides a good example of this struggle by explaining:

"There are many expectations of what this beach should look like. It depends on where you are coming from. If you are a tourist operator or you are a business owner in town or you are the mayor or you are a naturalist... everybody has their own expectation of what we should be doing to manage this beach appropriately."

In addition to describing perceptions and expectations as a challenge, beach managers also described another challenge with the public. Six beach managers (43\%) described situations where they are faced with the challenge of trying to balance protecting the natural environment while still providing people with sufficient recreation space and enough accessible access points and boardwalks. Examples of this include: expanding sand dunes that are beside a boardwalk and pushing sand onto it; not mechanically grooming to protect species at risk but losing beach space to vegetation; pressure to keep sand for volleyball courts looking meticulous. BM9 explains this struggle with balance between the two elements well by saying:

"We are trying to find that sweet balance, that sweet spot between providing recreational opportunities for people that come here because that beach is an economic engine not just for the town but for the entire region...so, there is the economic side of things and then there is managing the beach for protection because it's a sensitive habitat, it's a dynamic ecosystem, we've got some sensitive dunes out there...so, it's trying to find that balance between the two."

Six (43\%) beach managers mentioned that they receive complaints about how they are managing the beach if members of the public are not satisfied with what 
is being done. Another challenge multiple beach managers acknowledged is the struggle to protect sand dunes and allow them to grow and naturalize on the beach without disruption from the public. Four $(29 \%)$ of the beach managers declared this, and while a couple of these beach managers said the problem was not as severe because people were just wandering into the dune area, other beach managers described the situation to be very difficult to manage. BM2b said:

"We plant a series of grasses, then the next morning you'd come in the morning and those grasses would be removed from the sand. Because they [the local public] don't want them in a particular place on the beach, maybe it'll block their view or it'll change the aesthetic value for them"

The other beach manager, BM2a, representing the same beach added that:

"We often find people have gone down there too, with like weed rippers and stuff and just like knock down all the native plans that are growing, the grasses or really anything that they see out there. We have a number of people that like to take it upon themselves to move sand around, dump sand, that kind of thing"

Three other challenges listed involved in managing the beaches were:

overcrowded space, limited parking, and Phragmites. Each of these challenges was described by three $(21 \%)$ of the beach managers. Dealing with vandalism, removing garbage bins off the beach, and managing species at risk were challenges described by two (14\%) of the beach managers. The remaining challenges were only described by one $(7 \%)$ beach manager each, and these include: breakdown of grooming equipment, recycling contamination, lack of council support, dogs running on the beach, water levels, out-dated management plan, and lack of enforcement. It should also be noted that although it was not described as a current challenge, two (14\%) beach managers did say that water levels continuing to increase could pose a challenge in the future because there is less open beach then. 


\subsubsection{Most significant issue at the beaches}

The challenges listed above summarize all challenges listed by beach managers throughout the interviews. When specifically analyzing what each beach manager indicated to be the one biggest issue they deal with, the responses were still varied, but fell into one of two general categories: 1) physical or environmental issues at the beach 2) dealing with the people who use the public beach. These answers are summarized in Table 7 below.

Table 8 The most significant challenge listed by beach managers

\begin{tabular}{l|r|r}
\hline Type of challenge & $\boldsymbol{n}$ & \% \\
\hline Physical (environmental) & 7 & $50 \%$ \\
\hline People (expectations/perception) & 6 & $43 \%$ \\
\hline Not specified & 1 & $7 \%$ \\
\hline Total: & 14 & $100 \%$
\end{tabular}

Out of the fourteen beach managers, seven (50\%) listed a physical or environmental challenge as the biggest issue they have to deal with. These issues included: overcrowding and parking (BM4, BM11), water quality (BM5, BM12), litter/garbage, especially cigarette butts (BM6, BM10), and water levels (BM8). BM5 justified their perspective saying:

"The biggest problem is water quality...you can manage everything else. You can have enough garbage, you can have signage, you can have safety equipment, you can have a life ring, you can manage all that but you can't manage water quality"

BM6 explained their viewpoint on litter as the main challenge saying:

"I think litter is a natural answer...[we have] real concerns with smoking on the beach, which then leads to cigarette butts left in the sand"

The remaining six (43\%) beach managers, which is excluding BM7 who did not specify the one biggest challenge at the beach, indicated that the one main challenge they deal with is managing people at the beach and trying to change public perception and meet people's expectations while still protecting the beach. BM9 indicated, "The biggest challenge in managing the beach is managing 
expectations". BM1 explained their perspective about people being a challenge saying:

"Probably getting our people to buy into it, like the public... getting people to respect and to try to understand why we're doing some of the things we're doing, like with the grasses and the access points"

BM2a responded that the biggest challenge is people by saying:

"... public perception, kind of what they think it should look it... I don't think a lot of people understand it, or understand why or what we're doing"

There was no evident difference in opinion about the most significant challenge with beach management between the beaches that had the Blue Flag status in 2015 versus the beaches that did not have it. There was also no obvious similarity among beaches located on the same lake or closer proximity to each other.

\subsubsection{Management success stories at the beaches}

Beach managers were asked to share any success stories they have had in terms of beach protection. All beach managers provided at least one success story when probed, but not all of these responses were necessarily examples of successful environmental management of the beach. Some beach managers provided multiple success stories, and all of the answers are indicated in Table 8.

Table 9 Beach protection success stories

\begin{tabular}{l|r|r}
\hline Success story & $\boldsymbol{n}$ & $\boldsymbol{\%}$ \\
\hline Dune restoration or vegetation planting & 6 & $43 \%$ \\
\hline Educational activities & 6 & $43 \%$ \\
\hline Beach infrastructure & 5 & $36 \%$ \\
\hline Working to improve water quality & 2 & $14 \%$ \\
\hline Beach stewardship groups & 2 & $14 \%$ \\
\hline Phragmites removal & 2 & $14 \%$ \\
\hline Getting dispensation from Blue Flag & 1 & $7 \%$ \\
\hline
\end{tabular}
$n=14$

Note: total will not equal $100 \%$ as respondents may have provided more than one answer 
Six $(43 \%)$ of the beach managers said they have had success with dune restoration or vegetation planting. Two (14\%) of these beach managers indicated that because of their vegetation plantings they now have reduced issues with sand movement. BM12b said:

"The dune grass planting that we did at the main beach, we did it right along the boardwalk. We had this... garden there ... and then within a few weeks it would be full of sand. And then they dig all [the] sand out, and then they planted it again, and it would be full of sand... so we put in the dune grass, and we never had sand in the flowerbed again. And it's really thick now and it's so healthy and that used to just be all open sand."

BM10 indicated that less maintenance is now required, saying:

"Sand normally would just go out onto the street, so we would have to be maintaining like the parking lots and the streets a lot more, but because of the dunes we don't see a whole lot of need for work on the street and the parking lots...they are serving the purpose that they need to be serving, and they are doing a good job there. Before [the street adjacent to the beach] like could have some sand storm happening because of the sand from the beach coming up. The dunes have done a good job of mitigating that for sure."

Another success story stated by six (43\%) beach managers was educational activities being provided at the beach. These programs included: bringing students to the beach to learn about beach health and take part in beach cleanings; running the Butt Free Beach program to reduce cigarette butt pollution on the beach; offering youth information sessions on water safety and beach health. Five (36\%) beach managers listed some type of beach enhancement as a success story. These type of enhancements included: creating an overall beach enhancement plan that added to the infrastructure such as a boardwalk; developing designated parking and specific usage zones; building groynes ${ }^{1}$ to stabilize the shoreline; and improving the washroom facilities by building an outdoor shower. Working to improve water quality was mentioned as a success story by two $(14 \%)$ of the beach managers. BM5 explained that a temperature

${ }^{1}$ A groyne is an engineered structure built to reduce erosion along the shoreline 
logger has been installed onto a swim buoy in order to try to learn more about the correlation of the temperature at their beach at poor water quality results. BM4a described the success at his beach that effectively improved water quality:

"Several years ago it would never pass because of the E.coli... when it rained the water would wash, and our parking lot also, all the water would wash into the lake. So seven years ago [we] built a dyke system behind the beach which catches any of the water coming down off the hill or off the bluffs, catches the water, goes in to a natural swamp area, and gets cleaned behind and then when it gets so high it overflows, goes under the dykes and through another forest marsh area eastwards and then goes out into the lake. By the time it does all that it's clean.... and virtually since the year they have done that we have never had a 'beach closed' day"

Other success stories were only described by a small number of beach managers. Two (14\%) indicated that some type of beach stewardship group was a success story for them. Two (14\%) beach managers said that the effective removal of the invasive species Phragmites from was a definite success that took place at their beach. One $(7 \%)$ beach manager said that receiving the dispensation for the Blue Flag was a success, because despite a summer of bad water quality results the beach was able to receive a Blue Flag the following summer. More information on the dispensation from Blue Flag will be explained later in the paper.

\subsection{Tools and strategies for beach management}

Beach managers were asked if there were any specific tools or strategies that they use for beach management and beach protection. The beach manager representing the beach that has not ever yet successfully obtained the Blue Flag status was not included in this sample, so the following section only includes thirteen beach managers. The responses to this question were extremely varied, and did not produce any one or two answers that represented the majority of the beach managers. 


\subsubsection{The use of Blue Flag as an environmental management tool}

A key finding is that only three $(23 \%)$ beach managers said that they consider the Blue Flag program or criteria to be a useful tool without any prompt. All three of these beach managers were representing one beach that had Blue Flag status in 2015. The consensus with these managers was that the criteria are useful as a clear guideline of what is required at a beach with quality standards, and without it the beach may not be managed to that standard. An additional two (15\%) beach managers later in the interview said that Blue Flag is a program that has made a noticeable difference for them. One beach manager said it has resulted in them spending more time cleaning, which would suggest it is an environmental management tool. The other beach manager though said it was a benefit in terms of recognition, which would still not suggest it is an environmental management tool. These findings imply that the majority of the beach managers who have been involved in the Blue Flag program do not consider it to be an effective environmental management tool.

\subsubsection{Opportunity for Blue Flag to improve environmental management of the Great Lakes \\ Although Blue Flag is the only formal beach management program in Ontario, beach managers indicated the program did not necessarily have the capacity to act as a mechanism for municipalities to have a role in managing the Great Lakes at all. BM5 explained that it is too complicated for the municipality to play a role:}

"It is difficult because the municipality is the lowest tier and the Feds have a role in the Great Lakes, the province has a role in the Great Lakes and the municipality is the level of government with the fewest resources, no legislative tools... where there is a gap in the federal or provincial actions, the municipality can't rush in to fill every gap because there's simply not enough money."

There was little involvement by the beach managers in any tools or strategies other than Blue Flag that were focused on the protection of the beaches along the Great Lakes. Two (15\%) beach managers said they subscribe to emails from the Great Lakes Beach Association network. These beach managers have attended conferences put on by this association in the past to learn more about 
beach management along the Great Lakes. Two (15\%) beach managers specified that they had heard of the Great Lakes and St Lawrence Cities Initiative, but they said they did not know if their municipality was a part of it. One (8\%) beach manager mentioned participation in a zebra mussel program, which is an invasive species in the Great Lakes. Beach managers were asked if they felt that there were opportunities for them to be involved in management of the Great Lakes by managing their beaches. Although few beach managers expressed a strong opinion about this, four (31\%) beach managers stated that doing any small part could help, and taking responsibility for the direct area they manage can only have a positive result. These beach managers stated that their role protecting the environment at their beach was really to add to the collective impact.

\subsubsection{Partnerships as key to environmental management}

A theme emerged that forming partnerships was very important to the successful management of the beaches. Four $(31 \%)$ beach managers stated their main tool or strategy was working with an external partner in some way (BM3, BM5, BM7, BM13). The partnerships described included: working with bylaw for enforcement purposes; working with a conservation authority to improve water quality; working with a health unit for water testing and results; and working with an environmental organizations and the Ministry of Natural Resources. Although only four $(31 \%)$ beach managers actually listed a partnership as a tool they use when directly asked, a theme found throughout the interviews was the importance of creating and utilizing partnerships when managing the beach. Ten ( $77 \%$ ) beach managers throughout the interview acknowledged that a partnership has been key to their environmental protection in some way. BM1 stated in regards to their beach management decisions "I would be lost without some kind of assistance". According to BM8, "We [the municipality and an environmental organization] have a partnership together, and we do everything together". BM9 also mentioned partnerships "... in this world, you have to be creative, and you have to work with partnerships" when discussing a beach stewardship program that had been created. It would seem that an important 
finding of the research is that partnerships are key to the process of successful beach management, and may be the tool that beach managers value the most.

4.3.3 Lack of clarity and specific tools or strategies for environmental management In addition to the few beach managers who responded that the Blue Flag criteria is a beach management tool or that forming partnerships is an important tool, there were minimal responses to the question about tools and strategies. Three (23\%) beach managers included their grooming equipment as a tool for beach management. Two (14\%) beach managers said that signage is an important tool, and two $(14 \%)$ beach managers said that they use sand fencing for management. Other more abstract strategies given were: cleaning the beach early, communicating with the public using a Facebook page, keeping the beach staffed constantly, applying the mandate of the park, issuing work permits for maintenance on the beach, and focusing on swimming lessons. There was very little consistency in these answers, and beach managers had very different opinions on what a tool or strategy for beach management included. These types of tools also did not address environmental management or environmental protection in any way.

It was a key finding that very few of the responses given were specifically for a strategy used for what could be considered environmental protection or conservation. The responses tended to be quite vague, and to imply that there is not a formal strategy determining how to effectively manage each of the beaches for successful environmental protection. According to BM7, "There's nothing revolutionary about what we're doing". BM10 responded when asked about tools or strategies by saying "none that I'm really aware that would be unique to what other municipalities are doing". After reflecting on the question BM2b responded "we could probably use a few more tools in place... I think more tools probably would be helpful ... now that you've mentioned it", which indicates that specific beach tools and strategies are not really available for effective environmental management. 


\subsection{Role of Blue Flag in environmental protection success stories}

Beach managers were asked if they think that having the Blue Flag designation

played a role in successful beach protection at their beach(es). The beach

manager representing the beach that has never successfully obtained Blue Flag status was excluded from this sample. The following results include the remaining thirteen beach managers. Four $(31 \%)$ of the beach managers clearly stated that yes, the Blue Flag program has a played a role in their success stories for environmental protection. It is important to note that three of the beach managers included here are three of the same beach managers that previously stated the Blue Flag program is a tool they use for beach management. This indicates that there is possibly a distinct group of beach managers within the sample that value the Blue Flag program, and the remaining beach managers do not. BM5 explained why they think Blue Flag has played a role in beach success saying:

"I do... In terms of galvanizing the community around the importance of clean water, the Blue Flag program does that really well. I would consider this to be the first and the only environmental program that the municipality does, and to have it so specific to beaches, I think having that single point of focus makes it so easy to convey the benefits and the risks to people"

BM1 explained that they think the Blue Flag has played a role in success stories at their beach because "... a lot of times we maybe wouldn't get the money or the resources if we weren't to tie back to Blue Flag". BM2a also related the positive role of Blue Flag to getting more resources for management:

"Yeah, because again, like they set out a certain criteria that you have to follow and it becomes important to council that we can say 'hey we got our Blue Flag, right?' So, I think again without that, I don't think that, at least in this community, we would see so much going on there. I think it would probably be kind of just be left on its own.... like there wouldn't really be a beach management committee without Blue Flag. We wouldn't be looking at our water quality without Blue Flag. We wouldn't be ramping up our public education without them, all that stuff." 
These explanations suggest that the role of Blue Flag in beach management might be for use as a tool to manage the relationship with the municipality and justify needs for more funding for beaches. None of the beaches indicated that the role of Blue Flag was as management tool to ensure environmental protection or the overall environmental management of the beach. In addition, three $(23 \%)$ of the beach managers distinctly stated that they did not feel that Blue Flag played a role in their success at all. One (8\%) beach manager indicated that Blue Flag played a role only in terms of marketing, and one $(8 \%)$ other beach manager stated that the role it has played is educating the public. The other four (31\%) beach managers did not provide a definitive answer, however, two (15\%) of these beach managers did insinuate Blue Flag had not played a role because without being part of the Blue Flag program all management at the beach would still be the same.

\subsubsection{Blue Flag criteria for environmental protection}

Beach managers were asked if they felt that the Blue Flag criteria provided sufficient steps to protect their beach, which provided a mixed result. Four (40\%) of the beach managers did not clearly answer this question, so out of the ten responses, four ( $40 \%)$ of the beach managers clearly answered 'yes', four ( $40 \%)$ of the beach managers definitively answered 'no', one (10\%) beach manager indicated no but acknowledged it is the only program available, and one (10\%) beach manager implied there are certain situations it could be useful for protection, but it they are not using it for protection.

The beach managers who said that the Blue Flag criteria are useful for beach protection supported their opinions differently. One of the beach managers did not elaborate because they did not feel that they had enough knowledge to do so. BM2a supported their opinion:

"I think so, yeah... [because] we are almost at the bare minimum, there's so much more that we could do and use that tool to help us.... we're forever improving, and we can meet the bare minimum and still improve because there's more to do [to meet the criteria]" 
BM10 indicated they thought the criteria effectively protect the beach:

"I'm going to say yes because Blue Flag does its audits, so they set forth this criteria that you have to follow to be considered Blue Flag. The audits makes you accountable"

BM3 explained that "absolutely yeah" the criteria provides steps for protection, and stated it happens "at high levels with education and awareness" but not in the day-to-day operations at the beach. None of the beach managers that answered yes to this question gave any specifics of which criteria they felt were effective for protection, or exactly why having to follow the criteria would result in a protected and healthy beach. It is also worth noting that three of these beaches that responded they felt the criteria were sufficient steps to effectively protect a beach did not mention the Blue Flag program or criteria as a tool for beach management when they were asked that, which is contradictory.

The four ( $40 \%$ ) beach managers that stated that they did not feel the criteria are steps to effectively protect a beach also had a variety of opinions why they felt this way. BM1 justified their opinion:

"I don't think its environmental protection because I don't think they've helped us with that... they don't tell you what to do to preserve it, like to do the dunes and that. Like they maybe ask you for educational components or environmental but I think you need that other resource or that other expertise in keeping your beach. This [Blue Flag criteria] is sort of just on how it operates in the summer, whereas you need to worry about the longterm effects, so the beach is there for a long time....it's more of a showcase those guidelines l'd say...it's for the aesthetics and to get people there for the summer to your beach, and keep them safe, and but it doesn't talk about the long term stuff"

BM8 also clearly answered no to the question:

“No, they [the Blue Flag criteria] don't. They don't give you any guidance or any information. They don't provide the tools and the how to. They don't provide any of that. There are no resources."

BM4a also indicated that they did not see a link between Blue Flag criteria and protection of a healthy beach: 
"I don't know if they [the Blue Flag criteria] protect the beach, because this [engineered wetland and sand dune] behind the Blue Flag [beach] area, they really don't care about this area here, this is what is protected"

An interesting viewpoint by BM12b is that in the past the criteria did provide environmental protection, but that recently the Blue Flag program has lost its integrity by not enforcing the criteria, so this beach manager no longer sees the criteria or program as providing environmental protection.

BM7 responded to the question stating "That's basically the only guideline that's out there for sort of a beach management standard", but then stated that all of the work done at the beach(es) managed by them was independent of the Blue Flag program and criteria, and that the beach would be at the same standard without it. This implies that BM10 does not really view the criteria as sufficient steps to protection. BM9 answered the question by indicating that they do not use Blue Flag criteria for environmental protection, but that it may be useful for another municipality with less experience in environmental protection. This suggests that this beach manager does think the criteria are sufficient to protect the beach, although the same beach manager also indicated that they don't think environmental protection and conservation is the role of the Blue Flag program, so a clear answer cannot be determined.

\subsubsection{Benefits of participating in Blue Flag certification}

All beach managers were asked what they feel are the biggest strengths of Blue Flag, and what benefit their municipality received from being a part of the Blue Flag program. Many of the beach managers responded with multiple strengths and benefits throughout the interview, which are all included, and not limited to just the first answer given to the direct question. One beach manager chose not to specify any direct benefits of the program, so the sample is out of thirteen beach managers. The strengths and benefits described by beach managers are summarized below in Table 9. 
Table 10 Strengths and benefits identified of the Blue Flag program

\begin{tabular}{l|r|r}
\hline Strengths and benefits & $\boldsymbol{n}$ & $\%$ \\
\hline Recognizable symbol \& awareness & 6 & $46 \%$ \\
\hline More funding (from council or grants) & 5 & $39 \%$ \\
\hline Being given the criteria & 4 & $31 \%$ \\
\hline Being made accountable to a standard & 4 & $31 \%$ \\
\hline Support from Environmental Defence & 4 & $31 \%$ \\
\hline Increasing education and communication to public & 3 & $23 \%$ \\
\hline Increasing partnerships and collaboration & 2 & $15 \%$ \\
\hline$n=13$
\end{tabular}

Note: total will not equal $100 \%$ as respondents may have provided more than one answer

Beach managers were asked about whether or not they specifically felt that Blue Flag had increased tourism or been an economic benefit to them. None of the managers were able to definitively state that this was the case, because beach managers did not have any research in their possession to be able to come to such a conclusion. Three $(23 \%)$ of the beach managers did indicate that they assumed Blue Flag has the potential to be attracting new people to their beach (BM1, BM2, BM11). BM3 also stated that although they can't comment that attendance has increased, they could assume that people are "...more at ease with using the beaches knowing that they are certified for Blue Flag."

\subsubsection{Blue Flag as a communication tool}

Although findings indicate that most beach managers may not use the Blue Flag program as a management tool, it may be a useful as a communication tool for beach managers to help convey their management decisions to the public. BM10 summed up this idea:

"It's not necessarily that we are seeing an influx of numbers coming because we're a Blue Flag beach, but we can say to visitors, or we can say to the public, we are Blue Flag certified so if you want to know what you are getting, this is what you are getting, and we can pass them the criteria, we can say this is what we are achieving and what we meet. I think that's a huge benefit, if you don't keep track of your number, you don't know where people are coming from... or why they are coming there, it's hard to quantify numbers but you can say you have this in your pocket. To say these are the criteria that we meet, we are a clean beach, 
we are family friendly beach, we are accessible. You know what you are getting when you go to a Blue Flag beach."

BM9 also indicated clearly that although the program has not improved management of the beach, it has been used to improve communication about the beach:

"I'm not of the opinion that Blue Flag has brought something new to our toolkit that enables us to manage the beach better, or at a higher standard. I think if anything it has created an opportunity for us to communicate better with external parties, such as the town, about why protecting the beach and managing the beach in environmentally sustainable way is important. I think it has enhanced our ability to communicate that. I think it's even enhanced our ability to say, hey, you know what, we have been managing this beach to a Blue Flag standard for decades, it's nice to be recognized through this certification program that we are managing the beach appropriately."

\subsubsection{Changes made due to Blue Flag participation}

All beach managers were asked to provide any specific examples of management or operation changes they had to make in order to comply with or obtain Blue Flag certification. Throughout the interview, if other changes due to Blue Flag were described while answering another question, those answers were included as well. BM13 did not answer this question, so the response is out of thirteen beach managers. The answers are summarized below in Table 10. 
Table 11 Changes made in order to comply with Blue Flag requirements

\begin{tabular}{l|r|r}
\hline Management or operational change & $\boldsymbol{n}$ & $\boldsymbol{\%}$ \\
\hline Additional water testing & 7 & $54 \%$ \\
\hline Signage & 4 & $31 \%$ \\
\hline Safety equipment & 4 & $31 \%$ \\
\hline Educational programming & 4 & $31 \%$ \\
\hline Keeping track and reporting & 3 & $23 \%$ \\
\hline Creating a beach committee & 1 & $8 \%$ \\
\hline Garbage and cleaning & 1 & $8 \%$ \\
\hline Grooming & 1 & $8 \%$ \\
\hline Drinking water & 1 & $8 \%$ \\
\hline No dogs on the beach & 1 & $8 \%$ \\
\hline No vehicles on the beach & 1 & $8 \%$ \\
\hline No changes & 2 & $15 \%$ \\
\hline
\end{tabular}

$n=13$

Note: total will not equal $100 \%$ as respondents may have provided more than one answer

The change that was most commonly mentioned was additional water testing, which seven (54\%) beach managers gave as an example. Most of these beach managers said that although the health unit was already testing the water, an additional test was required in order to comply with Blue Flag. Other common answers were signage, safety equipment, and educational programming, which were all mentioned by four (31\%) beach managers each. Three (23\%) beach managers also said that their change was keeping track of and reporting on the management that was already happening at the beach. It is important to note that two of the beach managers stated that no changes at all were made to comply with Blue Flag when directly asked, but at some point in the interview did mention a change. It is also interesting to note that the two beach managers that listed the most number of changes at their beach due to Blue Flag when answering this question are two of the beach managers that listed Blue Flag as a tool or strategy they use for beach management.

\subsubsection{Minimal changes required for criteria}

A key theme that arose was that beach managers viewed the changes they needed to make in order to be compliant with the criteria as minimal. 
Participating in Blue Flag did not significantly change the beach management strategies for many of the beaches. BM3 summarizes this point:

"So it was this kind of like tightening up and tweaking what already was going on... I think we were very close, and it's just kind of like dove-tailing everything together to qualify. I think we were there...I don't really think it was a massive leap for us."

BM7 indicated that before receiving the Blue Flag the beach was already ensuring that it followed all best practises:

"Their timing was really good because a lot of what was happening is things that we're undertaking any way, as far as we're already doing water testing, we were already doing signage, we are already doing washroom maintenance."

BM9 expressed that he did not feel obtaining the Blue Flag certification resulted in the beach being managed to a higher quality:

"The reality is that we have always managed this beach to a higher level, a high standard. I'm not of the opinion that Blue Flag has brought something new to our toolkit that enables us to manage the beach better, or at a higher standard."

BM10 similarly indicated that receiving Blue Flag meant they were being recognized for something they were already doing, not changing their management practises to be able to qualify:

"We could probably meet most of these criteria and we were already doing a lot of this stuff. If we can get a certification and get recognized for things that we are already doing then let's do that"

\subsubsection{Motivation to receive the Blue Flag}

All of the fourteen beach managers were asked what originally motivated their municipality to become Blue Flag certified. The results are summarized in Table 11 below. The majority of responses indicated that the motivation to receive a Blue Flag was for tourism and promotion or for the recognition of meeting an international standard. 
Table 12 Motivation of municipality to receive the Blue Flag

\begin{tabular}{l|r|r}
\hline Motivation & $\boldsymbol{n}$ & $\boldsymbol{\%}$ \\
\hline Tourism and promotion & 5 & $36 \%$ \\
\hline Recognition & 4 & $29 \%$ \\
\hline Improve water quality & 2 & $14 \%$ \\
\hline Increase sustainability & 1 & $7 \%$ \\
\hline Unknown/not specific & 2 & $14 \%$ \\
\hline Total: & $\mathbf{1 4}$ & $\mathbf{1 0 0 \%}$
\end{tabular}

BM14 provided an example of tourism and promotion being the main motivator:

"...so this municipality has a tourism group, and they got onto Blue Flag and they saw it as a good opportunity to kind of promote our beach as a nice clean kind of, you know everything that Blue Flag stands for. In hopes to, I mean get more business down there"

This beach manager later expanded on what they felt Blue Flag does stand for:

"... it's that clean, well taken care of beach. Has clean water, clean beach, clean facilities, there's an information board. I mean Blue Flag stands for quite a bit and it's just getting Blue Flag so people know that that's what our beach is."

BM1 also described the desire for increasing tourism as the reason behind their desire to get Blue Flag:

"A committee of council and the public who thought it was a good idea. Our tourism department was right up on the fact that Blue Flags would, or Blue Flag could increase our tourism sector...it was kind of prestigious at the time to have a Blue Flag because there weren't very many."

BM7 indicated that it was for recognition of the work that had been done that motivated his municipality to adopt the Blue Flag program:

"I think the combination of being an internationally recognized program where we knew that we could attain that level to really show to the public that huge strides have been made to improve a combination of the water quality and the beach quality." 
BM5 provided information on how a community group wanting to improve water quality was the reason that her beach obtained Blue Flag:

"It was a community initiative... [the community group] came to Council, they made a presentation and requested that the council seek Blue Flag status. Their goal was to improve water quality. So it was actually driven by the community themselves"

\subsection{Future potential of Blue Flag}

Some themes emerged in the discussions about how Blue Flag could further assist beach managers. Eight $(57 \%)$ beach managers indicated how Blue Flag taking on a role to create more networking opportunities or to provide more resources would be beneficial. Six $(43 \%)$ of the beach managers specifically stated the usefulness of networking with other Blue Flag beach managers, and how it could be a benefit for Blue Flag to take on the role of coordinating that more. They expressed the desire to be able to learn more from each other how other beach managers with a Blue Flag beach are dealing with problems or having successes. Six (43\%) beach managers also identified that getting more resources from the program would be useful. The resources mentioned by the beach managers included: educational programming ideas, examples of success stories from other beaches, webinars on specific topics, recommendations for long term beach planning.

\subsubsection{Barriers for new municipalities to receive Blue Flag} Beach managers were asked what they felt were barriers to other municipalities obtaining the award. Thirteen of the beach managers gave a response to this question, and some beach managers provided more than one potential barrier that they saw. The results are summarized below in Table 12 . 
Table 13 Potential barriers for new municipalities to receive the Blue Flag

\begin{tabular}{l|r|r}
\hline Barrier & $\boldsymbol{n}$ & $\boldsymbol{\%}$ \\
\hline Water quality & 7 & $54 \%$ \\
\hline Cost & 7 & $54 \%$ \\
\hline Time and staff requirement & 5 & $38 \%$ \\
\hline Lack of physical amenities & 2 & $15 \%$ \\
\hline Not well enough known & 2 & $15 \%$ \\
\hline Fear of what may change & 1 & $8 \%$ \\
\hline No champion pushing for it & 1 & $8 \%$ \\
\hline$n=13$
\end{tabular}

Note: total will not equal $100 \%$ as respondents may have provided more than one answer

Water quality and the costs of the program were most commonly answered as potential barriers. Beach managers agreed that some municipalities at this point would just not be able to meet the criteria for water quality despite doing everything within their own control. Cost was listed as a potential barrier both because of the application cost, and also the cost of meeting all the criteria. BM10 gave some thoughts about how the Blue Flag program could overcome these barriers:

"What municipalities want to know when they are getting involved in things like this, how does this change how we maintain it, and what is it going to cost us. I think you'd probably see a lot more beaches trying to sign up for it if they knew that a lot of this stuff is already what they are doing its just formalizing it and putting it on paper."

\subsection{Conclusion}

This findings chapter first covered a profile of the beaches, outlining their staff, beach grooming practices, and water testing practices. Main challenges were determined next, and were found to be either environmental in nature, such as litter problems, or involved dealing with the public's expectations. The top success stories of beaches, including dune restoration, educational activities, and beach infrastructure were then outlined. Tools and strategies being used by Blue Flag beach managers to manage their beach were covered, and only $23 \%$ of managers described Blue Flag to be a useful tool. There was a lack of clarity and detail provided about tools and strategies used at beaches, but partnerships 
were identified to be important. This chapter then addressed the role of Blue Flag in beach success stories, with only $31 \%$ of beaches saying that Blue Flag played a role in their success. The chapter then addressed benefits of Blue Flag, including the recognizable symbol and additional funding, and next addressed changes made by beaches to qualify for the program. Following that it was revealed that the motivation to receive Blue Flag listed by the most municipalities was for tourism and promotion. Finally this chapter covered the future potential of Blue Flag and possible barriers to receiving the eco-award. The next chapter will be a discussion of the key themes and issues from these findings. 


\subsection{Discussion}

\subsection{Introduction}

This section will discuss the 10 key themes found in this research. Figure 7 below provides an overview of the organization of these key themes, which will be discussed sequentially throughout the chapter. First, the issues with Blue Flag that have been identified will be discussed, then second, a discussion of the benefits for a municipality participating in the Blue Flag program will be provided, followed by the theme that is neither clearly a benefit or an issue. The chapter will then conclude with recommendations.

Figure 7 Model of the key themes from the study outlining the issues, benefits, and overlapping theme

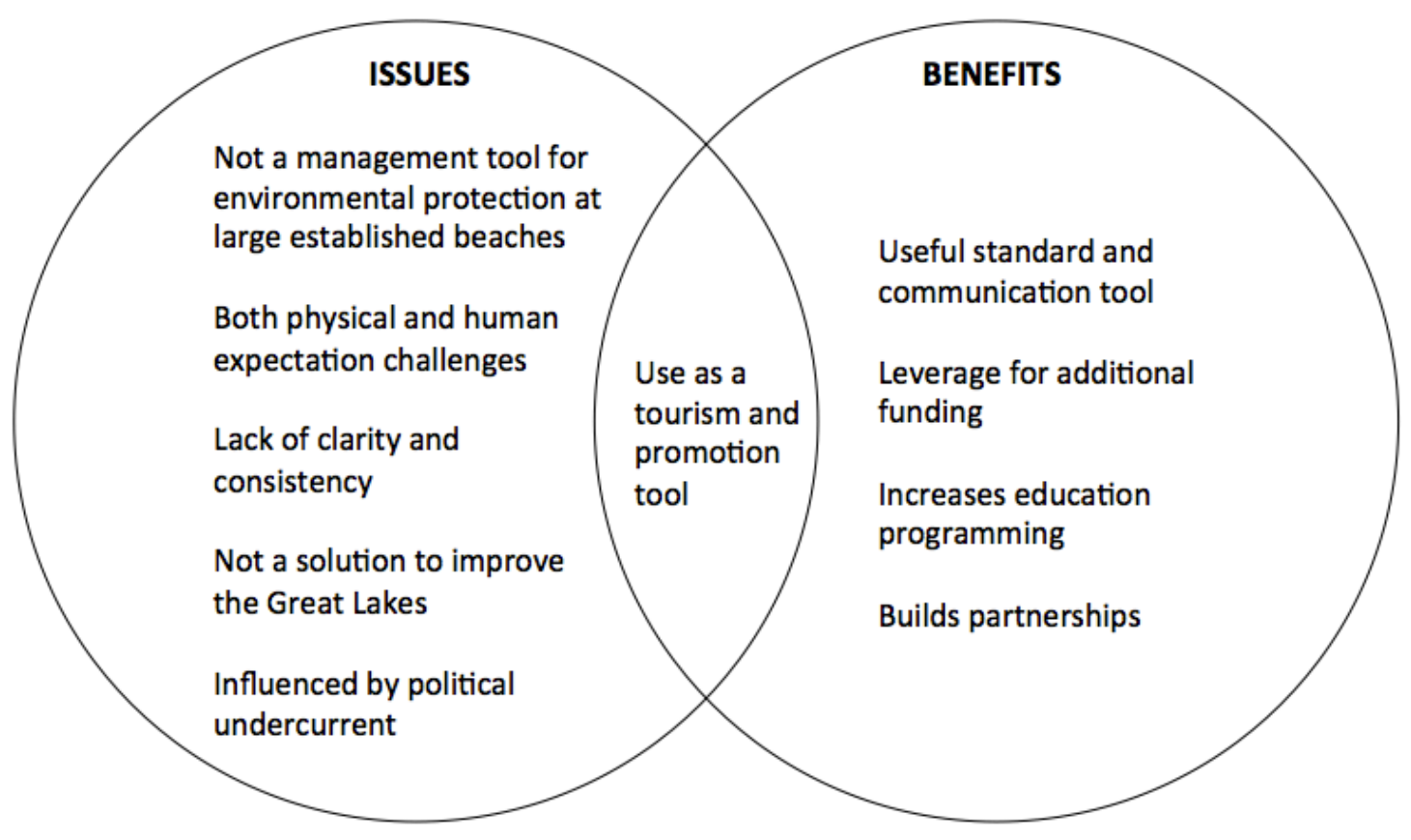

\subsection{Issues with Blue Flag in Ontario}

\subsubsection{More effective for smaller municipalities than larger, established beaches} The first key theme that this research uncovered was that the Blue Flag program was seen to be more effective for smaller beaches than larger, established beaches. The majority of beach managers did not indicate through their responses that they value the program for environmental protection, and 
indicated that their beaches already were at the standard of environmental management that the Blue Flag criteria require. In most cases, the beach managers are not using Blue Flag as a tool for environmental protection because it is not offering them anything above or beyond what they already were doing. Only a few beach managers indicated that they felt the program and criteria provided the sufficient steps for environmental protection, but these beach managers did not offer strong arguments to support this. Answers were vague, and very few examples of how this is accomplished were given. Other beach managers clearly indicated that in their opinion the Blue Flag program and criteria does not result in environmental protection. It was indicated that Blue Flag was not actually providing any mechanism or guidance to protect the physical beach ecosystem above what the beach managers would be doing anyway. This exact point was addressed by a beach manager who said that Blue Flag is a showcase piece to attract people to the beach, but isn't about environmental protection because beach managers aren't assisted with long term preservation. Many of the tools and strategies listed for management had very little to do with environmental protection, and finding a way to balance the natural environment with recreation was identified as a common struggle. This finding supports Mir-Gual, et al., (2015) who concluded that Blue Flag does not offer protection of ecosystems. This finding refutes the claims by Creo and Fraboni (2011) and Pencarelli et al. (2016) who determined that Blue Flag is a successful tool for municipalities to incorporate environmental protection.

The findings do suggest, however, that a smaller municipality will get more benefit for environmental protection out of the Blue Flag program than a larger municipality. Beach managers that answered the questions consistently indicating that they did feel Blue Flag has been a useful management tool for them and has played a role in their success were usually representing smaller municipalities. These beach managers were also very keen about learning more about beach management. They were the only managers that mentioned that they subscribe to the Great Lakes Beach Association emails. They also gave 
examples of changes made at the beach because of Blue Flag that are clear examples of working to improve the environment, such as making a bylaw that no dogs are allowed, reducing mechanical grooming, and putting in bird deterrents to improve water quality. Therefore, these beaches may be examples of beaches that Pencarelli et al., (2016) were describing. A perceived benefit of Blue Flag from Pencarelli et al.'s, (2016) study was that there is an improvement in environmental quality when the minimum standard at a beach needs to be met and results in improvement. In Ontario, most Blue Flag beaches already meet the minimum requirements for Blue Flag before obtaining the award. The results therefore would not be increased environmental protection. Blue Flag may be a program and a resource that only has impact on environmental protection to a small municipality that is just beginning to formally manage a beach. In a smaller municipality there aren't as many other groups or people helping the beach managers with their management decisions. There may also be less partnership opportunities available in small municipalities, so getting involved in a program such as Blue Flag would be one of the main relationships developed involving managing the beach. Where larger cities have the Health Unit doing daily testing for them, and departments specifically designated to environmental education programs, small municipalities do not. This is exactly the kind of situation that BM9 was describing:

"Blue Flag I think it would be more valuable to an organization that doesn't have that experience, so if you were a municipality, and you were just getting into the business of managing a beach for public use and let's say it was a beach that was always there, but only a few people used it, mainly people who lived next to it, now you are developing parking lots and letting people in. Absolutely Blue Flag and the criteria Blue Flag brings to the table very important for someone to consider all these things, and balance all these things as they are getting into managing a beach."

\subsubsection{Both physical challenges and public expectation challenges}

The next key theme that the findings uncovered was the split between the physical challenges at beaches, and the challenge of public expectation. The Blue Flag program does not appear to address either one of these types of 
challenges sufficiently, which indicated this theme would be considered an issue in the model shown above. There was no strong connection between the beach managers that specified that they had the same type of biggest issue, meaning there no clear explanation for the cause of this obvious divide. The beach managers who gave consistent positive responses about Environmental Defence were also split between a physical challenge and human expectation, which does not indicate that Blue Flag is benefiting beach managers by supporting one type of challenge more than another. One interesting link, however, is that four of the six beach managers who felt that dealing with people's expectation and recreational use of the beach were also the four beach managers that had a species at risk on their beach. Perhaps the requirement of additional environmental protection due to the presence of protected habit was part of the reason why these beach managers felt that was their biggest challenge. If a beach did not have those constraints and the beach manager was easily able to prioritize recreational use over environmental protection, perhaps that would be when a physical challenge, such as litter or water quality, becomes the main issue.

\subsubsection{Lack of clarity and consistency}

A key theme that emerged from the interviews is that there is a lack of clarity and consistency within Blue Flag, which leads to very different interpretations depending on the beach manager that is managing the program. This theme is a clear issue with the program, and the model shown above in Figure 7 indicates this. The key issues are with the beach committee, water testing, and mechanical grooming. These will be explained in further detail below. Reflecting on these issues is useful to determine what factors may be hindering the Blue Flag program from providing a more effective management tool that beach managers can rely on.

\subsubsection{Beach committee}

There is confusion over the beach committee requirement of Blue Flag, and it is not playing a key role in encouraging sustainability at most of the Blue Flag beaches in Ontario. Creating a beach committee is a requirement of the Blue 
Flag program, and is listed as an imperative criterion, which suggests that this aspect is very important. Beach managers indicated that to their knowledge there are no strict guidelines explaining to them the specifics of the committee, such as: how often this committee should meet, what the purpose of the committee should be, who should be a member of the committee. However, the Blue Flag criteria does set out the following guideline for the committee:

"The beach management committee is a means of ensuring that these personnel continue working together throughout the years to maintain Blue Flag standards. The committee should also include representatives of community groups, clubs, non-profits and conservation authorities. The committee should meet at least twice a year to discuss the management of the beach and ensure that all criteria are being met. Committee members may also take a hands-on approach, such as providing support to the beach manager, facilitating environmental education activities and promoting the program." (Environmental Defence 'Criteria for Beaches', n.d., pg 10).

It is unclear if the beach managers have just not been made aware of these guidelines, or if this is not enforced. In some municipalities existing committees of council were used as the beach committee in order to fulfill the criteria requirement, while others created a brand new committee. Some of the committees that were described were very active and engaged, had five or six meetings a year, and included many different stakeholders, such as: representatives from a conservation authority, the local health unit, and a park adjacent to the beach. On the other end of the spectrum, other committees were made up entirely of municipal staff and only had one meeting at the beginning of the beach season. One beach manager revealed that there actually was no active beach committee even though during the 2015 season the beach achieved Blue Flag and a beach committee is considered an imperative criteria. This criterion is clearly not being enforced, and beach managers are interpreting it in different ways. The range of involvement and importance placed on the beach committee at each beach is completely different, and without more guidance on the role of this committee it might not be having as significant an impact as it could. Zielinski and Botero (2015) determined that the most important aspect of 
beach certification schemes is the creation of a beach management authority. If this is the case, the Blue Flag beaches in Ontario need to better understand what the role of this beach committee should be, and follow up is needed to ensure that a beach committee is active and is making environmental protection a priority.

\subsubsection{Water quality standard}

Findings from this research conclude that there is inconsistency with the reporting of water quality within the Blue Flag program. It is a requirement that all Blue Flag beaches are tested for both E.coli and intestinal enterococci at least five times per season, as stated in the criteria. Water quality results are then submitted in the application for Blue Flag for the following year. For instance, 2015 water testing samples are one of the determining factors to decide if a beach will be awarded the Blue Flag again the following year. Beach managers at all the Blue Flag beaches are meeting the minimum requirement for the number of tests that need to take place, but some beaches supplement the required weekly health unit tests, so they have more tests than needed to fill out the application. The majority of beach managers stated that all water quality samples taken at their Blue Flag beach are sent in as part of their Blue Flag application, whether they are good or bad, however, there were a couple beach managers that disclosed they could select certain samples to omit because they had more samples than needed. The criteria says that in the event that a water sample result exceeds the allowable limit, that sample may be excluded from the data spreadsheet for the application This means that some beach managers are able to leave out their worst water quality results. This has the potential to diminish the quality of the program, because although a beach may appear to be meeting the Blue Flag water quality standard, it is only being based on their best test results. It is suggested in the Blue Flag application that if additional tests beyond the required five samples are collected all of the results should be included. Based on the findings of this research this does not appear to be strictly enforced. One beach manager divulged that it was suggested to them by their Blue Flag contact that they remove their worst samples in order to meet the 
standard:

"There's only a certain amount of samples that they want you to take per year and we actually exceed that. So we then kind of pick and choose what numbers we put in there and send it back to them....that was one of the things I learned last year, because I just put everything in there, and then [the person reviewing the application] said, because we didn't meet water quality.... 'well take these really bad numbers out because you only need so many samples'. We still didn't meet the water quality but it was getting closer".

This quote highlights another inconsistency with the water quality criteria of the Blue Flag program. The beach manager above is recognizing that the water quality results they submitted from 2014 did not meet the requirements, and yet this is a beach manager who had Blue Flag status is 2015. When a beach does not meet the requirements of $80 \%$ of water samples exceeding the provincial limit, the beach manager can ask for a dispensation in order to still receive their Blue Flag. There were a few different scenarios described by beach managers of instances where this needed to happen at their beach because they did not meet the water quality requirement, however, they always had their flag re-instated the following year. A newspaper article from 2013, (Murray, 2013), discussed dispensation at one of the beaches included in this study. In this case the beach only met the standard 57.14 per cent of the time instead of the required 80 per cent, however, the municipal councillors still decided to go ahead with the application. According to the deputy mayor at the time, it was felt that if the beach was awarded the Blue Flag after not meeting the criteria then "That decision would water down the program" because the point of the program is to strive to meet certain standards (Murray, 2013). This beach was successful with this application and was awarded a Blue Flag even with water quality well below the required limit. As one beach manager stated: "I think that [water quality testing] exception makes the integrity [of Blue Flag] poor". This is a key issue for effective environmental management, not only is it lowering the standards of the program and therefore not encouraging water quality improvements, but it is also affecting the image of the program and resulting in beach managers questioning if they want to be a part of it. 


\subsubsection{Mechanical beach grooming}

The findings of this study conclude that a high use of mechanical grooming is taking place at Blue Flag beaches in Ontario. The vast majority of the beach managers utilized mechanical beach grooming at their Blue Flag beach in 2015. The Blue Flag criteria does identify that less invasive hand raking is the preferable option to meet the criteria of a clean beach, but recognizes that mechanical grooming will still possibly take place at beaches with the award. The criteria states:

"Depending on the size of your beach and the resources at your disposal, you may clean your beach by hand or use a mechanical groomer. Where possible, hand-picking is preferable because it has the least impact on the natural ecosystem. Large beaches however, can be difficult and timeconsuming to groom by hand." (Environmental Defence "Criteria for Beaches', n.d., pg 11)

Beach managers that were interviewed did not provide consistent interpretation on what the stance of Blue Flag is on beach grooming, and the process and timing of the grooming at each beach was very different. BM7 said that Blue Flag actually suggested on days that the beach is not mechanically groomed, the flag should be lowered since it is not meeting the standard, and that the program does in fact "...expect daily mechanical grooming". However BM10 gave the complete opposite viewpoint when they stated, "Blue Flag I think would prefer not to do that route of the daily [mechanical] raking of the beach". These findings suggest that beach managers are not receiving a clear message about mechanical grooming from the program, and this is resulting in a large variation of grooming practices. The mechanical grooming plan is up to the individual beach managers, and the decisions may not be what are best for a healthy beach ecosystem. The majority of the beach managers specified grooming takes place on a regular schedule, which can lead to unnecessary grooming when it is not actually needed. Excessive mechanical grooming at a beach can have serious negative affects on the ecosystems and health of the beach, and award schemes that allow for this practice have been criticized in the literature (Boevers, 2008; Gilburn, 2012). Gilburn (2012) argued that mechanical grooming 
is much more likely at a beach with an award, and this was supported when a beach manager acknowledged that they only started grooming when the beach became a Blue Flag beach. Although the Blue Flag program recognizes that some mechanical grooming will need to take place at the larger beaches, it would be very useful to provide a clearer expectation of raking, and perhaps be more encouraging to limit the intensive regularly scheduled grooming. A recommendation to reduce the use of mechanized grooming at beaches where the staff cleaning manually is not enough could be to work with a local partner to develop a program where volunteers are responsible for cleaning and taking care of certain sections of the beach (LHCCC, 2012).

\subsubsection{Not a solution to improve the Great Lakes}

Another key theme that this research uncovered is the lack of a strong link between the Blue Flag program and a shoreline management strategy that will impact the Great Lakes. There was no support for a strong connection between the program and improving the Great Lakes directly. No link was made that Blue Flag is a tool that is being used to improve the shorelines of the Great Lakes in any direct way. Although municipalities are responsible for beach management, beach managers agreed that because the Great Lakes are under multiple levels of government, it would be hard for a municipality to feel they have a real role using a beach certification scheme. BM10 summed up this idea:

"I'm not sure that Blue Flag does provide that mechanism, because we are talking about so many different levels of government. It's an issue that probably goes beyond Blue Flag".

Beach managers agreed that any small action to improve the shoreline can have a collective impact eventually, but the idea that more beaches implementing Blue Flag improve the Great Lakes was not supported. Ontario's Great Lakes Strategy has specified a goal to restore and protect shorelines, including beaches. This strategy made reference to utilizing the Blue Flag program and encouraging municipalities to participate in it as a point of action to reach this goal (Government of Ontario, 2012). It is key that the findings of this study determine 
that beach managers do not directly see that connection, and are not using Blue Flag for the purpose of environmental protection of the Great Lakes.

\subsubsection{Political implications}

Another key theme that emerged from the study was the political undercurrent that is impacting the Blue Flag program in Ontario. It is evident that the decision to adopt Blue Flag is primarily made by the Council and the Mayor. Many beach managers brought up points about what impact their municipal government had on the program and indicated that if the council sees value in a component of Blue Flag, then that is what the beach will work towards. A beach manager that was representing a beach that used to have Blue Flag but no longer holds the flag acknowledged that previously the municipality's council was motivated to get the program, but that "political tides change" and that is not necessarily the case anymore. An example was also provided detailing how even when a beach manager wants to run a new environmental program, if the Mayor and Council say no to it, then it wouldn't happen, despite the benefit to the beach and the positive environmental impact. It became evident that many of the decisions and the choice to participate in the Blue Flag program are not typically in the beach manager's direct control.

There are also much larger scale political implications affecting the program. It was found that the Blue Flag coordinator for Canada is married to a Toronto City Councilor. Close to half of the beaches in Ontario that have the Blue Flag program are Toronto beaches, so this political connection could be having a tremendous impact on the program. According to one beach manager: "It's [the marriage] something that has had an effect on this program in the city. Because you have a city councilor that is now asking what [the Blue Flag coordinator] is asking for". The Blue Flag program in Ontario has also received funding from the Ministry of the Environment's Great Lakes Guardian Community Fund (GLGCF) and the Ministry of the Environment and Climate Change (MoECC). According the Blue Flag Canada website, funding the eco-award is one way that the MoECC is fulfilling the mandate to protect Ontario. Ontario's Great Lakes 
Strategy (2012) is also supporting Blue Flag and encouraging more municipalities to adopt the program. It appears that both the federal and provincial government are supporting Blue Flag with the expectation that it will have a positive impact on environmental protection. The political implications are included in the model above as an issue due to the fact that they are having influence on the program in Ontario.

\subsection{Benefits of the Blue Flag program}

Although there are issues with the Blue Flag program, a number of benefits also exist and should not be discounted. The key benefits and strengths of Blue Flag identified throughout this study will be detailed below. These key themes are included in Figure 7 as obvious benefits of Blue Flag.

\subsubsection{Useful communication tool}

The Blue Flag program does have the benefit of being an internationally recognized program and beach managers suggested that this known standard is what makes the program useful. The Blue Flag is being used as a communication tool for beach managers to help convey their management decisions to the public and to municipal councilors. The Blue Flag criteria provide a clear list of what is taking place at the beach that gives beach managers the ability to provide that criteria if they ever need support for their beach management choices. When a local resident complains about a beach that has driftwood on it or that beach grass ruining the aesthetics of the beach, using Blue Flag as a justification is a useful tool that the public can have an easier time understanding and hopefully then supporting. One beach manager summarized this well:

"I think if anything it has created an opportunity for us to communicate better with external parties"...about why protecting the beach and managing the beach in an environmentally sustainable way is important".

\subsubsection{Leverage for additional funds}

Blue Flag beach managers identified that having the eco-certification can result in additional funding for the beach that they would not otherwise receive. Blue Flag makes it easier for beach managers to justify why certain management practices need to happen and allow beach managers to provide a clear reason 
for management choices. This can assist with communication to municipal councilors, and will result in more financial resources being dedicated to the beach. In one example provided, because the municipality wanted the beach managed to comply with Blue Flag, the beach manager was allocated the funding for an additional three staff that were dedicated to beach maintenance throughout the summer months. This finding supports the literature that has claimed beach certification schemes will give beach managers leverage to obtain additional financial resources for beach management (Lucrezi et al., 2016; McKenna et al., 2011).

\subsubsection{Additional educational programming}

The findings determined that the educational programming criterion of Blue Flag is an environmental management element of the program that beach managers feel is the largest benefit. Although Blue Flag may not have a large impact on most environmental management practises at the beach, the program is useful for encouraging the creation of environmental education programs that would not likely happen otherwise. BM2a outlined, “We wouldn't be ramping up our public education without them [Blue Flag]". Due to this required programming and education one of the positive shifts at some Blue Flag beaches has been increased awareness by the public about the importance of sand dunes and the reasons for not trampling over the dune grasses. Additional environmental programming was considered a key change for environmental management in both Creo and Fraboni (2011) and Pencarelli et al. (2016) when the authors concluded that Blue Flag has benefit to the environment. This research supports the claim that environmental education initiatives would not be happening in the absence of Blue Flag.

\subsubsection{Partnerships}

Partnerships were also identified as an important factor for successful beach management. Throughout the interviews, the majority of beach managers listed different forms of partnerships that benefitted their beach management and some of these partnerships took place specifically because of the Blue Flag program. For example, BM5 talked about how they had learned that partnering with 
another organization was a way to have more successful environmental education initiatives that fulfill the Blue Flag criteria. Multiple beach managers discussed the benefit of working with school groups to complete vegetation plantings and dune restoration at their beach, and also the advantage of teaming up with the health unit to complete all the requirements for water testing. These partnerships take place when a municipality is involved in the Blue Flag program because multiple groups are needed in order to fulfill the criteria.

\subsection{Blue Flag as a tourism and promotion tool}

A key theme that emerged from the research was about the use of Blue Flag for tourism and promotion. When asked what the strength of Blue Flag was, the answer given most often by the beach managers was that it is a recognizable symbol that brings awareness to the beach. These findings suggest that Blue Flag beach managers are not obtaining the certification to use it as a management tool for environmental protection, but as tool for tourism and brand recognition. Beach managers felt it was a benefit to be able to have the criteria from Blue Flag as a promotional tool to express the standard they were reaching at their beach. BM2a said, "You're going to want to go to Blue Flag beach because you know what it is". BM11a said, "The Blue Flag is a good way of promoting that you're doing environmentally safe practices to maintain your waterfront." This supports the findings of Pencarelli et al. (2016) who determined that municipalities in Italy are mostly interested in obtaining Blue Flag status for the brand and the image of the program.

Despite the findings that verify beach manager's interest in Blue Flag as a potential promotion tool, none of the beach managers were able to provide any metrics to prove that receiving the Blue Flag status actually correlated to an increase in tourism or to a the public changing their perception of the beach's quality. Although beach managers are motivated to receive the Blue Flag mainly for tourism and brand recognition, there is no evidence to support the idea that the Blue Flag is a successful tool for tourism and promotion. Previous research 
support this finding, so there is a clear disconnect between the perceived value of Blue Flag for tourism and actual research (Lucrezi and Saayman, 2014; Lucrezi et al, 2015; Marin et al., 2009; McKenna et al., 2011; Morgan, 1999; Nelson et al., 2000). Some of the beach managers interviewed indicated that they guessed that might be the case. BM12b stated: "I really don't think people know [about Blue Flag]. And I don't think they care." BM3 stated: "Honestly I don't know if some people are even attuned to it [Blue Flag status]. They're just going to a beach." Additionally, beach managers do not feel that maintaining the Blue Flag status will be critical to continuing to attract people to their beach. BM11a said: "Would I go as far as to say we saw an increaseEli of public use because of it [the Blue Flag]? I don't think so. For us they were coming anyways. We are a tourism destination. So I don't think Blue Flag, from an economic development perspective, did anything significant for us." BM7 said, "If Blue Flag was to leave tomorrow. I don't anticipate my numbers would go anywhere but up." In addition, none of the beach managers that no longer held Blue Flag in 2015 identified that there was a lower attendance at their beach without the status. This suggests that although the common motivation to get Blue Flag is for tourism and promotion, not only are the beach managers not actually able to determine if there has been any impact on visitation, they expect that tourism would be increasing without the eco-certification. Therefore, the use of Blue Flag for tourism and promotion has the potential to be a benefit, but there are no data to support this. This is reflected in the model above (Figure 7) by including this final key theme in the overlapping area between issues and benefits.

\subsection{Recommendations for improving effectiveness of Blue Flag} From the findings, key recommendations to improve the current state of Blue Flag were revealed. These include networking opportunities, providing additional resources, enforcing Blue Flag criteria and providing feedback to beach managers that will be further explained in this next section.

\subsubsection{Networking opportunities}

Many of the beach managers stated that they would appreciate more networking opportunities between each other. Beach managers mentioned that Blue Flag 
does put on some workshops, however, indicated even more networking would be beneficial. A number of beach managers stated that the networking is the most useful part of any of the Blue Flag workshops. The discussions between each other allowed beach managers to figure out what other beach managers were doing and why they were making certain management choices. There was a strong desire to be able to share success stories and lessons learned. BM1 said, "sometimes you feel like you are sort of on your own", which would be improved by Blue Flag taking on a facilitating role between beach managers. Even when logistically it isn't feasible for all beach managers to meet, if a webinar was made available to the Blue Flag beach managers detailing successful educational programs and improvements made for environmental protection, the beach managers would still be able to share their information and receive that benefit.

\subsubsection{Additional resources}

In order for the cost of the program to be viewed as worthwhile to more beaches, beach managers described a number of resources that they thought the Blue Flag program could provide in order to give them more benefit for participating in the program. BM8 expressed that they did not feel they were getting much back from the program and suggested that the Blue Flag program provide beach managers with more complete packages for potential environmental programming, similar to the Butt Free Beach program that was developed by the Lake Huron Centre for Coastal Conservation and is now being distributed to Blue Flag beaches (see Appendix $G$ which includes a photo from Goderich beach with the signage from this program, or visit the Coastal Centre's website at http://lakehuron.ca/index.php?page=butt-free-beach). This program provides the idea, information, and signage readily available for beach managers to utilize.

Other suggestions included resources that would assist with long term planning of beach health, for example more knowledge about dune placement and types of vegetation. The final resource that was requested was additional information about the benefits of why beach managers are doing what they are doing, and specifically how that is improving their beach. Although Environmental Defence is 
usually an advocacy organization, more assistance with these management actions would be beneficial from Blue Flag's administering organization in order to provide beach managers and Ontario beaches with more benefit.

\subsubsection{Enforcement and feedback}

A key recommendation was for the Blue Flag criteria to be strictly adhered to, and for appropriate feedback to be given when this is not the case. Perhaps the issues with Blue Flag in Ontario that are reducing the positive impact as a management tool for environmental protection are not due to the program and criteria itself, but due more to the implementation of the program. Multiple beach managers discussed the audits, and said that they are a good measure to ensure compliance. It was recommended by beach managers however, that the feedback from these audits be timelier. If a beach audit is taking place in August and a beach manager does not get their feedback until after beach season is over, there was no chance for them to make any adjustments to ensure they were fully complying with the program. More communication in general from Environmental Defence could be beneficial. According to one beach manager, they only hear from Environmental Defence once a year about the application, and that, "to be frank they [Environmental Defence] don't do any follow up". There were examples provided throughout the interviews of criteria that were not being complied with, and exceptions that were being made, and yet beaches were still awarded a Blue Flag. The Blue Flag certification program is internationally recognized for its strict standards and stringent criteria requirements. In order for beach managers and even the public to continue to view Blue Flag this way, the integrity of the program needs to be maintained. 


\subsection{Conclusion}

This research addressed a gap in literature on the use of Blue Flag as a management tool for effective beach protection, particularly in Ontario. The purpose of this thesis was to determine to what extent the Blue Flag certification program is an effective management tool for environmental protection of beaches. It was determined that beach managers are not utilizing the Blue Flag program as a tool to ensure environmental protection on beaches along the Great Lakes shoreline. Further detail elaborating on each objective will be provided below.

\subsection{Meeting the objectives}

Five objectives were outlined and met in order to assist in answering the research question.

\subsubsection{What are the key issues municipalities face with regard to beach protection?} The primary research determined what challenges beach managers are facing, both in general, and specifically relating to environmental protection. The findings established many key issues that municipal beach managers face, and revealed specifically what they considered to be their one biggest issue. Findings show that beach managers are dealing with physical environmental issues such as litter, overcrowding, and water levels. They are also experiencing the challenge of balancing environmental protection with the expectations and recreation needs of people who visit the beach. There was a nearly even split of beach managers stating that a physical challenge is the biggest issue versus beach managers stating that balancing the human expectation is the biggest issue.

\subsubsection{What successes municipalities have accomplished with regard to beach protection?}

The interview findings showed that there are varied success stories taking place across Ontario at Blue Flag beaches, but the two most commonly mentioned success stories were dune vegetation planting and increased environmental education activities. 


\subsubsection{Which of these successes can be attributed to Blue Flag criteria?}

Responses about successes were varied, however, the majority of beach managers did not indicate that they felt Blue Flag had played a role in their success. Changes that had taken place at the beach that benefited the natural environment were often said to have happened without influence from Blue Flag. The beach managers who did express that some of their success could be attributed to Blue Flag explained it was because the criteria ensured certain actions would be done to meet the criteria. For example, the program assisted beach managers to get more funding, and the program provided environmental education criteria to help with communication to both the community and local municipality and politicians. Success stories involving a partnership were also often related to Blue Flag.

\subsubsection{What motivations or hindrances managers have in adopting the Blue Flag program?}

The motivations or hindrances that beach managers have in adopting the Blue Flag program were first explored in the literature review, which reviewed past studies of Blue Flag for the use of marketing, public awareness, and the economic impact. This objective was then addressed in the primary research. It was uncovered that Blue Flag was often adopted for tourism and promotion. Beach managers viewed the recognition that a beach received by adopting the Blue Flag to be positive. Findings also revealed a deterrent to continue applying for Blue Flag is the cost and administration work if no obvious benefits were being received. There is a need for more resources from the program to increase the benefit of the Blue Flag program. Beach managers stated that likely the two biggest barriers for other municipalities to join the Blue Flag program were limited funding and poor water quality.

\subsubsection{What extent Blue Flag is being used as a management tool for environmental protection versus a driver for tourism or economic benefit? \\ Very few beach managers indicated that they were utilizing Blue Flag as a} management tool for environmental protection. The majority of beach managers indicated that they did not feel the criteria and the program were resulting in effective protection of the beach and the Great Lakes. Only one beach manager 
said the municipality adopted Blue Flag to increase sustainability, and that is the same beach manager who represents a beach that no longer applies for Blue Flag. The majority of beach managers stated that their municipality was involved in Blue Flag because the recognizable symbol provides branding for their beach and may be good for tourism and promotion. Although no beach managers had solid data to support the use of Blue Flag as a driver for tourism or economic benefit, they did indicate this was the benefit of the program over the use of it for environmental protection.

\subsection{Summary of key findings and recommendations}

The key findings of this research reveal that currently Blue Flag is not being used as an effective beach management tool for environmental protection in Ontario. There are significant issues with the Blue Flag program, including a lack of clarity and consistency with some of the criteria. This was the first study to uncover that beach managers do not think that municipalities adopting Blue Flag will have a direct effect on improving the health and protection of the Great Lakes. One of the largest impacts on environmental protection that Blue Flag currently does have is the increase in educational programming that it requires. There is also indication that Blue Flag can be a useful starting point for a smaller municipality that does not have experience with beach management and environmental protection.

It is recommended that the Blue Flag program ensure that all criteria are indeed met by each beach consistently. The standard of Blue Flag should be enforced, and exceptions should be limited. The compliance audits should continue to take place, but should be earlier and should provide immediate feedback to allow beaches to improve and achieve better environmental protection. Increasing the networking opportunities for beach managers and providing them with more resources to support environmental protection will be beneficial for the Blue Flag program in Ontario. 


\subsection{Academic contribution of the research}

Based on the limited amount of research that has been conducted to determine the validity of using Blue Flag as a management tool, particularly in Ontario, this research contributes to the academic literature. Beach certification schemes have been suggested in the literature for use as a management tool, however, this study was the first to focus on the role of Blue Flag as a management tool for beach managers in Ontario. This study determined that the Blue Flag program is not being used by the majority of Blue Flag beach managers as a tool for effective environmental protection, rather as a communication tool. This study was also the first study to identify the key issues with the Blue Flag program that are preventing it from being more useful to beach managers. The study also contributes new knowledge about the importance of partnerships and the need for networking and communication between beach managers and Blue Flag administration for effective beach management to protect the environment. The study confirmed that similar to other countries that have the Blue Flag program, municipalities in Ontario are motivated to receive Blue Flag for tourism, promotion and branding associated with the certification scheme, even though there is no evidence supporting that Blue Flag status increases visitation to the beach. This research can be used as a starting point to develop more knowledge of beach management along the Great Lakes and in Ontario. It also contributes to the international research on the use of Blue Flag and other beach certification schemes as a management tool.

\subsection{Implications of the research}

There are two important implications of this research: first for beach management in Ontario and second, for the Blue Flag program in Canada. First, this study provides evidence that recommending more municipalities pursue Blue Flag certification for their beaches will not have a direct effect on improving the health and ensuring the protection of the Great Lakes and their beaches. This has a major implication because Ontario's Great Lakes Strategy (2012) specifically identified the adoption of the Blue Flag program by more municipalities along the shoreline as a point of action to improve Great Lakes beaches. Second, this 
study identified some key inconsistencies and issues with the Blue Flag program in Ontario. The study identified the need for stricter enforcement of the high standards that the criteria specify, including water quality reporting and formation of a beach committee. Findings also highlighted the need for guidance from the Blue Flag program for issues such as: their stance on beach grooming, how to better balance tourism with the environment, and timely feedback after yearly audits. In addition, the study uncovered that there are some beach managers questioning the benefit of the Blue Flag program in Ontario. Additional networking opportunities and resources being provided could help beach managers to see greater value in the Blue Flag program.

\subsection{Potential future research}

This thesis adds to the literature by presenting research that has not been conducted before. This thesis determined the effectiveness of Blue Flag as a management tool for beaches. Mir-Gual et al (2015) used environmental variables to determine if the Blue Flag program does ensure an improvement in the environment, and Zielinski \& Botero (2015) evaluated beach certification criteria to assess how effective they are at increasing sustainable development. However, there has still not been qualitative inquiry to determine how effective Blue Flag is as a management tool for beach managers internationally. It may be valuable to do a similar study to this one in Europe or another international location with Blue Flag. As this study is qualitative in nature the results only represent the Blue Flag beach managers from Ontario, therefore, it cannot be assumed that they represent other beach managers who have adopted the program internationally. The majority of Blue Flag beaches are found in Europe, and conducting similar research there could allow for links to be made between the Blue Flag program on an international scale.

This study focused only on beaches that have been involved with the Blue Flag program. It may be valuable to do a study that compares this research to nonBlue Flag beaches in Ontario in order to learn more about the management tools that they are using. Although the findings from this research conclude that Blue 
Flag is not an effective management tool for Ontario beaches, the need to effectively manage the Great Lakes beaches is still an important and relevant issue. This study determined that partnerships and networking are important for environmental protection at a beach, but additional Ontario beaches might provide further insights. Research aimed to learn more about beach management in Ontario could assist in development of a strategy that will assist beach managers in making the link between their roles and protecting the Great Lakes.

It may also be useful to do further research evaluating how beach certification schemes are used as communication tools, as current literature on beach certification schemes does not presently address this theme. Blue Flag beach managers in Ontario stated that they are able to better communicate their management strategies to the public and the municipal government who determines their budget, which resulted in some of the largest benefits from the program. Further investigation at other international Blue Flag beaches could help to determine to what extent this is a benefit for the beach managers. It is possible that this use as a communication tool may be more beneficial than using the Blue Flag for tourism and promotion, since multiple studies have concluded there to be little connection between the public's choice of beach destination and beach awards.

Lastly, it would be beneficial for research to be conducted on how effective Blue Flag's environmental education initiatives are at improving the awareness and knowledge of the public. Findings of this study supported Creo and Fraboni (2011) and Pencarelli et al. (2016) who found that one the largest impacts of the Blue Flag award in terms of contributing to environmental protection was the increase in environmental education activities. However, there has not been research conducted to determine if the increase in environmental educational programming is truly having an impact on public education. A study to determine if Blue Flag is actually resulting in higher awareness of important beach health 
issues would determine if these programs are actually successful, and if this criterion is benefiting the beach and community. Investigation of the knowledge of both locals and tourists at Blue Flag beaches on issues such as the need for vegetation for a healthy dune, the role of non-point source pollution in water quality, and the harmful effects of cigarette butts in the sand would be valuable. 


\section{Appendices}

\section{Appendix A - Blue Flag Criteria for Beaches}

Environmental Education and Information

1. Information about the Blue Flag program must be displayed.

2. Environmental education initiatives must be offered and promoted to beach users.

3. Information about recreational water quality must be displayed.

4. Information relating to the local ecosystem must be displayed.

5. A map of the beach indicating different facilities must be displayed.

6. A code of conduct that reflects appropriate laws governing the use of the beach and surrounding areas must be displayed.

Water Quality

7. The beach must fully comply with the water quality sampling and frequency requirements.

8. The beach must fully comply with the standards and requirements for water quality analysis.

9. No industrial, wastewater or sewage-related discharges should affect the beach area.

10. The beach must comply with the Blue Flag requirements for the microbiological parameter Escherichia coli (E.coli) and intestinal enterococci (streptococci).

11. The beach must comply with the Blue Flag requirements for the following physical and chemical parameters.

Environmental Management

12. The local authority/beach operator must establish a beach management committee.

13. The local authority/beach operator must comply with all regulations affecting the location and operation of the beach.

14. Sensitive areas must be managed accordingly.

15. The beach must be clean.

16. Seaweed or natural debris should be left on the beach.

17. Garbage bins must be available at the beach in adequate numbers and they must be regularly maintained.

18. Recycling bins must be available at the beach.

19. An adequate number of toilet or restroom facilities must be provided.

20. The restroom facilities must be kept clean.

21. The toilet or restroom facilities must have controlled sewage disposal. 
22. Camping, driving and dumping are prohibited on the beach.

23. Domestic animals must be prohibited from beach.

24. All buildings and beach equipment must be properly maintained.

25. Marine and freshwater sensitive habitats (such as coral reefs or sea grass beds) in the vicinity of the beach must be monitored.

26. A sustainable means of transportation should be promoted in the beach area.

Safety and Services

27. Appropriate public safety control measures must be implemented.

28. First aid equipment must be available on the beach.

29. Emergency plans to cope with pollution risks must be in place.

30. There must be management of different users and uses of the beach so as to prevent conflicts and accidents.

31 . There must be safety measures in place to protect users of the beach.

32. A supply of drinking water should be available at the beach.

33. At least one Blue Flag beach in each municipality must have access and facilities provided for the physically disabled. 


\title{
Appendix B - Interview Questions (before piloting)
}

\author{
Interview Guide
}

This study is investigating beach management trends in municipalities along the Great Lakes. Interviews for this research will be semi-structured and guided by the following questions. It is estimated that the interviews will take approximately one to two hours.

1. What is your specific role/job description with the municipality?

a) Do any other staff have similar roles involved in beach or shoreline management?

b) How long have you held your current position?

2. Could you give me an overview of the beaches your municipality manages?

a) How many beaches is your municipality involved in managing?

a) Where are the beaches located?

b) What size are the beaches? (Length, width, or square kilometers)

c) What type of beaches are they? Sand? Natural? Etc.

b) Are there any specific tools/strategies that you use to manage your beach?

3. What is the biggest issue or problem that you and/or your municipality face when managing your beach(es)?

a) Are there problems with litter, trampling, overcrowding, water quality, sand quality, etc?

b) How is your beach cleaned? How is garbage collected?

4. What specific challenges do you have concerning environmental protection and conservation of your beach?

a) Do you have any unique challenges with management? (Such as Species at Risk, a sensitive area, etc.?)

5. Would you please share any success stories you have in terms of beach protection? Any specific programs or plans that you feel have made the most difference?

a) What have been the most successful management tools to implement environmental protection measures at your beach? Why?

6. What role has Blue Flag played in this success?

a) How has the Blue Flag provided you guidance on how to improve environmental protection at your beach?

b) Do you have any specific examples of management changes in order to comply with the Blue Flag criteria?

c) Do you have any specific examples of operation changes in order to comply with the Blue Flag criteria?

7. Do you feel that the Blue Flag criteria are sufficient steps to take to effectively protect your beach? 
8. What motivated your municipality to become Blue Flag certified?

a) What specific benefit(s) has your municipality received from your Blue Flag status? (Prompts: more funding for water testing; increased tourism; additional partnerships with other organizations; increased support from municipality (funding, recycling containers, staff); knowledge of proper beach management; etc.

9. What do you think are the biggest strengths of Blue Flag?

a) Has Blue Flag generated any economic benefit?

b) Has Blue Flag increased tourism?

c) Has Blue Flag been useful to provide information for successful environmental protection at a beach?

10. Do you believe there are any issues or problems with the Blue Flag eco-certification program? E.g.

a) Do you think there are any barriers for municipalities to want to achieve this award? How do you think this could be overcome?

b) Why do you think all beaches do not implement the Blue Flag program?

How do you think this could be overcome?

11. To what extent do you believe that Blue Flag certification is a valuable way for municipalities in Ontario to work to protect:

a) Their beaches?

b) The Great Lakes in general?

12. Do you know of any other initiatives that would give Ontario municipal governments the ability to formally participate in managing their beaches in some way?

13. Is there anything I have missed or you would like to add?

14. Is there anyone else you think I should speak with regarding this topic?

THANK YOU FOR YOUR TIME 


\section{Appendix C - Interview Questions (after piloting)}

1. What is your specific role/job description with the municipality?

a) Do any other staff have similar roles that involve beach or shoreline management?

b) How long have you held your current position?

2. Could you give me an overview of the beaches your municipality manages?

a) How many beaches is your municipality involved in managing?

b) Where are the beaches located?

c) What size are the beaches? (Length, width, or square kilometers) Do you have an aerial map or photo you could send?

d) What type of beaches are they? Sand? Cobble? Wet? Dry?

e) How is your beach cleaned? How is garbage collected?

3. What is the biggest issue or problem that you and/or your municipality face when managing your beach(es)?

Prompts: problems with litter, overcrowding/too busy, poor water quality, people wandering where they shouldn't/vegetation trampling, etc?

4. What specific challenges do you have concerning environmental protection and conservation of your beach?

a) Do you have any unique challenges with management? (Such as Species at Risk, a sensitive area, etc.?)

b) Are there any specific tools/strategies that you use to manage your beach?

5. Would you please share any success stories you have in terms of beach protection? (such as: stopping erosion, introducing a new educational program, completing planting of native dune grasses, etc).

a) Any specific programs or plans that you feel have made the most difference?

b) What have been the most successful management tools to implement environmental conservation/protection measures at your beach? Why?

6. Do you think Blue Flag has played a role in this success?

IF YES: explain

IF NO: explain why not

a) Are there any ways in which Blue Flag provided you guidance on how to improve environmental protection at your beach?

b) Do you have any specific examples of management changes in order to comply with the Blue Flag criteria?

c) Do you have any specific examples of operation changes in order to comply with the Blue Flag criteria? 
7. Do you feel that the Blue Flag criteria are sufficient steps to take to effectively protect your beach?

a) Have you had any challenges understanding how to meet the criteria?

If yes, how did you overcome this?

8. What motivated your municipality to become Blue Flag certified?

a) What specific benefit(s) has your municipality received from your Blue Flag status?

Prompts: more funding for water testing; increased tourism; additional partnerships with other organizations; increased support from municipality (funding, recycling containers, staff); knowledge of proper beach management; etc.

9. What do you think are the biggest strengths of Blue Flag?

a) Has Blue Flag generated any economic benefit?

b) Has Blue Flag increased tourism?

c) Has Blue Flag been useful to provide information for successful environmental protection at a beach?

10. Do you believe there are any issues or problems with the Blue Flag ecocertification program? E.g.

a) Do you think there are any barriers for municipalities to want to achieve this award? How do you think this could be overcome?

b) Why do you think all beaches do not implement the Blue Flag program?

How do you think this could be overcome?

11. To what extent do you believe that Blue Flag certification is a valuable way for municipalities in Ontario to work to protect:

a) Their beaches?

b) The Great Lakes in general?

12. Do you know of any other initiatives that would give Ontario municipal governments the ability to formally participate in managing their beaches in some way?

13. Is there anything I have missed or you would like to add?

14. Is there anyone else you think I should speak with regarding this topic? THANK YOU FOR YOUR TIME 


\section{Appendix D - Email Recruitment Script}

Dear Mr./Ms.

My name is Laura Klein. I am a Masters student in the Environmental Applied Science and Management program at Ryerson University. I am currently completing research focusing on the management of Ontario's beaches along the Great Lakes.

I am writing to you to ask if I could meet with you and potentially interview you. I am conducting interviews with individuals that are involved in management of Ontario's Great Lakes' beaches. I would like to learn more about the challenges involved in managing a beach, what success stories you have seen, and what barriers exist to better protecting beaches.

Ryerson's Research Ethics Board has reviewed this research project. Attached is a copy of the consent form for you to review, which will give you a more detailed explanation of the research, including conditions for your participation. Participation in this research is completely voluntary. Please let me know if you would be willing to participate in this research project. If so, we can set up a time that is convenient for you to meet at a location of your choosing. I do hope you will be able to speak to me as I expect your knowledge and insights will greatly improve the outcome of the project.

If you have any questions please do not hesitate to contact me at the email address listed below.

Thank you for your time and consideration.

Laura Klein

lmklein@ryerson.ca 


\section{Appendix E - Example of NVivo nodes and theme organization}

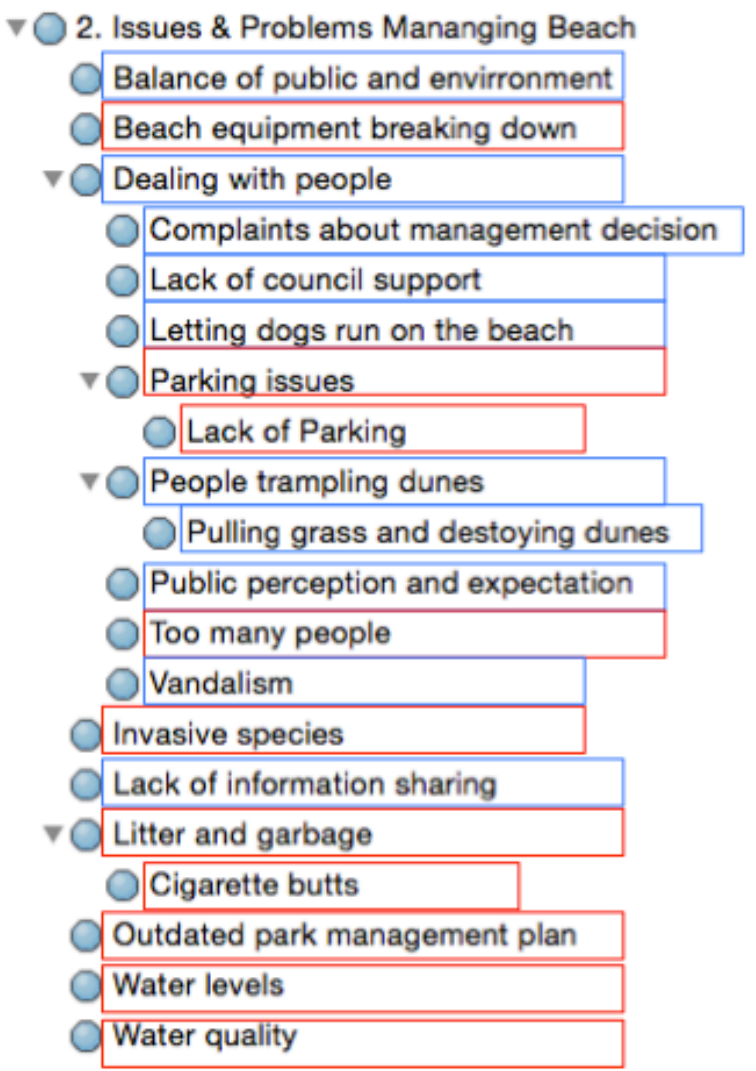

Codes that relate to dealing with people and expectations

Codes that relate to physical and environmental problems 


\section{Appendix F - Interview Consent Form}

\section{RYERSON}

UNIVERSITY

\section{Ryerson University Consent Agreement}

You are being asked to participate in a research study. Before you give your consent to participate, it is important that you read the following information and ask as many questions as necessary to be sure you understand what you are being asked. Participation in this study is entirely voluntary.

Study Title: Management Tools Protecting Ontario's Great Lakes Beaches

Investigator: This research is being conducted by Laura Klein and Dr. Rachel Dodds from the Ted Rogers School of Hospitality and Tourism Management at Ryerson University.

Purpose of the Study: This study aims to understand what barriers municipalities are facing when trying to improve the environmental protection and management of their beaches, and determine what management tools are useful in protecting the beaches for municipalities. The research also wants to determine what could improve this process of protecting beaches along the Great Lakes.

Your Role in the Research: If you volunteer to participate in this research, you will be asked to participate in a semi-structured interview at a private location, preferably a place of your choosing. Myself will interview you, and the expected duration of the interview will be approximately 60 minutes.

Benefits: Participation in this research project will contribute to a better understanding of the challenges and opportunities for municipalities to protect Ontario's Great Lakes' beaches. The knowledge gained from this interview will make a valuable and novel research contribution.

Data Management: The data collected for this study will be used for academic purposes only. Records will be kept strictly confidential (locked in storage and/or password protected) and only the investigator and graduate supervisor will have access to interview data. Data will be stored securely at the researcher's home office and personal laptop for a period of up to two years subsequent to the completion of the research project and then will be destroyed. Confidentiality will be maintained to the extent allowed by law.

Confidentiality: Any information conveyed during interviews will be kept strictly confidential. Your identity will be kept confidential, and the knowledge you share will 
not be linked to you or your participation. Your participation and identity will not be shared or disclosed. I will be removing potential identifiers from any written documents that will be made public. Specific job titles will not be used, and organization indicators will be broad. If I wish to share publicly any information you provide in our interview, I will seek your permission prior to using the information. Draft excerpts will be shared with you prior to inclusion in the final research paper to ensure information accuracy and to reconfirm your permission. No information that you share with me will be used without your consent.

Risks: There is a risk from being interviewed. The risk of participating in this interview is the potential disclosure of sensitive information you share may result in adverse professional and economic consequences, such as loss of employment. It could be possible for someone to identify a participant if they see or overhear some information being given during the interview. To protect against this, the researcher will take all necessary precautions to ensure the information in this interview is kept strictly confidential.

Incentives to Participate: Participants will not be paid to participate in this study.

Questions about the Study: If you have any questions about the research now, please ask. If you have questions later about the research, you may contact me or my academic advisor directly:

Laura Klein, BES

Telephone Number: (519) 801-5782

lmklein@,ryerson.ca

Dr. Rachel Dodds, Associate Professor

Ted Rogers School of Hospitality and Tourism Management, Ryerson University

Telephone Number: (416) 979-5000 ext. 7227

r2dodds@ryerson.ca

If you have questions regarding your rights as a human subject and participant in this study, you may contact the Ryerson University Ethics Board for information.

Research Ethics Board c/o Office of the Vice President, Research and Innovation Ryerson University 350 Victoria Street

Toronto, ON M5B 2K3

416.979.5000 ext. 7112

The undersigned hereby acknowledges his/her review and understanding of the consent agreement and consents to participate in the study 
Date

Permission to be audio-taped Signature of Participant 


\section{Appendix G - Photos of Blue Flag beaches included in the study}

(Blue Flag signage at Bluffer's Beach, sand and boardwalk at Grand Bend Main Beach, dunes at Grand Bend Main Beach, Wasaga Beach Area 1 including Piping Plover habitat, 'Butt Free Beach' signage at Goderich Main Beach)

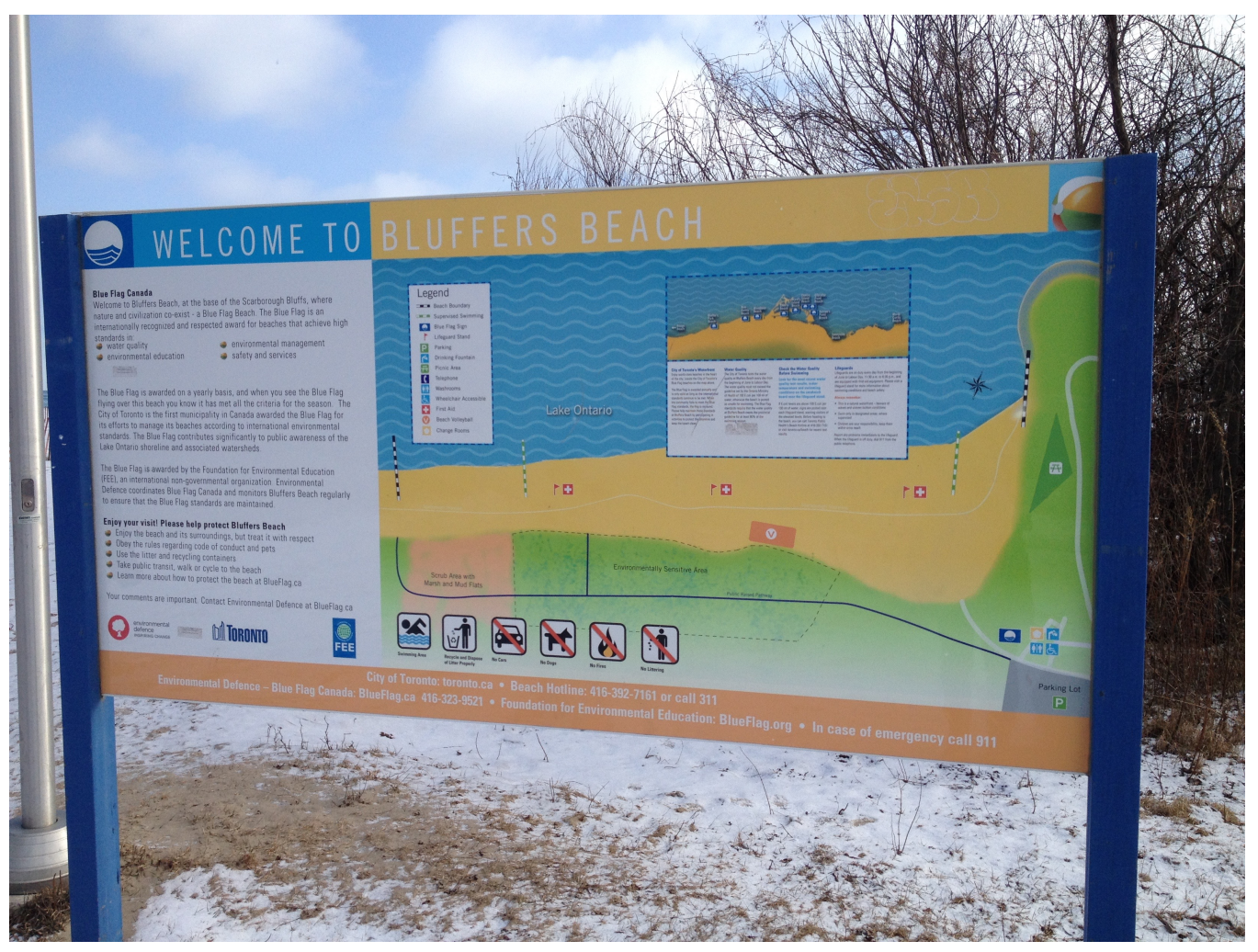



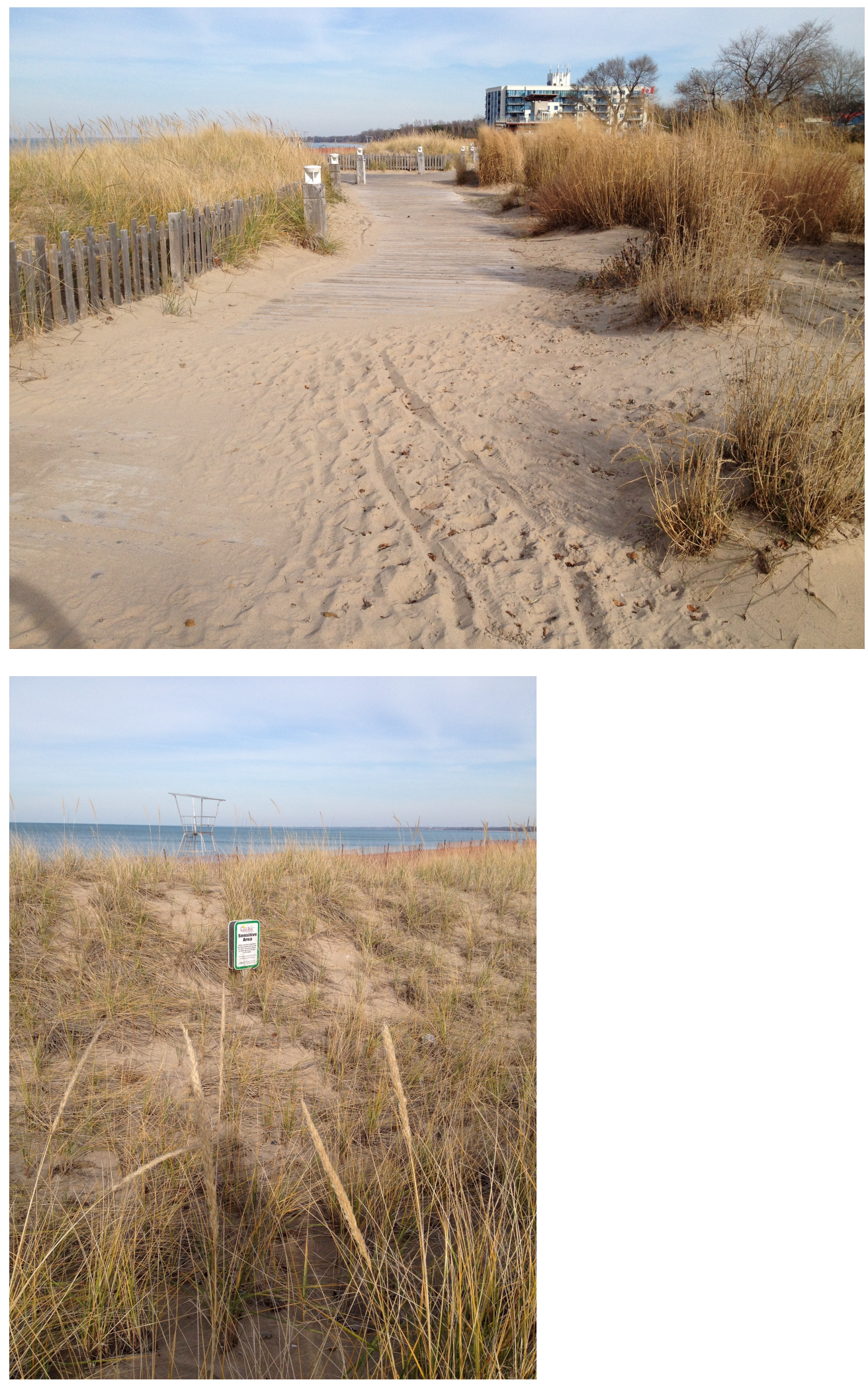

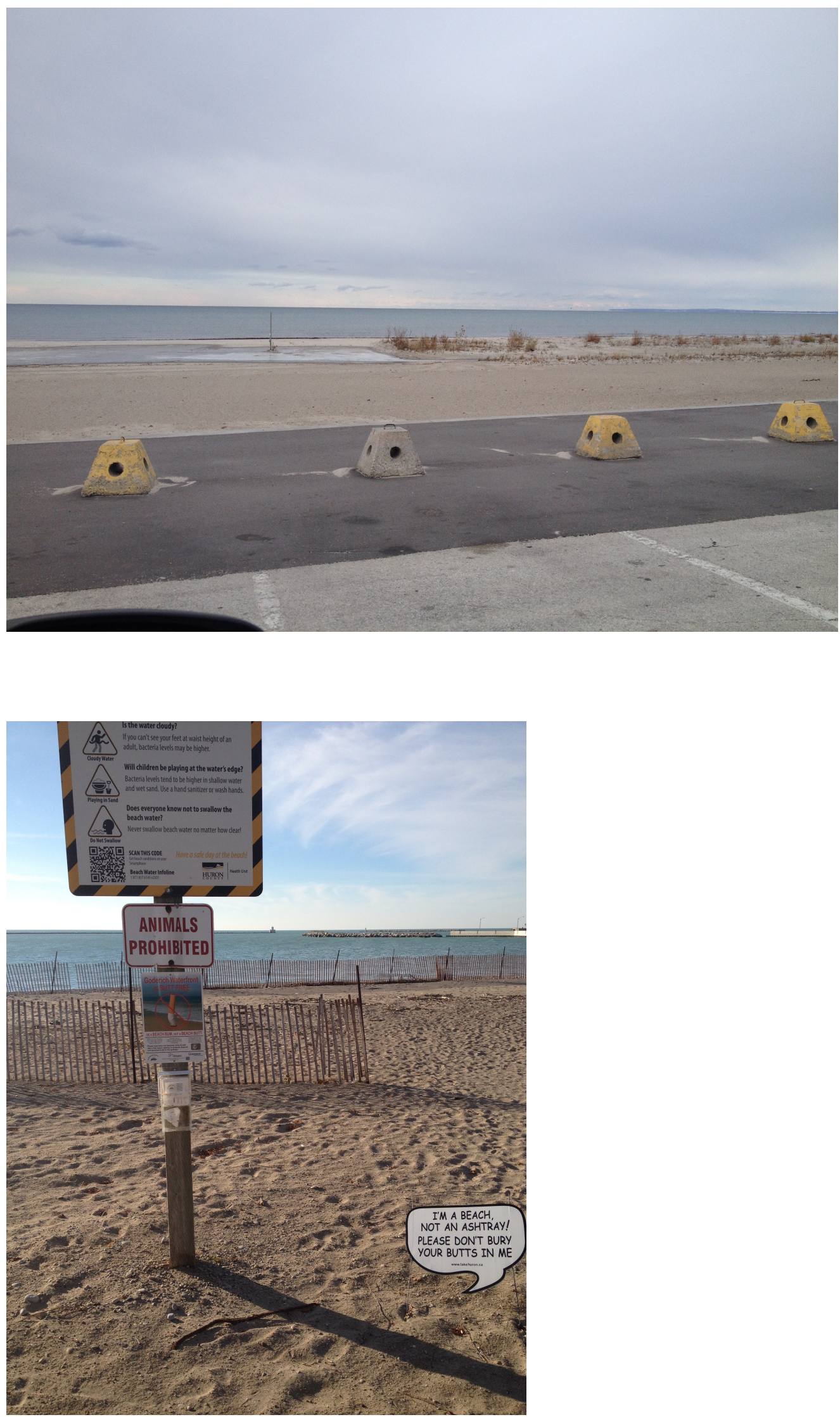


\section{References}

Amyot, J., \& Grant, J. (2014). Environmental Function Analysis: A decision support tool for integrated sandy beach planning. Ocean \& Coastal Management, 102, 317-317.

Ariza, E., Jimenez, J. A., \& Sarda, R. (2008). A critical assessment of beach management on the Catalan coast. Ocean \& Coastal Management, 51, 141-160.

Ariza, E., Sarda, R., Jimenez, J. A., Mora, J., \& Avila, C. (2008). Beyond performace assessment measurements for beach management: Application to Spanish Mediterranean beaches. Coastal Management, 36, 47-66.

Bill 66, Great Lakes Protection Act. (2015). [PDF]. Retrieved from http://www.ontla.on.ca/bills/bills-files/41_Parliament/Session1/b066ra.pdf

Blackman, A., Naranjo, M. A., Robalino, J., Alpizar, F., \& Rivera, J. (2014). Does Tourism Eco-Certification Pay? Costa Rica's Blue Flag Program. World Development, 58, 41-52.

Blue Flag. (n.d.). Blue Flag Sites: All. Retrieved from http://www.blueflag.global/all-bf-sites/

Blue Flag (n.d.). Our History. Retrieved from http://www.blueflag.global/missionand-history/

Blue Flag. (n.d.) Our Programme. Retrieved from http://www.blueflag.global/our-programme/

Boevers, J. (2008). Assessing the Utility of Beach Ecolabels for Use by Local Management. Coastal Management, 36(5), 524-531.

Boote, D. N., \& Beile, P. (2005). Scholars before Researchers: On the Centrality of the Dissertation Literature Review in Research Preparation. American Educational Research Association, 34(6), 3-15.

Botero, C., Pereira, C., Tosic, M., \& Manjarrez, G. (2015). Design of an index for monitoring the environmental quality of tourist beaches from a holistic approach. Ocean \& Coastal Management, 108, 65-73.

Brown, A.C. \& McLachlan, A. (2002). Sandy shore ecosystems and threats facing them: some predictions for the year 2015. Environmental Conservation, 29(1), 62-77. 
Buckley, R. (2002). Tourism Ecolabels. Annals of Tourism Research, 29(1),183208

Capacci, S., Scorcu, A. E., \& Vici, L. (2015). Seaside tourism and eco-labels: The economic impact of Blue Flags. Tourism Management, 47, 88-96.

Creo, C., \& Fraboni, C. (2011). Awards for the sustainable management of coastal tourism destinations: The example of the blue flag program. Journal of Coastal Research, 61, 378-381.

David Suzuki Foundation. (2014). The Great Lakes. Retrieved from http://www.davidsuzuki.org/publications/books/the-great-lakes/).

Dodds, R. (2010). Determining the Economic Impact of Beaches: Lake Huron Shoreline from Sarnia to Tobermory. Ted Rogers School of Hospitality and Tourism Management.

Dodds, R. (2014). Determining the Potential for Environmentally Sustainable Recreation in the Lake Simcoe Watershed. Ministry of the Environment and Climate Change.

Dodds, R., \& Joppe, M. (2005). CSR in the Tourism Industry? The Status of and Potential for Certification, Codes of Conduct and Guidelines. Study prepared for the CSR Practice Foreign Investment Advisory Service Investment Climate Department. [PDF] Retrieved from http://siteresources.worldbank.org/INTEXPCOMNET/Resources/CSR_in_t ourism_2005.pdf

Environmental Defence. (n.d.). Criteria for Beaches: Blue Flag Canada Criteria for Beaches. [PDF]. Retrieved from http://environmentaldefence.ca/report/guide-blue-flag-criteria-for-beaches/

Environmental Defence. (n.d.) Steps to The Blue Flag Award. Retrieved from http://environmentaldefence.ca/blue-flag-operator/

Font, X. (2002). Environmental certification in tourism and hospitality: progress, process and prospects. Tourism Management, 23, 197-205.

Galletta, A. (2013). Mastering the Semi-Structured Interview and Beyond: From Research Design to Analysis and Publication. New York, NY: New York University Press.

Gilburn, A. S. (2012). Mechanical grooming and beach award status are associated with low strandline biodiversity in Scotland. Estuarine, Coastal and Shelf Science, 107, 81-88. 
Gore, C., \& Stoett, P. (2009). Environmental Challenges and Opportunities: Local-Global Perspectives on Canadian Issues. Toronto, ON: Emond Montgomery Publications

Government of Ontario. (2012). Ontario's Great Lakes Strategy. Retrieved from https://www.ontario.ca/document/ontarios-great-lakesstrategy

Government of Ontario. (2014). Beach Management Guidance Document. [PDF]. Retrieved from http://www.health.gov.on.ca/en/pro/programs/publichealth/oph_standards/ docs/guidance/guide_beach.pdf

Government of Ontario. (2016a). Great Lakes Guardian Community Fund. Retrieved from https://www.ontario.ca/page/great-lakes-guardiancommunity-fund

Government of Ontario. (2016b). Canada Ontario Great Lakes Agreement. [PDF]. Retrieved from https://www.ontario.ca/page/canada-ontario-greatlakes-agreement\#section-2

Government of Ontario. (2016c). Ontario's Great Lakes Strategy 2016 Progress Report. Retrieved from https://www.ontario.ca/page/ontarios-great-lakesstrategy-2016-progress-report\#section-6

Gowan, R. (2015). Blue Flag taken down at Sauble. Owen Sound Sun Times. Retrieved from http://www.owensoundsuntimes.com/2015/06/17/blue-flagtaken-down-at-sauble

Graci, S., \& Dodds, R. (2015). Certification and labeling. In (Stefan Gössling, C. Michael Hall, Daniel Scott (eds)) The Routledge handbook of tourism and sustainability, London, Taylor and Francis.

Great Canadian Shoreline Cleanup. (n.d.). Year-Round Impact. Retrieved from http://www.shorelinecleanup.ca/en/take-action/year-round-action

Great Lakes Beach Association. (2016). About us. Retrieved April 28, 2016 from http://www.great-lakes.net/glba/about.html

Great Lakes St. Lawrence Cities Initiative. (n.d.). About Us. Retrieved from http://glslcities.org/about-the-great-lakes-and-st-lawrence-cities-initiative

Great Lakes St. Lawrence Cities Initiative. (n.d.). Great Beaches and Coasts. Retrieved from http://glslcities.org/initiatives/past-initiatives/great-beachesand-coasts/ 
Great Lakes St. Lawrence Cities Initiative. (2009a). Healthy Great Lakes and St Lawrence Beaches: A National Priority. [PDF]. Retrieved from http://glslcities.org/wp-content/uploads/2015/05/Beaches_2009.pdf

Great Lakes St. Lawrence Cities Initiative. (2009b). In Backgrounder: Ontario Mayors' Five Point Collaborative Action Plan to Protect the Great Lakes. Retrieved from http://www.glslcities.org/documents/MCAPBackgrounderMay5-FINAL2.pdf

Haliburton, Kawartha, Pine Ridge District Health Unit. (n.d.). Why Beaches are Posted. In Environments, Beach Water Testing. Retrieved from http://www.hkpr.on.ca/InfoSet/Environments/BeachWaterTesting/WhyBea chesArePosted.aspx

Health Canada. (2012). Environmental and Workplace Health: Recreational Water. Retrieved from http://www.hc-sc.gc.ca/ewh-semt/watereau/recreat/index-eng.php

Jaakson, R., Buszynski, M.D. \& Botting, D. (1976). Carrying Capacity and Lake Recreation Planning: A Case Study from North-Central Saskatchewan, Canada. Town Planning Review. 46: 359-373.

James, R. J. (2000). From beaches to beach environments: linking the ecology, human-use and management of beaches in Australia. Ocean \& Coastal Management. 43, 495-514.

Kelly, D. (2014). Study finds most Lake Michigan Beach Trash comes from visitors. Retrieved from http://www.lakescientist.com/study-finds-lakemichigan-beach-trash-comes-visitors/

Khanna, M., \& Brouhle, K. (2009). The effectiveness of voluntary environmental initiatives. In Governance for the Environment: New Perspectives. Cambridge University Press.

Kozak, M., \& Nield, K. (2004). The Role of Quality and Eco-Labelling Systems in Destination Benchmarking. Journal of Sustainable Tourism, 12(2), 138148.

Krantzberg, G., \& deBoer, C. (2008). A valuation of ecological services in the Laurentian Great Lakes Basin with an emphasis on Canada. Journal of the American Water Works Association, 100(6),100-111

Kvale, S. (1996). Interviews: An Introduction to Qualitative Research Interviewing. Thousand Oaks, CA: Sage Publications, Inc. 
Lake Huron Centre for Coastal Conservation. (n.d.). Invasive Species. Retrieved from http://lakehuron.ca/index.php?page=invasive-species

Lake Huron Centre for Coastal Conservation. (2012). Grooming Beaches? Time to Re-Think the Process. Retrieved from http://lakehuron.ca/index.php?mact=News,cntnt01,detail,0\&cntnt01articlei $d=15 \&$ cntnt01 returnid $=228$

Lake Ontario Waterkeeper. (n.d.). Ontario's Great Lakes Protection Act. Retrieved April 28, 2016 from http://www.waterkeeper.ca/case-greatlakes- protection-act/

Lucrezi, S., \& Saayman, M. (2014). Beachgoers' Demands vs. Blue Flag Aims in South Africa. Journal of Coastal Research. http://dx.doi.org/10.2112/JCOASTRES-D-14-00062.1

Lucrezi, S., \& van der Merwe, P. (2015). Beachgoers' Awareness and Evalution of the Blue Flag Award in South Africa. Journal of Coastal Research, 31(5), 1129- 1140

Lucrezi. S., Saayman, M., \& Van der Merwe, P. (2015). Managing beaches and beachgoers: Lessons from and for the Blue Flag award. Tourism Management. 48: 211-230.

Lucrezi. S., Saayman, M., \& Van der Merwe, P. (2016). An assessment tool for sandy beaches: A case study for integrating beach description, human dimension, and economic factors to identify priority management issues. Ocean \& Coastal Management. 121: 1-22.

Maack, E., Banas Mills, S., Borick, C., Gore, C., \& Rabe, B.G. (2014). Environmental Policy in the Great Lakes Region: Current Issues and Public Opinion. Issues in Energy and Environmental Policy. 10: 1-20.

Marin, V., Palmisani, F., Ivaldi, R., Dursi, R., and Fabiano, M. (2009). Users' perception analysis for sustainable beach management in Italy. Ocean \& Coastal Management. 52: 268-277.

Marine Conservation Society. (n.d.).Good Beach Guide: Helping You Find The Best UK Beaches. Retrieved from: http://www.goodbeachguide.co.uk

McKenna, J., Williams, A.T., \& Cooper, J. A. (2011). Blue flag or red herring: do beach awards encourage the public to visit beaches? Tourism Management, 32, 576-588. 
McLachlan, A., Defeo, O., Jaramillo, E., \& Short, A. D. (2013). Sandy beach conservation and recreation: Guidelines for optimizing management strategies for multi-purpose use. Ocean \& Coastal Management, 71:256268

Ministry of Health and Long Term Care. (2014). Beach Management Guidance Document. Retrieved from http://www.health.gov.on.ca/en/pro/programs/publichealth/oph_standards/ docs/guidance/guide_beach.pdf

Ministry of the Environment and Climate Change. (2015). Great Lakes Protection Act 2015 Overview [PDF file]. Retrieved from http://lakeerieforum.org/sites/default/files/7_Great_Lakes_Protection_Act_ Carolyn_ONeill.pdf

Mir-Gual, M., Pons, G.X., Martín-Prieto, J.A., \& Rodríguez-Perea, A. (2015). A critical view of the Blue Flag beaches in Spain using environmental variables. Ocean \& Coastal Management. 105: 106-115. doi:10.1016/j.ocecoaman.2015.01.003

Micallef, A. \& Williams, A.T. (2002). Theoretical strategy considerations for beach management. Ocean \& Coastal Management. 45: 261-275.

Micallef, A. \& Williams, A.T. (2004). Application of a novel approach to beach classification in the Maltese Islands. Ocean \& Coastal Management. 47: 225-242.

Mondoux, L. \& May, G. (2011). Eight down, three more to go: Toronto's hard work pays off with Blue Flag beach honours. Retrieved from: http://www.mynewwaterfronthome.com/blueflagbeach.aspx

Morgan, R. (1999). A novel, user-based rating system for tourist beaches. Tourism Management. 20:393-410.

National Wildlife Federation. (2015). Great Lakes. Retrieved August 25, 2015 from: https://www.nwf.org/Wildlife/Wild-Places/Great-Lakes.aspx

Nelson, C., \& Botterill, D. (2002). Evaluating the contribution of beach quality awards to the local tourism industry in Wales-The Green Coast Award. Journal of Ocean and Coastal Management, 45, 157170.

Nelson, C., Morgan, R., Williams, A.T., \& Wood, J. (2000). Beach awards and management. Ocean and Coastal Management. 43(1): 87-98.

Neuman, W. L. \& Robson, K. (2009). Basics of Social Research: Qualitative and Quantitative Approaches. Toronto, Canada: Pearson Canada Inc. 
Palys, T. \& Atchison, C. (2014). Research Decisions, Quantitative, Qualitative, and Mixed Methods Approaches. ( $5^{\text {th }}$ ed.). Toronto, Canada: Nelson Education Ltd.

Peach, G. (n.d.). Piping Plover An Endangered Species. Retrieved from http://lakehuron.ca/uploads/pdf/Piping.Plover.pdf

Peach, G.H., Bowles, J., \& Porter, L. (2007). Conserving a Delicate Balance: Management Plan for North Sauble Beach, Ontario, Canada. Prepared by the Lake Huron Centre for Coastal Conservation.

Pencarelli, T., Splendiani, S., \& Fraboni, C. (2016). Enhancement of the "Blue Flag" Eco-label in Itlay: an empirical analysis. Anatolia. 27: 28-37.

Sarda, R., Valls, J. F., Pinto, J., Ariza, E., Lozoya, J. P., Fraguell, R. M., Marti, C., Rucabado, J., Ramis, J., \& Jimenez, J. A. (2015). Towards a new Integrated Beach Management System: The Ecosystem-Based Management System for Beaches. Ocean \& Coastal Management, 118, 167-177

Schlacher, T. A., Dugan, J., Schoeman, D. S., Lastra, M., Jones, A., Scapini, F., McLachlan, A. and Defeo, O. (2007), Sandy beaches at the brink. Diversity and Distributions, 13: 556-560.

Sekaran, U. (2000). Research methods for business: a skill building approach. New York: John Wiley \& Sons, Inc.

Sustain Our Great Lakes. (2014a). The Great Lakes. Retrieved from http://www.sustainourgreatlakes.org/about/our-lakes/

Sustain Our Great Lakes. (2014b). Shoreline Habitat. Retrieved from http://www.sustainourgreatlakes.org/about/our-lakes/

Wasaga Beach Tourism Strategy. (2007). [PDF] Retrieved from http://www.wasagabeach.com/Document\%20Library/Tourism\%20Strategy \%20final.pdf

Williams, A. T. \& Micallef, A. (2009). Beach management: Principles and practice. London: Earthscan.

Zielinkski, S. \& Botero, C. (2015). Are eco-labels sustainable? Beach certification schemes in Latin America and the Caribbean. Journal of Sustainable Tourism, 23(10), 1550-1572. 